\title{
WestVirginiaUniversity
}

THE RESEARCH REPOSITORY @ WVU

Graduate Theses, Dissertations, and Problem Reports

2009

\section{Verbal time estimation in clutterers and non-clutterers}

\author{
Emily O. Garnett \\ West Virginia University
}

Follow this and additional works at: https://researchrepository.wvu.edu/etd

\section{Recommended Citation}

Garnett, Emily O., "Verbal time estimation in clutterers and non-clutterers" (2009). Graduate Theses, Dissertations, and Problem Reports. 2793.

https://researchrepository.wvu.edu/etd/2793

This Thesis is protected by copyright and/or related rights. It has been brought to you by the The Research Repository @ WVU with permission from the rights-holder(s). You are free to use this Thesis in any way that is permitted by the copyright and related rights legislation that applies to your use. For other uses you must obtain permission from the rights-holder(s) directly, unless additional rights are indicated by a Creative Commons license in the record and/ or on the work itself. This Thesis has been accepted for inclusion in WVU Graduate Theses, Dissertations, and Problem Reports collection by an authorized administrator of The Research Repository @ WVU. For more information, please contact researchrepository@mail.wvu.edu. 


\title{
Verbal Time Estimation in Clutterers and Non-Clutterers
}

\author{
Emily O. Garnett
}

Thesis submitted to the College of Human Resources and Education at West Virginia University in partial fulfillment of the requirements for the degree of

\author{
Master of Science \\ in \\ Speech-Language Pathology
}

Kenneth O. St. Louis, Ph.D., Chair

Norman J. Lass, Ph.D.

Mary Ellen Koay, Ph.D.

Department of Speech Pathology and Audiology

\author{
Morgantown, West Virginia \\ 2009
}

Key words: Cluttering, Time, Estimation, Speech, Disfluency, Rate Copyright 2009 Emily O. Garnett 


\section{ABSTRACT \\ Verbal Time Estimation in Clutterers and Non-Clutterers}

\section{Emily O. Garnett}

Research has suggested that people with fluency disorders, i.e., individuals who stutter, have difficulty with time estimation. A sub-group of fluency disorders are persons who clutter, whose speech is characterized by a rapid and/or irregular rate of speech that is accompanied by excessive disfluencies, abnormally placed pauses, and/or excessive coarticulation. One frequently reported symptom of cluttering is a lack of awareness of one's own cluttering, which may be related to rate deviations. It is possible that persons who clutter may also lack the awareness of the amount of time required to say something, and thus, demonstrate difficulty estimating the amount of time required for an utterance. To test this hypothesis, by pressing a computer mouse button, six adults who clutter and six matched controls estimated the time required to complete 50 self-formulated utterances after given a scenario prompt. An example was "Do you prefer cats or dogs and why?" Each estimated time was then compared to the actual amount of time required to say the utterance immediately upon releasing the mouse button. Although mean statistical differences did not differentiate cluttering and control groups, both groups overestimated time in general, and clutterers demonstrated a trend of overestimating more than controls. Individual cluttering-control pair differences revealed trends suggesting that twothirds of each group overestimated speaking time, one-sixth underestimated speaking time, and the remaining one-sixth estimated speaking time fairly accurately. Additionally, participants who clutter had more variability in their estimated times when compared to controls, while actual times were more similar. These trends suggest that individuals who clutter have some disruption in their ability to estimate time. This may be caused by an internal time clock that is disrupted in some way, or due to an increase in time required to form an utterance. 


\section{Acknowledgments}

First I would like to thank the members of my thesis committee, Dr. Norman Lass and Dr. Mary Ellen Koay, for all of their advice and suggestions. It has been a pleasure to have committee members with whom I felt it was easy to work. That is a rare gem.

I would also like to express tremendous gratitude to Dr. Klaas Bakker at Missouri State University for statistics advice, providing helpful suggestions, and, in super-secret James Bond fashion, editing and sending a version of his CLASP program to use specifically for my thesis.

Most importantly, I would like to thank my thesis chair, Dr. Ken St. Louis. "Thank you" cannot convey the gratitude I have for his mentorship and friendship. Probably against his better judgment, he agreed to chair a third thesis, and I am so grateful for that decision. Without his ideas, guidance, patience, and tolerance of my frequent emails, this thesis would not have been possible. He always gave me the perfect blend of direction and independence, and the right amount and type of encouragement. Many positive changes in my life are a direct result of our collaboration, primarily that I (finally) know "what I want to be when I grow up," and that is a teacher and researcher. To have been given the opportunity to have the experiences I needed to discover and start to become confident in my professional "self" is a truly a special gift.

In everyone's life, at some time, our inner fire goes out. It is then burst into flame by an encounter with another human being. We should all be thankful for those people who rekindle the inner spirit. - Albert Schweitzer 


\section{Table of Contents}

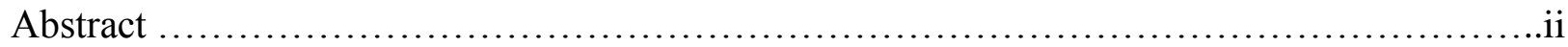

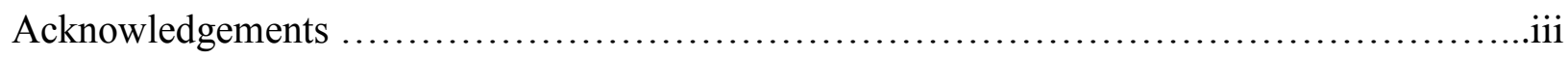

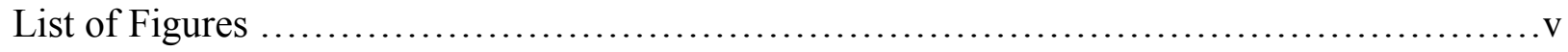

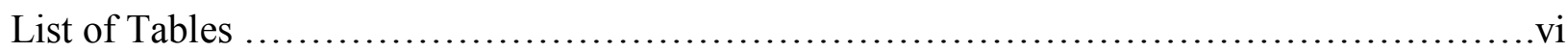

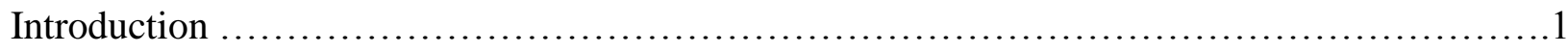

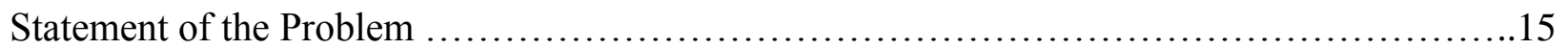

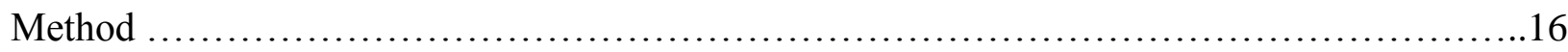

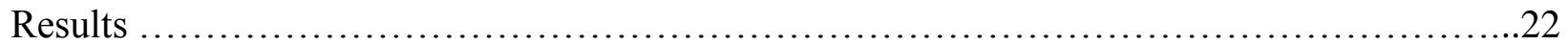

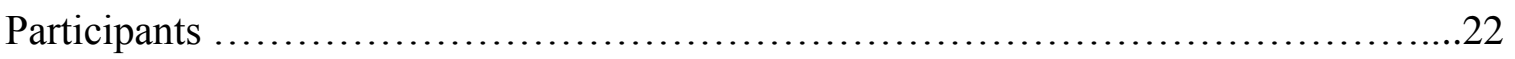

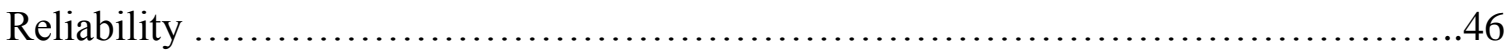

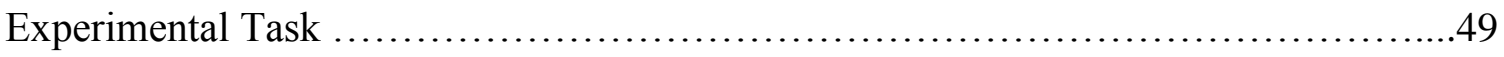

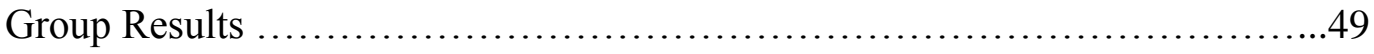

Individual Clutterer-Control Pairs ......................................56

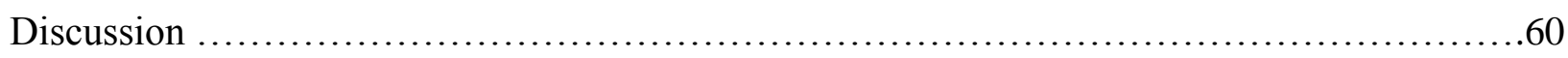

Conclusions and Suggestions for Future Research ....................................6 69

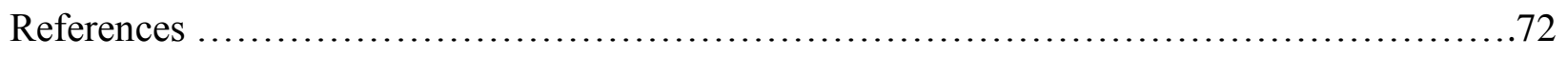

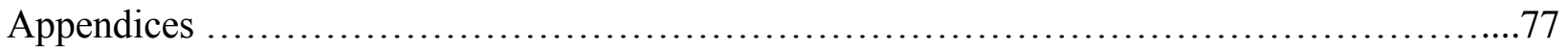




\section{List of Figures}

Figure 1. Mean perceptual rankings of all categories of rate, as judged by each participant, the researcher, and a friend of the participant

Figure 2. Mean perceptual rankings of all categories of articulation, as rated

by each participant, the researcher, and a friend of the participant

Figure 3. Mean perceptual rankings of all categories of language, as rated

by each participant, the researcher, and a friend of the participant .36

Figure 4. Mean perceptual rankings of all categories of disfluencies, as rated

by each participant, the researcher, and a friend of the participant

Figure 5. Total disfluencies by clutterers and controls during conversation

Figure 6. Distribution of disfluency by type for clutterers .43

Figure 7. Distribution of disfluency by type for controls

Figure 8. Estimated times across all 50 experimental tasks for clutterers .52

Figure 9. Estimated times across all 50 experimental tasks for controls .53

Figure 10. Actual times across all 50 experimental tasks for clutterers .54

Figure 11. Actual times across all 50 experimental tasks for controls .55

Figure 12. Mean estimated times and actual times showing emerging trends in clutterers .58

Figure 13. Mean estimated times and actual times showing emerging trends in controls 


\section{List of Tables}

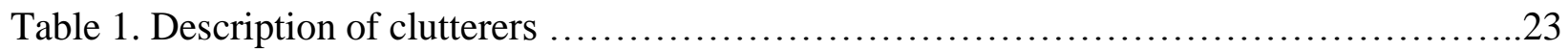

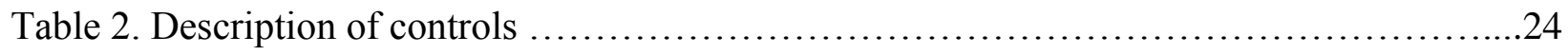

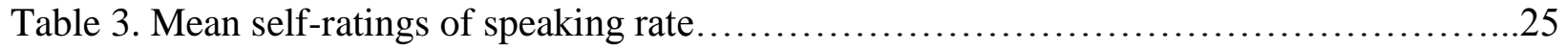

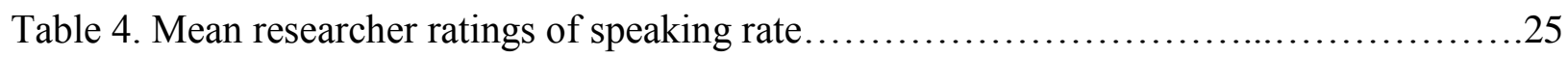

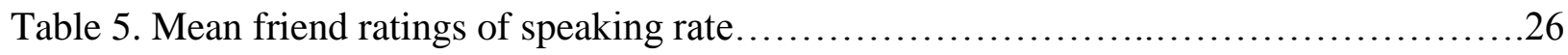

Table 6. Rate in syllables per minute for clutterers..................................... 28

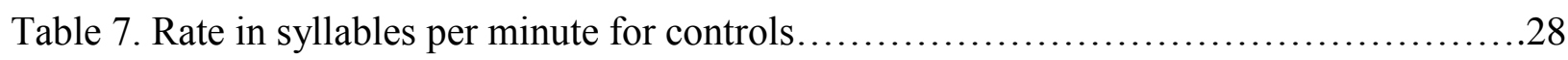

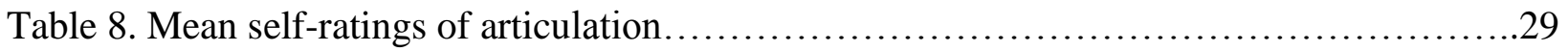

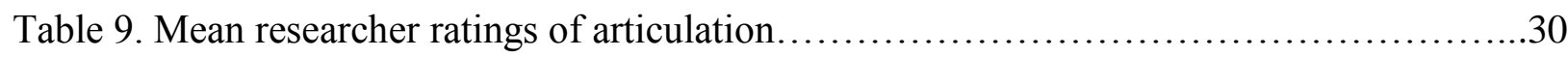

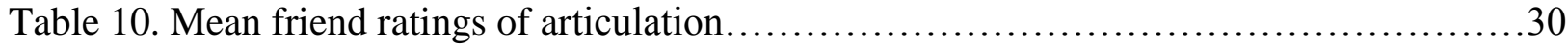

Table 11. Articulation accuracy during reading of 31 multisyllabic words.....................32

Table 12. Frequency of excessive coarticulation during reading of 31 multisyllabic words......33

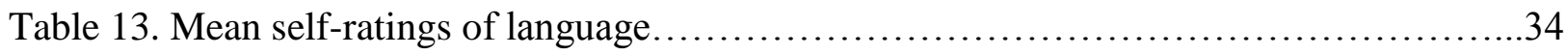

Table 14. Mean researcher ratings of language.........................................

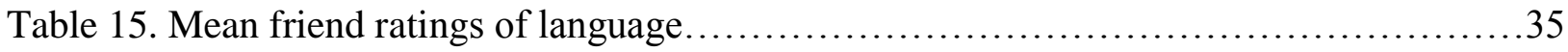

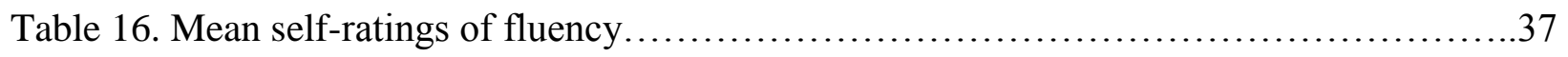

Table 17. Mean researcher ratings of fluency........................................ 38

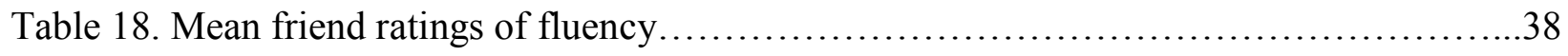

Table 19. Disfluency analysis by type for clutterers................................. 42

Table 20. Disfluency analysis by type for controls................................ 44

Table 21. Mean inter- and intra-rater reliability for clutterers...........................48

Table 22. Mean inter- and intra-rater reliability for controls $\ldots \ldots \ldots \ldots \ldots \ldots \ldots \ldots \ldots \ldots \ldots \ldots . \ldots 48$ 
Table 23. Group means, standard deviations (SD), and coefficient

of variation $(\mathrm{CV})$ for estimated, actual, and estimated minus

actual times for clutterers and controls.

Table 24. Mean estimated times, actual times, and difference between

estimated and actual times for clutterers....................................57

Table 25. Mean estimated times, actual times, and difference between estimated and actual times for controls...........................................

Table 26. Differences in estimated, actual, and estimated minus actual times for clutterer-control pairs............................................57 


\section{Introduction}

Fluency disorders are a sub-group of speech disorders that are marked by some disruption in the flow of speech. Fluency is concerned with aspects of speech such as rate, continuity (i.e. fluency/disfluency), rhythm, smoothness, and effort involved in speaking (Starkweather, 1987). Thus, speakers who are fluent do not exhibit significant deviations in the flow of their speech. Guitar (2006) defines fluency as "the effortless flow of speech" (p. 15). Many authors find it easier to describe what fluency is not, rather than what it is. Fluency disorders are comprised of stuttering, including its various subgroups of neurogenic and psychogenic stuttering, and a lesser-known and understood fluency disorder called cluttering (American Speech-LanguageHearing Association [ASHA], 1999).

\section{Stuttering versus Cluttering}

Considering the aspects of speech that are typically disrupted in a fluency disorder, stuttering usually involves prolongations, repetitions, and/or blocks (silent or audible). These core behaviors may be accompanied by secondary behaviors that are used to escape from or avoid stuttering, such as eye blinks, stalling, changing words, or faking a cough (ASHA, 1999). There are many similarities and differences between cluttering and stuttering. Both are disorders of fluency, as they involve some perceived disruption in what is considered to be "normal speech," or disfluencies; however, these disfluencies differ in each disorder. Stutterers typically exhibit syllable repetitions, whole-word repetitions, part-word repetitions, prolongations, or blocks, while clutterers are reported to show an excessive number of normal disfluencies, intelligibility problems that are worse when the person speaks rapidly, and may omit or run syllables together (St. Louis, Myers, Bakker, \& Raphael, 2007). Clutterers may have difficulty planning or knowing what they want to say, or talk too fast or in bursts, while stutterers typically 
have no problems planning their utterances, yet have involuntary interruptions in their speech output, both of which are perceived by the listener as disfluent (St. Louis, 1998). In a description of cluttering for the general public, St. Louis and Hinzman (1986) further described people who clutter in part as seeming not to be clear about what they wanted to say.

\section{Cluttering Defined}

Cluttering is defined by ASHA as, "a fluency disorder characterized by a rapid and/or irregular speech rate, excessive disfluencies, and often other symptoms such as language or phonological errors and attention deficits" (ASHA, 1999, p. 10). Weiss (1964) attributed the symptoms of cluttering to a "central language imbalance" (p. 1). Daly and Burnett (1996) define cluttering as "a disorder of speech and language processing, resulting in rapid, dysrhythmic, sporadic, unorganized, and frequently unintelligible speech" (p. 239). They regard language formulation problems as essential and nearly always present, rather than a rapid rate; however, they recognize that the symptoms of cluttering vary significantly, which presents a problem in diagnosis.

Somewhat similarly, Myers $(1992,1996)$ suggests a synergistic framework, one tenet of which is that rate, fluency, language, and coarticulation can "function interdependently," meaning that cluttering may be a symptom of interactions (or a lack thereof) between one or more of these systems. Further, a breakdown in communication between these systems is likely to produce disfluency: in this case, cluttering. Regarding rate, Myers (1996) suggests that rate can be a factor, but it is the way in which it interacts with the person's speech that should be considered:

Is the clutterer's overall absolute speaking rate, as measured by such indices as syllables per second, faster than the normal range? Is a fast rate in absolute terms a necessary 
condition for an individual to be considered a clutterer? Or, is it more the case that the clutterer's speaking rate is faster relative to the capacity of his or her system? If the clutterer is speaking faster than the system can handle, is it the case that the linguistic and articulatory components lose synchrony and therefore synergy, giving rise to misarticulations, disfluencies, and linguistic anomalies? (p. 73-74).

As Myers points out, there are speakers who speak fast with ease, and there are speakers who speak slowly but disfluently. Her position is that each person's fluency should be measured in comparison with his own capacity. When the demands of speech exceed the capacities, disfluency - in this case in the form of deletions and misarticulations - may occur (Myers, 1996).

Conversely, some authors (St. Louis, Raphael, Myers, \& Bakker, 2003; Scott \& St. Louis, in press; St. Louis \& Schulte, in press) do not consider cluttering to be a language disorder, and instead place it into the category of fluency disorders. One reason for this placement is concern that cluttering will be lost among the many other language disorders in the field of speech-language pathology. Further, as cluttering is defined primarily as a rate disorder, in that rate is central to diagnosis and actually causes the other symptoms, it follows that it should be placed into a category that implies a disruption in the flow of speech (St. Louis et al., 2007). Thus, the most recent working definition of cluttering is that of St. Louis et al. (2007) which states that:

Cluttering is a fluency disorder characterized by a rate that is perceived to be abnormally rapid, irregular, or both for the speaker (although measured syllable rates may not exceed normal limits). These rate abnormalities further are manifest in one or more of the following symptoms: (a) an excessive number of disfluencies, the majority of which are not typical of people who stutter; (b) the frequent placement of pauses and use of 
prosodic patterns that do not conform to syntactic and semantic constraints; and (c) inappropriate (usually excessive) degrees of coarticulation among sounds, especially in multisyllabic words (p. 299-300).

In this definition, the term "coarticulation" is used in the way in which Dalton and Hardcastle (1989) described, which they termed "over coarticulation." This refers to collapsing of syllables and doing so much more frequently than normal speakers, so much more in fact that many multisyllabic words are unintelligible. All speakers coarticulate to some degree to enable them to speak faster and more efficiently (Starkweather, 1987). Clutterers do this more often and more “severely." Similar terms used for this phenomenon are "collapsing" or "telescoping" words. For the purposes of this study, the term "coarticulation" is used in the above described manner.

While their primary characteristic is some deviation in rate, clutterers can also show a variety of other symptoms including: language and conversation problems, unawareness that their speech is different, the ability to improve their speech when told to slow down or speak clearly, slurring words (especially longer words), compromised intelligibility, relatives with fluency disorders, messy handwriting, and problems at school or work due to their symptoms (Daly \& Burnett, 1996; St. Louis et al., 2007; Weiss, 1964).

A new version of this working definition is currently in press (St. Louis \& Schulte, in press) and is as follows:

Cluttering is a fluency disorder wherein segments of conversation ${ }^{a}$ in the speaker's native language $e^{b}$ typically are perceived as too fast overall ${ }^{c}$, too irregular ${ }^{d}$, or both. The segments of rapid and/or irregular speech rate must further be accompanied by one or more of the following: (a) excessive "normal" disfluencies ${ }^{e} ;(b)$ excessive collapsing ${ }^{f}$ or deletion of syllables; and/or (c) abnormal pauses, syllable stress, or speech rhythm. 
${ }^{a}$ Cluttering must occur in naturalistic conversation, but it need not occur even a majority of the time. Clear but isolated examples that exceed those observed in normal speakers are sufficient for a diagnosis.

${ }^{b}$ This may also apply to the speaker's mastered and habitual non-native language, especially in multilingual living environments.

${ }^{c}$ This may be true even though syllable rates may not exceed those of normal speakers.

"Synonyms for irregular rate include "jerky," or "spurty."

${ }^{e}$ These disfluencies are often observed in smaller numbers in normal speakers and are typically not observed in stuttering.

${ }^{f}$ Collapsing includes, but is not limited to, excessive shortening, "telescoping," or "overcoarticulating"various syllables, especially in multisyllabic words.

This new definition adds several important points. While continuing to emphasize the importance of some deviation of rate, the new definition also stresses that cluttering typically occurs during conversation. Additionally, it now formally includes the fact that cluttering does not have to occur during every instance of speaking, and in fact many clutterers do normalize during testing. Many researchers have found this to be true (e.g. Daly \& Burnett, 1999; Daly \& St. Louis, 1998; St. Louis et al., 2007), and this new definition now accounts for those findings. Cluttering has also been described in terms of its motor involvement. Lees, Boyle, and Woolfson (1996) reported a case study of a 15-year-old clutterer whom they evaluated following a referral from a fluency disorders specialist. The client was reported to be difficult to understand due to elisions (i.e. omission of one or more syllables), disfluencies, a rapid rate, and phonological problems, with difficulties in reading and spelling as well. In their evaluation, the authors found interjections, repetitions, revisions, variable rate, and elisions that considerably 
lowered his intelligibility. In conclusion, the authors found "slow movement of articulators, slow diadochokinetic rates, short phonation time, and fast speech rate when only perceptually fluent utterances were assessed” (p. 286). Lees et al. suggest that these results support Myers' (1992) assertion that clutterers speak faster than they are able, and further suggest that this may be due to poor motor control of many aspects of the speech mechanism.

\section{Co-existence of Cluttering With Other Speech and Language Disorders}

Generally, most clinicians and researchers agree that cluttering can and often does cooccur with other speech and language problems (St. Louis, Ruscello, \& Lundeen, 1992; St. Louis et al., 2007). In the 2007 chapter, St. Louis et al. discuss coexistence in two main categories: (a) those disorders that are generally agreed upon as commonly coexisting; and (b) those that have "reasonable theoretical rationale" in support of further research regarding their contributions to cluttering. Rate deviations, stuttering, articulation disorders, language disorders, attention deficit/hyperactivity disorders, and specific learning disabilities comprise the first group, while central auditory processing disorders, basal ganglia syndrome, apraxia of speech, and possible subgroups of cluttering comprise the second group.

\section{Stuttering}

As mentioned previously, often the most frequently reported disorder with which cluttering co-exists is stuttering. A summary article by St. Louis (1996) in a Journal of Fluency Disorders (JFD) Special Issue: Research and Opinion on Cluttering included data from 29 clutterers in 12 articles. Thirty-one percent of the 29 clutterers also were reported to stutter. Van Riper's Track II stutterers are those who likely have both stuttering and cluttering. Analysis of his numbers suggests that approximately $14 \%$ of his stutterers fell into this category (Van Riper, 1971, p. 108-111). Typical disfluencies exhibited by stutterers according to the Systematic 
Dysfluency Analysis (SDA; Campbell \& Hill, 1994) include sound or syllable repetitions, prolongations, and blocks.

Disfluencies exhibited by non-stutterers (and possibly clutterers), according to the SDA, include hesitations, interjections, revisions, unfinished words, and phrase repetitions (St. Louis et al., 2003). These disfluencies are sometimes called normal disfluencies, in that they are also evident in the speech of persons without fluency disorders, but may still detract from the overall flow of speech. An example of an interjection might be "like" or "you know," while a revision might look like, "I was going to... the other day I went... Dad and I went to the store yesterday" (St. Louis \& Myers, 1998; St. Louis et al., 2007). It can be said, then, that clutterers typically exhibit an excessive number of these so-called normal disfluencies (St. Louis et al., 2007). Further, these symptoms tend to occur more often and more severely in clusters, and are usually worse in strongly cluttered utterances (Myers, St. Louis, \& Faragasso, 2008; St. Louis et al., 2003). In the aforementioned summary of 29 clutterers in 12 articles, authors reported that $86 \%$ of clutterers had excessive disfluencies (St. Louis, 1996).

Another important distinction between stuttering and cluttering is that clutterers do not have anxiety about saying particular words or sounds in the way that stutterers do; rather, their anxiety may be regarding certain situations (Scott \& St. Louis, in press; St. Louis et al., 2007), which some stutterers experience also. A final means of distinguishing clutterers from stutterers is that, by and large, stutterers know exactly what they want to say yet have difficulty saying it, while clutterers have difficulties figuring out what they want to say, and how to say it. Thus, when clutterers begin to speak, they may have not finished deciding what to say, and their speech is then likely to sound disjointed and disorganized (St. Louis \& Myers, 1998; St. Louis et al., 2007). 


\section{Articulation Disorders}

Articulation refers to pronunciation or enunciation, and when this is disrupted, errors will be noticed by listeners, and, typically, intelligibility and speech naturalness will be negatively affected. From the 29 clutterers in the JFD Special Edition, over half (55\%) had articulation errors (St. Louis, 1996). Some misarticulations exhibited by clutterers include reduced voice onset times, irregular syllable durations, severely shortened vowels, and compressed consonant clusters (St. Louis et al., 2003). Neutralization of sounds occurs in most speakers to some degree as a result of normal coarticulation, but clutterers do so more often and more severely. For example, a clutterer may say "explation" for "explanation” or "inbi-ity” for "inability" (St. Louis et al., 2007).

Clutterers may also exhibit more traditional articulation events such as distortions or substitutions, especially those involving /s/, /r/, and /l/ (Daly \& Burnett, 1999). Myers and St. Louis (1996) found one of the two subjects described in their study had misarticulations of /r/. This could be related to inappropriate or underdeveloped articulatory movements further disrupted by clutterers' unawareness of — and inability to monitor — their own speech.

\section{Language Disorders}

As mentioned previously, one of the most commonly debated issues regarding cluttering is whether or not there is a true language component to cluttering, or if language problems simply coexist with cluttering, as they do with many other disorders. Although some clutterers have been identified who did not present with language components (St. Louis et al., 2007), many researchers have found the coexistence of language problems. Again, from the Special Issue: Research and Opinion on Cluttering, out of 29 clutterers in 12 articles, 28\% and 14\% of clutterers also evidenced expressive and receptive language disorders, respectively (St. Louis, 
1996). Myers (1996) concluded that clutterers can have problems with pragmatics, or the social aspects of speech, and narratives, which involves forming a cohesive thought process that ties ideas together coherently.

Mazes, originally discussed by Loban (1963), also are frequently found in the speech of clutterers, and involve "rambling, run-on verbalizations that add nothing to the content of the message" (St. Louis et al., 2003, p. 5). Mazes frequently include false starts and disfluent speech (St. Louis \& Myers, 1997), and are thought to be linguistically or cognitively based (St. Louis et al., 2007). In a study by Teigland (1996), clutterers were almost three times more likely than non-clutterers to exhibit mazes when giving verbal directions. Further, the "organization" of the mazes differed between groups. Clutterers' mazes “consisted of unusual syntactical structures making messages uninterpretable or especially difficult to understand" while mazes of nonclutterers "consisted of discontinuity and corrections in the same turn that generally resulted in well-formulated and unambiguous messages in accordance with the speaker's intention" (p. 211). Additionally, clutterers exhibited mazes in both rapid and "normal" speech rates, which could be due to word-finding difficulties or the stress of formulating cohesive and coherent speech.

The Teigland study also provides evidence to suggest that clutterers have difficulties in monitoring their own speech, even aspects as basic as the content of the message they are conveying. In this study, clutterers not only did not provide sufficient information to their conversation partners, they were also unaware of that fact, unless their partners asked "repair questions" (p. 212).

In the above-mentioned study of two young clutterers (Myers \& St. Louis, 1996), on the Clinical Evaluation of Language Fundamentals Revised (CELF-R; Semel, Wiig \& Secord, 1987) 
one subject, $\mathrm{S} 23$, scored in the $1^{\text {st }}$ and $5^{\text {th }}$ percentiles, respectively, on two subtests (formulated sentences and sentence assembly), receiving a low expressive language score, although all of his receptive test scores were above the $90^{\text {th }}$ percentile. The other subject, S24, scored generally lower on both receptive and expressive subtests, with expressive subtests percentiles all falling below the $37^{\text {th }}$ percentile.

\section{Rate}

The working definitions by St. Louis et al. (2007) and St. Louis and Schulte (in press) clearly point to rate as the primary symptom of cluttering, and thus is required for diagnosis. Clutterers can either speak too fast or speak too irregularly. The data that St. Louis (1996) summarized from 29 clutterers in 12 articles indicated that $86 \%$ of the clutterers were reported to manifest a rate of speech that was too fast and $86 \%$ of the clutterers had a rate of speech that was too irregular. Irregular rate is variable and choppy, filled with abnormally placed pauses that are possibly due to attempting to plan a coherent utterance. Additionally, these authors do not consider excessively rapid speech (ERS) alone to be cluttering (St. Louis \& Schulte, in press). Myers and St. Louis (1992) maintain that while rate is likely the most important factor in disfluencies exhibited by clutterers, the ways in which rate causes cluttering are still speculative. While little objectively obtained data exist on this topic (as it would be hard to reliably assess what is occurring in someone's thoughts), subjective reports from clutterers indicate that this is indeed what is occurring, at least in some instances (St. Louis et al., 2007). Not all researchers agree that rate deviations are obligatory, however (e.g., Weiss, 1964; Daly \& Burnett, 1999), and this is still an area of debate in the field.

The way in which rate is defined is also an important consideration. While the average syllables per minute (SPM) of adult speakers is 180-220 (Ingham, 1984; St. Louis et al., 2003), 
rate need not be measured so strictly when evaluating cluttering. Although SPM is used most often, syllables per second [SPS] as a measure of "articulation rate" may be an effective means of studying rate when it is important to extract pauses from a speech sample. Typically SPS discounts pauses, so including pauses that occur in cluttered speech could actually reduce the measured rate. As clutterers may have many forms of pauses in their speech (such as hesitations or blocks), deleting pauses and then using SPS may provide useful information to supplement ordinary speaking rate measures using SPM (St. Louis, et al., 2007). In either case, there are several aspects of rate to be considered in determining whether or not one has an "excessive" rate. According to Myers (1996), rate can be: (a) relative to that of normal speakers, (b) indicative of the sequencing of the articulators, (c) reflective of utterance planning, (d) relative to how words in an utterance fit together (i.e., juncture), and (e) reflective of suitable conveyance of information in a conversation.

\section{Rate and Time Estimation}

If rate is centrally important to the diagnosis and management of cluttering, and if most clutterers are not aware that they have a rate problem, it is plausible that their rate problems may be in fact related to a lack of awareness of and an inability to monitor their own speech. If clutterers are unaware of the characteristics of their speech, such as their rate, they also may be likely to be unaware of the amount of time required to say something.

While aspects of timing, such as the ability to estimate various characteristics of time, have not been studied in cluttering research, timing has been studied in the related fluency disorder of stuttering. Although some research had previously been completed that showed stutterers were poor time estimators, one of the first to compare time estimation of stutterers to nonstutterers was by Ringel and Minifie (1966). In this study, subjects were divided into three 
groups based on the fluency characteristics of their speech: group 1 was composed of normal speakers, group 2 of mild stutterers, and group 3 of moderate-to-severe stutterers. In the study, subjects were given one of five tasks, then asked to hold down a button at the beginning of the task, and to release the button after 10 seconds. The five tasks were silence, oral reading, silent reading, listening (being read to by the experimenter), and spontaneous speech. The authors found that all subjects overestimated the length of time in each of the five tasks. They also found that the only significant difference between conditions was when comparing silence to the other tasks. Further, mild stutterers were not significantly different from nonstutterers, but both were significantly different than moderate-to-severe stutterers. Thus, mild stutterers are more like nonstutterers than they are moderate-to-severe stutterers with regard to time estimation.

In a study by Barasch, Guitar, McCauley, and Absher (2000), stutterers and non-stutterers were given the Duration Pattern Sequence Test (DPS). In the DPS, subjects are presented 30 series of three tones, monaurally, in each ear. The subjects then report the duration of each of the tones in the series, e.g. "long, short, long." Following the administration of the DPS, subjects were asked to estimate protensity, or the perceptual judgment of the amount of time that has passed (Barasch et al., 2000). To measure protensity, the subjects completed various tasks in estimating lengths of tones and blocks of silences between tones. Finally, they were asked to estimate the length of time they had been in the room. They were not allowed to keep track of time in any way (taps, clicks, watches, clocks, and so on).

Each group (stutterers and non-stutterers) were further assessed with regard to their disfluencies, and were placed into groups of "more disfluencies" and "less disfluencies," in order to look at fluency in general as well as between group differences. Overall results from this study provide support for the notion that fluency lies on a continuum. The authors found that subjects 
with more disfluencies had lower DPS scores (i.e. they did poorer on the test than subjects with fewer disfluencies). Additionally, subjects with more disfluencies had overall longer time estimates. Finally, the authors found that degree of disfluency was a more important factor than whether or not one stutters with regard to performance on the DPS and time estimation tasks. However, when they combined all data from all estimates, the mean estimates of each group were the same. This study is important because it indirectly supports a hypothesis by Kent (1984) that verbal fluency is correlated with temporal processing ability in that it suggests that people with fluency disorders may have difficulties with temporal processing in general.

Another study involving time estimation by stutterers was conducted by Ezrati-Vinacour and Levin (2001). In this study, stutterers and non-stutterers estimated the length of four verbal tasks, two of which involved speaking and two of which did not, and used two methods of estimation: production and reproduction. In production, the subjects engaged in a behavior and ended it after the time period expressed to them had passed. Production typically results in overestimation of time passed. In reproduction, the subjects engaged in a task, were stopped by the researcher, and were then asked to estimate the length of time they were in that task. Reproduction typically results in underestimation (Zakay, 1990, 1993). The four tasks were as such: silent reading of a story, listening to a story recording, reading aloud a story, and conversation, all of which were randomly assigned and counterbalanced.

The results of this study are complex, but support the idea that fluent speakers are better estimators of time than stutterers. This finding supports the results reported by Ringel and Minifie (1966), although they only used the production method. Like the previously summarized study, Ezrati-Vinacour and Levin's study also grouped subjects by stuttering severity. The authors found that severe stutterers estimated time less accurately than mild stutterers, and found 
no difference between stutterers and non-stutterers. Additionally, and conversely to the Ringel and Minifie study, both stutterers and non-stutterers estimated time less accurately on oral versus non-oral tasks, which may be attributed to the amount of internal processing and planning that occurs during speaking. Further, stutterers were poorer estimators during the oral tasks than nonstutterers; however, the tasks that provided these results were in conversation versus listening, not between silent reading and reading aloud, which the authors suggest may be due to the "automaticity" of reading aloud. Finally, mild stutterers estimated time more accurately than severe stutterers.

Lass and Conn (1974) examined time perception abilities in 20 normal subjects in three conditions. In each condition, four time intervals were judged: 6, 27, 53, and 96 seconds. In the first condition, "empty passive," the subject estimated the duration of silent interval between two tones. In the second condition, "speech-filled passive," subjects listened to prerecorded speech. Finally, in the third condition, "speech-filled active," the subjects engaged in reading. The results suggested that no significant differences existed in the time estimation abilities in any of the three conditions. In the empty passive condition, subjects underestimated the two shortest intervals, and overestimated the longer, with the reverse being true in the speech-filled passive condition. Subjects underestimated the time of all four intervals in the speech-filled active condition, with differences ranging from 0.25 seconds to 2.25 seconds, and increasing as the time interval increased.

An unpublished master's thesis (Brock, 2008) investigated the rate of covert versus overt speech in normal speakers. In this study, participants were instructed to think of the first thing that came to mind, say that utterance to themselves using inner speech (covert), and then say it out loud (overt). Participants timed their covert and overt utterances, allowing rate to be 
calculated. The mean rate for covert speech was not significantly different than overt, differing only by 0.1 seconds, suggesting that, for normal speakers as a group, covert and overt speech have the same rate. Some individual differences did exist. Twelve of the 20 participants had significant differences between the two conditions: six had significantly higher overt rates and six had significantly higher covert rates. Accordingly, out of all of the participants, $60 \%$ showed significant differences in covert and overt rates, while $40 \%$ had no difference. Additionally, the covert samples evidenced more variability than the overt samples.

\section{Statement of the Problem}

The purpose of this study was to determine if clutterers' awareness of the duration of their own speech duration is different than that of non-clutterers. The literature suggests that in general, persons with fluency disorders have an impaired ability to estimate duration of different types of events, such as tones, speech, and elapsed time. While these studies all involved the fluency disorder of stuttering, stuttering and cluttering are related, and often even coexist. Therefore, it is possible that the same brain structures, pathways, or mechanisms are impaired in clutterers as in stutterers (St. Louis et al., 2007). Further, this inability to estimate duration may be related to impaired monitoring or awareness of auditory input.

Difficulty in monitoring speech output can be associated with a breakdown, thus producing the classic symptoms of cluttering, as described by St. Louis et al. (2007), which are reiterated here. Cluttering is primarily a rate problem that further causes one or more of the following: (a) an excessive number of disfluencies, the majority of which are not typical of people who stutter; (b) the frequent placement of pauses and use of prosodic patterns that do not conform to syntactic and semantic constraints; and (c) inappropriate (usually excessive) degrees of coarticulation among sounds, especially in multisyllabic words. 
If it is true that clutterers attempt to speak faster than they are able as suggested by Myers (1996), it is possible that this emanates from a breakdown in their awareness and monitoring of their own speech. This breakdown, together with an inability to estimate time in varying tasks, could yield symptoms of cluttering. If this is true, clutterers will evidence a difference between actual speech time and estimated speech time of the same task.

This could be manifest in two ways. First, clutterers could have longer estimated times than actual times. That is, it could take clutterers less time to say something than they think it will take. Conversely, clutterers could have longer actual times than estimated times. That is, it could take clutterers longer to say something than they think it will.

Method

\section{Participants}

Six cluttering and six non-cluttering normal speakers participated in the study. Clutterers served as the experimental group, and were recruited by word of mouth from professionals via personal contact, phone, email, and/or mailing lists. Non-clutterers served as controls, were matched for age (within five years above or below) and sex with the experimental group, and were recruited from friends or colleagues of the researcher. All participants were able to control a computer mouse.

\section{Clutterers}

Screening procedure. In an attempt to verify that potential participants were in fact clutterers, a series of screening procedures were performed prior to the start of the study. First, it should be noted that one characteristic of cluttering that frequently occurs, and poses problems to the actual diagnosis of cluttering, is normalization. In fact, item number 10 on the Predictive Cluttering Inventory (Daly, 2006) is, "Speech better under pressure (improves short-term with 
concentration)." When clutterers are forced to attend to their speech, such as when they are being evaluated, they often exhibit few if any symptoms. A possible clutterer may arrive for an evaluation, with previously reported anecdotal evidence of cluttering, and speak perfectly with no deviations in rate, disfluencies, coarticulation, or prosody. Further, the presence and use of a recording device during the evaluation often evokes fluent speech, which then returns to cluttered speech upon removal of the tape recorder (Daly \& Burnett, 1996).

One could argue that this behavior serves as evidence against the notion that clutterers are unaware of their speech. If clutterers are not aware that they are speaking too quickly or erratically, how could they normalize? This behavior, however, is more likely a reaction to being observed, and is common in research studies. If a participant is aware that his speech is being evaluated, especially if he has been told the specifics of the suspected speech disorder, this could explain the normalization during evaluation and/or recording. In this investigation, audio recording of the session was essential, however, as it served as the source for extraction of the actual speech times during the present experiment. Thus, initial consent for recording was obtained verbally or through e-mail prior to the arrival of the participant for testing, and was then confirmed on the day of testing.

Further, the researcher was aware that capturing cluttering during an evaluation procedure may prove to be difficult. In order to combat this difficulty, as many of the following screening procedures as possible were employed. First, using perceptual rating scales developed by the researcher (Appendix A) targeting aspects of speech such as rate, articulation, language, fluency, pausing, intelligibility, and naturalness, when possible, the researcher rated the potential clutterers after each contact prior to the experiment being conducted. Second, one or more "referrers" (such as a parent, friend, or co-worker) completed the same rating scales based upon 
their interactions with the potential clutterer. Third, each clutterer also completed the rating scales upon arrival to testing, providing the researcher with at least three descriptions/evaluations of the clutterer.

Finally, after the experiment concluded, an additional rater was trained to complete the previously mentioned rating scales using a sample of cluttered speech that was not part of this study. This person was a recent graduate of a master's program in speech-language pathology who had coursework in the area of cluttering. Thereafter, this person rated recorded conversation samples for each participant, the order of which was randomized.

For this study, a clutterer was defined using the most recent published definition of cluttering (St. Louis et al., 2007), as described previously. A clutterer must have had a rapid and/or irregular rate of speech (as perceived by the researcher) that further caused one or more of the following: (a) above average frequency of normal disfluencies, (b) unnatural pausing, or (c) inappropriate coarticulation. To determine these and other aspects of speech, clutterers were given a battery of tests, including the Templin-Darley Tests of Articulation (Templin \& Darley, 1969) in which subjects read a total of 141 sentences, the Peabody Picture Vocabulary Test, 4th Edition (Dunn \& Dunn, 2007), the Predictive Cluttering Inventory (PCI; Daly, 2006) (Appendix B), Self-Awareness of Speech Index (St. Louis \& Atkins, 2005) (Appendix C), St. Louis Inventory of Life Perspectives and Speech/Language Difficulty (SL $\bullet L P-S / L$; St. Louis, 2005) (Appendix D), and a recorded speech sample. This speech sample was approximately five minutes in length and included oral reading, i.e., a list of words that increased in syllable length, other multisyllabic words (Appendix E), and the grandfather passage (Darley, Aronson, \& Brown, 1975) (Appendix F). The speech sample also included about three to five minutes of conversation in response to prompts (e.g., "Tell me about your family"). The recorded speech 
sample was orthographically transcribed to identify and/or demonstrate evidence of cluttering with regard to articulatory errors, rapid/irregular speech, prosodic abnormalities, and collapsing of multi-syllabic words. Finally, a hearing screening consisting of pure tones presented at $20 \mathrm{~dB}$ at frequencies of $1000 \mathrm{~Hz}, 2000 \mathrm{~Hz}, 3000 \mathrm{~Hz}$, and $4000 \mathrm{~Hz}$ was performed (ASHA, 1997).

Rate was calculated in multiple instances using different methods. First, a perceptual rating of three aspects of rate (speed, regularity, and pausing) was obtained using the abovementioned perceptual rating scales developed by the researcher. Second, rate, in syllables per minute (SPM), was also calculated for the short conversation sample and the orally read grandfather passage. Third, a sample of five experimental items (described in the procedures section below) was taken, and rate was calculated using syllables per second (SPS). As mentioned previously, clutterers typically exhibit a rapid and/or irregular rate of speech, with "cluttered" utterances often being produced in short bursts. Clutterers may not exhibit cluttered speech or a rapid rate during every utterance, or even part of every utterance.

\section{Non-clutterers}

Non-cluttering controls presented with none of the previously mentioned symptoms required for a diagnosis of cluttering, especially rate deviations (including excessive rapid speech). Rate was calculated in the same manner as clutterers. Controls were also normal with regard to speech, language, and hearing as determined by a screening protocol. Controls completed the same tests as the clutterers (see above) to assess their articulation, language, fluency, and hearing, and to rule out any abnormalities that may have been present.

\section{Materials and Procedure}

The experiment was conducted using a laptop computer (model Dell XPS M1210) preloaded with a version of the Cluttering Assessment Program developed by Klaas Bakker 
(CLASP; Version 3, 2005) which functioned as a stopwatch using a keyboard and a mouse. Participants estimated the amount of time required to complete an utterance, and then they verbally completed the utterance. All sessions were recorded using a Sony digital recorder (model ICD-P620). The participant and researcher sat at a table, with the participant facing the researcher and the laptop screen facing the researcher, which prevented the participant from seeing the screen and allowed the researcher to record the data.

Experimental speech task stimuli (see Appendix G) consisted of two types of questions: (a) "Given a situation, what is your reaction?" (e.g., "Someone walking in front of you slips on the ice, what do you do?") or (b) "Given a choice of two things, which do you prefer and why?" (e.g., "Do you prefer cats or dogs and why?"). Forty possible scenario questions were constructed for each type, with 80 total.

Following instructions from the researcher (see Appendix H) participants were first trained to ensure understanding and mastery of the procedure. Following a prompt from the researcher to say something (e.g., "Tell me your full name") participants were instructed to think about what they would say and then press and hold the mouse button down for the exact time they thought they would need to say it ("Estimated Time"). The participant then released the mouse button, and immediately said the same answer aloud ("Actual Time"). Next, immediately after each verbal utterance, the participant told the researcher how well their verbal output matched what they thought about for that item (i.e., Did they say aloud what they thought they would say?) on a scale of 1 to 5. The scale was as follows: 1 - Did not match at all; 2 - Matched less than half; 3 - Matched about half; 4 - Matched more than half; and 5 - Matched exactly. Participants were trained on this procedure using blocks of five trials until they reached three consecutive trials of 4 out of $5(80 \%)$ wherein they completed all of the parts of the task 
correctly (e.g., pressed the mouse button to estimate and released it before speaking) and their ratings of matches between planned and actual utterances were $4 \mathrm{~s}$ or $5 \mathrm{~s}$ for matches between planned and actual utterances. That is, participants must have rated 4 out of 5 utterances at 4 or above (ratings of 1, 2, and 3 were considered insufficient). Training stimuli consisted of 20 items (10 of each of the two types) that were similar in difficulty to the tasks used in the experiment proper. Training stimuli were reused during training if necessary until criteria was met, and were not included in the experimental tasks.

The experimental task then began using the same procedure that was used during training. Participants were presented with speech tasks and asked to first think about what they would say, press and hold the mouse button down for the exact time they think they would use to say it (Estimated Time), release the mouse button, and then immediately say the same thing aloud (Actual Time). The researcher wrote the estimated times, in seconds rounded to hundredths, after each trial from the CLASP screen. Actual times were extracted from the digital audio recordings at a later date using the CLASP program. In this case, the researcher played the recording of each participant, pressed the mouse button down when the participant began to speak, and released it when the utterance was finished, for each of the speech tasks. The resulting time, rounded to hundredths, was recorded.

The two types of questions were given alternately until the participant rated 50 utterances at 4 or 5 . If a participant rated an utterance below a 4, the item was marked as given but was not included for analysis. In this way, the researcher continued through the list of prompts, keeping track until 50 tasks were rated at 4 or above. After 50 items had been estimated and uttered satisfactorily, the experiment concluded. 
Following the experiment, a control procedure was administered to ensure that participants were adequately able to start and stop a timer corresponding, respectively, with the beginning and ending of an utterance and to permit comparison of all experimental and control subjects on a common timing task. Each participant listened to six pre-recorded sentences and pressed the mouse button to time each sentence. The researcher simply recorded each time in seconds, rounded to hundredths, for each of the six trials. Although the training portion of the experimental task assisted in ensuring that participants were able to time their "inner speech," this control procedure was also used for additional verification of timing abilities.

Results

\section{Participants}

\section{Demographics.}

Detailed data for all clutterers are provided in Table 1. It can be seen in column 2 that five males and one female served as the experimental cluttering group. The mean age of this group (column 3) was 36.0 years, ranging from 22 to 57 years. All clutterers had some college experience (column 4): one held a doctorate degree (Clutterer (CL) 4), two held or were pursuing a master's degree (CL1 and CL2), two were pursuing a bachelor's degree (CL3 and CL5), and one attended college for a short time and was working at the time of the experiment (CL6). One (CL1) was a practicing speech-language pathologist and another (CL3) had taken undergraduate courses in speech-language pathology. CL4 worked as a Dean in an agricultural field, CL2 was studying reproductive physiology, and CL6 was unemployed but was to begin working at WalMart in the coming days. All clutterers had received varying amounts of speech therapy in the past. (The remaining data in Table 1 are discussed below.) 
Table 1.

Description of clutterers.

\begin{tabular}{ccccccccccc}
\hline Subject & Sex & Age & Educ. & $\begin{array}{c}\text { TD } \\
\text { (\# errors) }\end{array}$ & $\begin{array}{c}\text { PPVT } \\
\text { SS }\end{array}$ & $\begin{array}{c}\text { PPVT } \\
\text { RS }\end{array}$ & $\begin{array}{c}\text { PCI }- \\
\text { Self }\end{array}$ & $\begin{array}{c}\text { PCI }- \\
\text { Exp. }\end{array}$ & SASI & $\begin{array}{c}\text { SL- } \\
\text { ILP }\end{array}$ \\
\hline CL1 & F & 48 & MS & 0 & 113 & 219 & 100 & 92 & 3.1 & 18 \\
CL2 & M & 25 & MS & 3 & 106 & 211 & 73 & 93 & 2.57 & 28 \\
CL3 & M & 42 & BS & 0 & 103 & 214 & 96 & 124 & 2.93 & 26 \\
CL4 & M & 57 & PhD & 5 & 114 & 220 & 124 & 111 & 2.6 & 14 \\
CL5 & M & 22 & BS & 5 & 97 & 199 & 60 & 100 & 1.86 & 25 \\
CL6 & M & 22 & Some & 41 & 104 & 204 & 80 & 133 & 2.79 & 38 \\
\hline Mean & & 36.00 & & 9.00 & 106.17 & 211.17 & 88.83 & 108.83 & 2.64 & 24.83 \\
SD & & 15.06 & & 15.84 & 6.43 & 8.33 & 22.68 & 16.92 & 0.43 & 8.35 \\
\hline
\end{tabular}

Parallel details for controls can be seen in Table 2. Five male participants and one female participant, matched for age and sex, with the clutterers as described earlier. The mean age for the control group was 38.3 years, ranging from 23 to 59. Two participants held a master's degree (Control [CO]1 and CO2), two held a bachelor's degree (CO3 and $\mathrm{CO} 4)$, and two attended college but did not have degrees (CO5 and CO6). CO1 was working as a speech-language pathologist. $\mathrm{CO} 2$ was an environmental consultant in the local area. $\mathrm{CO} 3$ was a software developer in a neighboring city. $\mathrm{CO} 4$ was a network administrator also working in a neighboring town. CO5 worked at a local Wal-Mart distribution center, and CO6 worked as a sheet metal worker in a bordering state. 
Table 2.

Description of controls.

\begin{tabular}{ccccccccccc}
\hline Subject & Sex & Age & Educ. & $\begin{array}{c}\text { TD } \\
\text { (\# errors) }\end{array}$ & $\begin{array}{c}\text { PPVT } \\
\text { SS }\end{array}$ & $\begin{array}{c}\text { PPVT } \\
\text { RS }\end{array}$ & $\begin{array}{c}\text { PCI- } \\
\text { Self }\end{array}$ & $\begin{array}{c}\text { PCI }- \\
\text { Exp. }\end{array}$ & SASI & $\begin{array}{c}\text { SL- } \\
\text { ILP }\end{array}$ \\
\hline CO1 & F & 52 & MS & 0 & 106 & 216 & 20 & 24 & 3 & 7 \\
CO2 & M & 29 & MS & 0 & 113 & 215 & 41 & 22 & 2.57 & 10 \\
CO3 & M & 43 & BS+ & 0 & 115 & 220 & 54 & 17 & 2.71 & 7 \\
CO4 & M & 59 & BS+ & 0 & 107 & 217 & 6 & 28 & 1.93 & 7 \\
CO5 & M & 24 & $\begin{array}{c}\text { Some } \\
\text { Uni. }\end{array}$ & 0 & 95 & 198 & 41 & 18 & 2.71 & 10 \\
CO6 & M & 23 & $\begin{array}{c}\text { Some } \\
\text { Uni. }\end{array}$ & 0 & 99 & 204 & 16 & 24 & 2.86 & 7 \\
\hline Mean & & 38.33 & & 0.00 & 105.83 & 211.67 & 29.67 & 22.17 & 2.63 & 8.00 \\
SD & & 15.25 & & 0.00 & 7.76 & 8.64 & 18.38 & 4.12 & 0.37 & 1.55 \\
\hline
\end{tabular}

Rate.

One measurement of rate was obtained using perceptual scales developed by the researcher (Appendix A). (Note: each section of this rating scale, i.e. rate, articulation, language, fluency, has been separated for ease of presentation.) Rating scale data for each of the three raters in totality are listed in Appendix I. The perceptual scales were completed by the researcher, the participant, and another person acquainted with each participant, such as a spouse, friend, or colleague. Participants' rates were judged on 7-point Likert scales in three areas: speed, regularity, and pausing. Possible speed judgments ranged from -3 (extremely slow) to 3 (extremely fast). Regularity had a possible range of 0 (regular) to 6 (extremely irregular) and pausing had a possible range of 0 (appropriate) to 6 (extremely inappropriate). Individual perceptual rate data, including t values and significance levels, can be seen in Table 3 (self), Table 4 (researcher), and Table 5 (friend), and Figure 1. It should be noted that the speed 
judgment was converted to the same 0 to 6 scale for ease of comparison. For speed, statistically significant mean differences only existed between clutterers and controls on ratings completed by the researcher, with clutterers being rated higher. For regularity, significant differences between clutterer and control means existed for all three ratings: self, researcher, and friends. For pausing, significant differences were found for self and researcher judgments, but not friend judgments.

Table 3.

Mean self-ratings of speaking rate for clutterers and controls.

\begin{tabular}{cccccc}
\hline Self Mean & CL & CO & df & t value & $\mathrm{p}$ \\
\hline Speed & 4.33 & 3.33 & 10 & 1.86 & 0.09 \\
Regularity & 3.50 & 0.67 & 10 & 4.71 & $<.001$ \\
Pausing & 3.17 & 0.50 & 10 & 5.06 & $<.001$ \\
\hline
\end{tabular}

Table 4.

Mean researcher ratings of speaking rate for clutterers and controls.

\begin{tabular}{cccccc}
\hline Researcher Mean & CL & CO & df & t value & p \\
\hline Speed & 5.00 & 3.00 & 10 & 5.47 & $<.001$ \\
Regularity & 3.67 & 0.00 & 10 & 11 & $<.001$ \\
Pausing & 2.67 & 0.00 & 10 & 4.78 & $<.001$ \\
\hline
\end{tabular}


Table 5.

Mean friend ratings of speaking rate for clutterers and controls.

\begin{tabular}{cccccc}
\hline Friend Mean & CL & CO & df & t value & $\mathrm{p}$ \\
\hline Speed & 4.00 & 3.00 & 10 & 1.58 & 0.14 \\
Regularity & 2.33 & 0.00 & 10 & 3.80 & $<.01$ \\
Pausing & 1.17 & 0.00 & 10 & 2.15 & 0.06 \\
\hline
\end{tabular}

Rate was also calculated during conversation and reading. Conversational samples were analyzed on the first 420 syllables which was the lowest number of syllables for any of the 12 participants. Actual syllable count for the grandfather passage was calculated for each subject and ranged from 174 to 184 syllables, dependent upon if the subject read the title or omitted, added, or misread words. The mean rate of the experimental group was 205 syllables per minute (SPM) during conversation (range 177 to 239) and 208 SPM during oral reading of the grandfather passage (range 172 to 231). Controls had a mean rate of 189 SPM during conversation (range 162 to 235) and 218 SPM during reading of the grandfather passage (range 171 to 254). Individual rates for clutterers (CL) and controls (CO) are displayed, respectively, in Tables 6 and 7. Additionally, to examine rate during the experimental tasks, every tenth utterance was selected for each participant, yielding a total of five utterances. For these experimental items which typically contained few pauses, syllables per second (SPS) were calculated. Syllables for individual items ranged from 2 to 24 , with means ranging from 5.00 to 17.20. The overall average length of the 30 utterances for clutterers was 2.28 s compared to $1.92 \mathrm{~s}$ for the controls. Mean rates for these relatively short spontaneous speech samples were 5.31 SPS for clutterers and 5.79 SPS for controls. These results are converted into SPM in the tables for 
Figure 1. Mean perceptual rankings of all categories of rate, as judged by each participant, the researcher, and a friend of the participant. Significant differences between clutterers and controls are marked with an asterisk $(*)$.

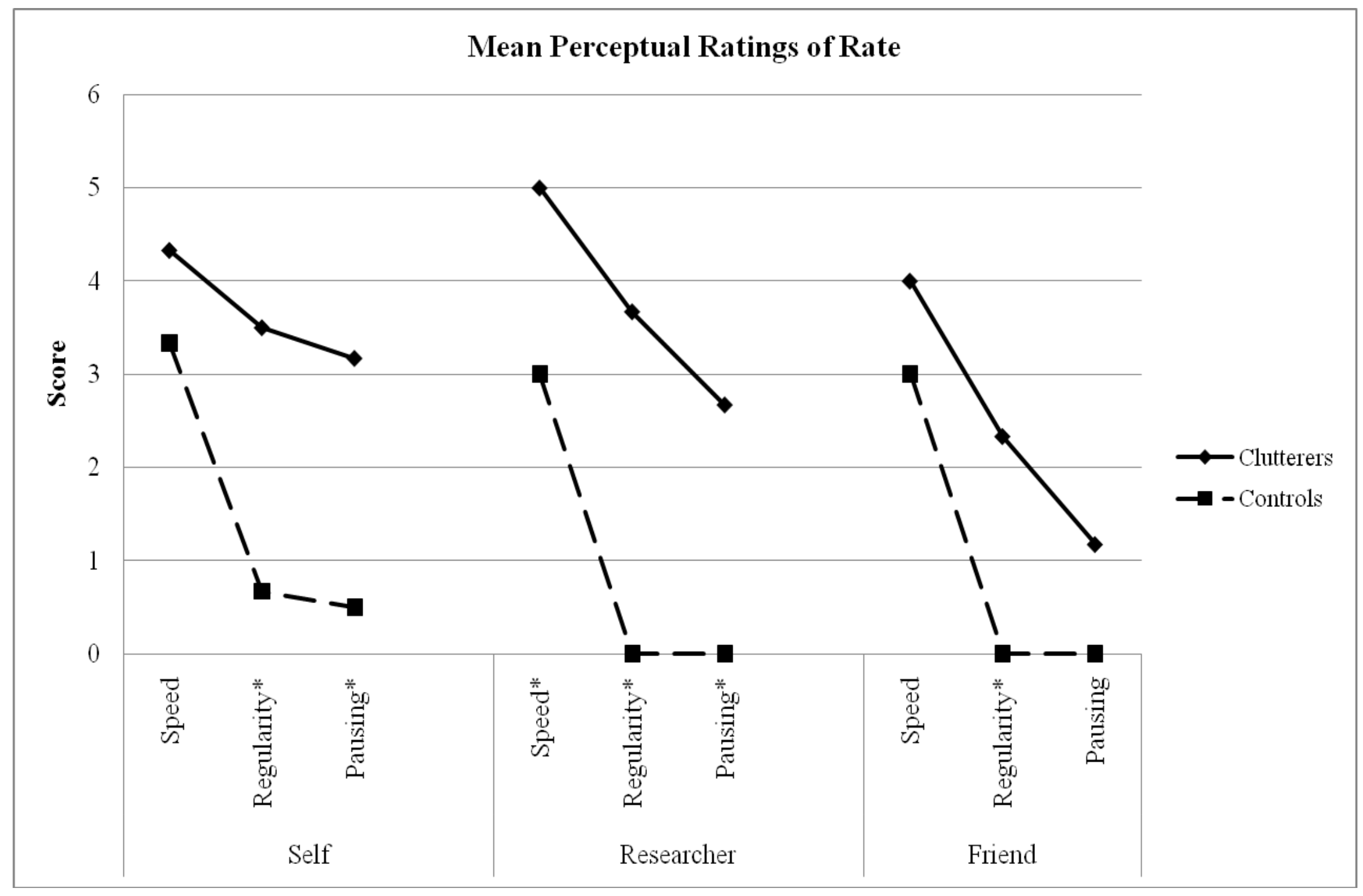


easy comparison, and transcriptions of the utterances are provided in Appendix J. These data taken together indicate that, while clutterers' mean measured rates in SPM were not above average, their perceived rates were faster than average. Their regularity and pausing were also perceived to be somewhat irregular as well.

Table 6.

Rate in syllables per minute for clutterers.

\begin{tabular}{cccc} 
& Reading & Conversation & Experiment \\
\cline { 2 - 4 } CL1 & 205 & 177 & 334 \\
CL2 & 227 & 213 & 334 \\
CL3 & 210 & 224 & 362 \\
CL4 & 172 & 200 & 272 \\
CL5 & 231 & 239 & 315 \\
CL6 & 208 & 179 & 296 \\
\hline MEAN & 208.83 & 205.33 & 318.60 \\
SD & 23.42 & 24.76 & 31.79 \\
\hline
\end{tabular}

Table 7.

Rate in syllables per minute for controls.

\begin{tabular}{cccc}
\hline & Reading & Conversation & Experiment \\
\cline { 2 - 4 } CO1 & 254 & 166 & 349 \\
CO3 & 197 & 193 & 337 \\
CO4 & 213 & 162 & 397 \\
CO5 & 225 & 235 & 289 \\
CO6 & 171 & 178 & 311 \\
\hline MEAN & 250 & 181 & 399 \\
SD & 218.33 & 185.83 & 347.10 \\
\hline
\end{tabular}




\section{Articulation.}

Articulation was also assessed on the perceptual scales developed by the researcher, which again was completed by the same three persons discussed above. Five primary areas of articulation were assessed, all on a 7-point scale ranging from 0 (never) to 6 (always), and included (a) collapsed syllables, (b) compressed clusters, (c) shortened vowels, (d) traditional articulation errors, and (e) intelligibility. Mean perceptual ratings for clutterers and controls are provided in Table 8 (self), Table 9 (researcher), and Table 10 (friend), and depicted graphically in Figure 2. Statistically significant differences favored controls over clutterers for nearly all ratings for the participants themselves, the researcher, and a friend. The two exceptions were self-ratings of intelligibility and friend ratings of articulation errors, in which there were no significant differences but trends were in the same direction.

Table 8.

Mean self-ratings of articulation for clutterers and controls.

\begin{tabular}{cccccc}
\hline Self Mean & CL & CO & df & t value & $\mathrm{p}$ \\
\hline Intelligibility & 1.60 & 0.50 & 9 & 2.11 & 0.06 \\
Collapsed Syllables & 3.50 & 0.50 & 10 & 7.35 & $<.001$ \\
Compressed Clusters & 3.67 & 0.33 & 10 & 11.19 & $<.001$ \\
Shortened Vowels & 3.17 & 0.33 & 10 & 7.60 & $<.001$ \\
Articulation Errors & 1.83 & 0.33 & 10 & 2.58 & $<.05$ \\
\hline
\end{tabular}


Table 9.

Mean researcher ratings of articulation for clutterers and controls.

\begin{tabular}{cccccc}
\hline Researcher Mean & CL & CO & df & t value & p \\
\hline Intelligibility & 2.33 & 0.17 & 10 & 4.78 & $<.001$ \\
Collapsed Syllables & 3.67 & 0.33 & 10 & 7.07 & $<.001$ \\
Compressed Clusters & 3.50 & 0.33 & 10 & 6.64 & $<.001$ \\
Shortened Vowels & 3.83 & 0.17 & 10 & 15.56 & $<.001$ \\
Articulation Errors & 2.17 & 0.00 & 10 & 3.61 & $<.01$ \\
\hline
\end{tabular}

Table 10.

Mean friend ratings of articulation for clutterers and controls.

\begin{tabular}{cccccc}
\hline Friend Mean & CL & CO & df & t value & $\mathrm{p}$ \\
\hline Intelligibility & 1.17 & 0.33 & 10 & 2.24 & $<.05$ \\
Collapsed Syllables & 2.00 & 0.50 & 10 & 3.50 & $<.01$ \\
Compressed Clusters & 2.67 & 0.17 & 10 & 3.93 & $<.01$ \\
Shortened Vowels & 2.50 & 0.33 & 10 & 2.89 & $<.05$ \\
Articulation Errors & 1.50 & 0.17 & 10 & 1.42 & 0.19 \\
\hline
\end{tabular}


Figure 2. Mean perceptual rankings of all categories of articulation, as rated by each participant, the researcher, and a friend of the participant. Significant differences between clutterers and controls are marked with an asterisk (*).

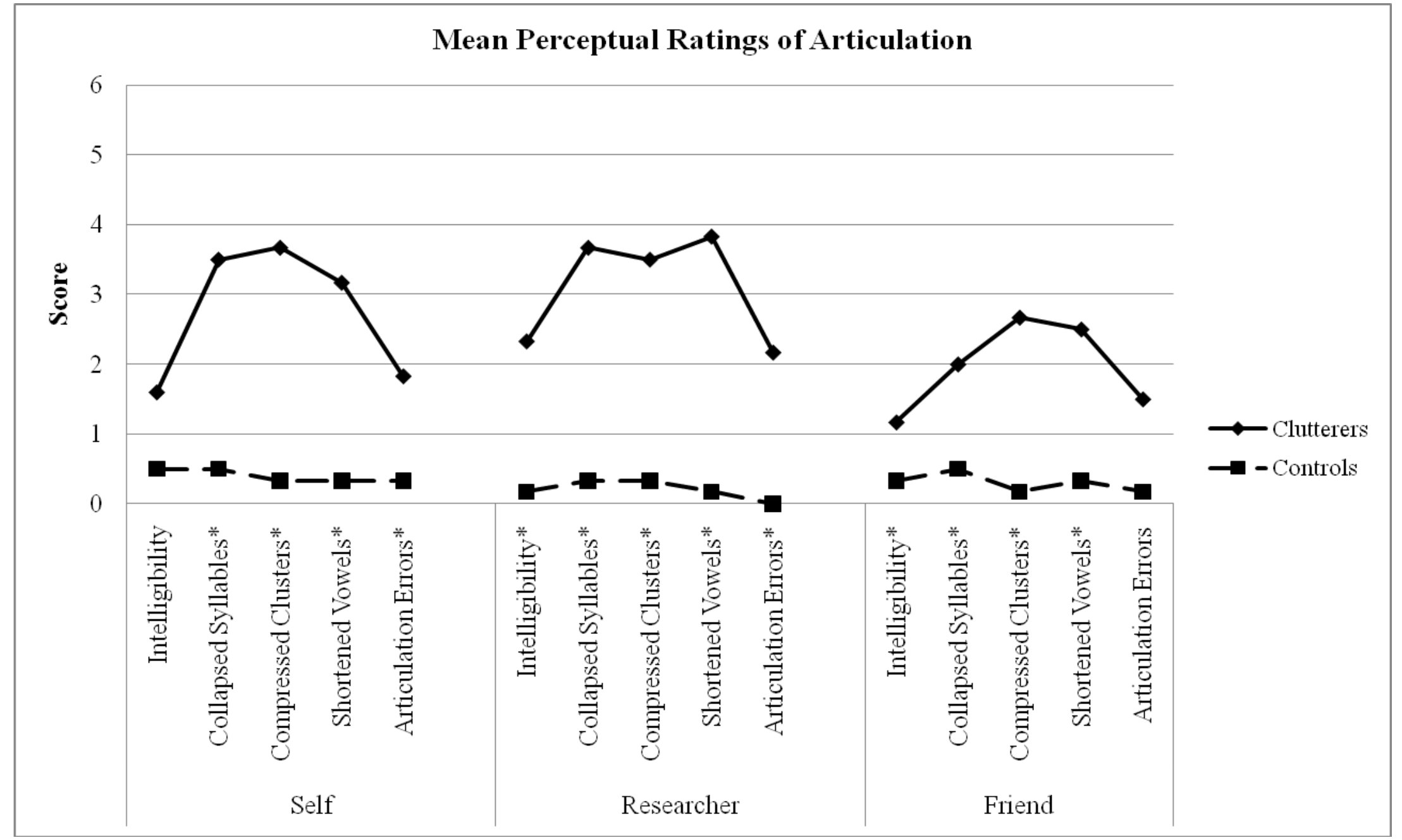


All participants completed the Templin-Darley Tests of Articulation (Templin \& Darley, 1969) wherein they read orally a total of 141 sentences. The total number of errors was calculated for each participant and can be seen in Table 1 (CL) and Table 2 (CO), column 4. The majority of clutterers evidenced little or no articulation difficulty, with the exception of CL6, who demonstrated consistent errors of $/ \mathrm{r} /$ and inconsistent errors of $/ 1 /$, in all positions. No controls had any errors on this test.

Finally, articulation accuracy was also calculated on the list of 31 multisyllabic words that each clutterer read (Appendix E). Two analyses were performed: (a) accuracy (Was the participant able to pronounce the word correctly on the first attempt?) and (b) excessive coarticulation (Was any part of the word excessively coarticulated?). The researcher listened to the recording of each participant reading the words, once for accuracy and once for excessive coarticulation. Clutterers' mean articulation accuracy of $83 \%$ was not statistically different than that of controls $(94 \%), t(10)=-1.13, p=0.28$, although the experimental group's mean was $11 \%$ lower than the control group (see Table 11). Clutterers did, however, have a statistically significantly higher percentage of excessive coarticulation $(M=24)$ than did controls $(M=3), t(10)$ $=3.06, p<.05$ (see Table 12).

Table 11. Articulation accuracy during reading of 31 multisyllabic words for clutterers and controls.

\begin{tabular}{ccccccccccccc}
\hline \multicolumn{11}{c}{ Articulation Accuracy } \\
\hline & CL1 & CL2 & CL3 & CL4 & CL5 & CL6 & CO1 & CO2 & CO3 & CO4 & CO5 & CO6 \\
Total & 28 & 26 & 28 & 30 & 30 & 13 & 29 & 30 & 31 & 31 & 25 & 28 \\
$\%$ & 90 & 84 & 90 & 97 & 97 & 42 & 94 & 97 & 100 & 100 & 81 & 90 \\
Mean & & $83 \%$ & & & & & $94 \%$ & & \\
\hline
\end{tabular}


Table 12.

Frequency of excessive coarticulation during reading of 31 multisyllabic words for clutterers and controls.

Excessive Coarticulation

\begin{tabular}{ccccccccccccc}
\hline & CL1 & CL2 & CL3 & CL4 & CL5 & CL6 & CO1 & CO2 & CO3 & CO4 & CO5 & CO6 \\
Total & 5 & 7 & 2 & 11 & 4 & 16 & 2 & 0 & 0 & 0 & 0 & 3 \\
$\%$ & 16 & 23 & 6 & 35 & 13 & 52 & 6 & 0 & 0 & 0 & 0 & 10 \\
Mean & \multicolumn{7}{c}{$24 \%$} & & & & & \\
\hline
\end{tabular}

Language.

Expressive language skills were assessed on the perceptual rating scales. Six primary areas of language were considered: (a) pragmatic difficulty, (b) syntactic errors, (c) semantic errors, (d) word finding difficulty, (e) narrative difficulty, and (f) mazes present. Each was judged using the same 7-point scale ranging from 0 (never) to 6 (always). Mean perceptual ratings for both groups are provided in Table 13 (self), Table 14 (researcher), and Table 15 (friend), and Figure 3. All ratings were higher for clutterers than controls. All of the researcher language ratings were significantly different. Also, significant differences existed between groups' self-ratings for all language areas except pragmatics and mazes. Finally, only friend ratings of pragmatics and semantics showed statistically significant differences between clutterers and controls. 
Table 13.

Mean self-ratings of language for clutterers and controls.

\begin{tabular}{lccccc}
\hline Self Mean & $\mathrm{CL}$ & $\mathrm{CO}$ & $\mathrm{df}$ & $\mathrm{t}$ & $\mathrm{p}$ \\
\hline Pragmatic difficulty & 2.00 & 0.50 & 8 & 1.57 & 0.15 \\
Syntactic errors & 2.80 & 0.33 & 9 & 3.84 & $<.01$ \\
Semantic errors & 2.17 & 0.33 & 10 & 2.88 & $<.05$ \\
Word finding difficulty & 3.33 & 1.33 & 10 & 3.35 & $<.01$ \\
Narrative difficulty & 1.50 & 0.67 & 10 & 1.39 & 0.20 \\
Mazes present & 2.00 & 0.33 & 10 & 2.33 & $<.05$ \\
\hline
\end{tabular}

Table 14.

Mean researcher ratings of language for clutterers and controls.

\begin{tabular}{lccccc}
\hline Researcher Mean & $\mathrm{CL}$ & $\mathrm{CO}$ & $\mathrm{df}$ & $\mathrm{t}$ & $\mathrm{p}$ \\
\hline Pragmatic difficulty & 2.17 & 0.00 & 10 & 7.05 & $<.001$ \\
Syntactic errors & 1.33 & 0.17 & 10 & 3.13 & $<.05$ \\
Semantic errors & 1.17 & 0.17 & 10 & 4.24 & $<.01$ \\
Word finding difficulty & 1.67 & 0.17 & 10 & 4.02 & $<.01$ \\
Narrative difficulty & 2.67 & 0.17 & 10 & 9.30 & $<.001$ \\
Mazes present & 3.00 & 0.00 & 10 & - & - \\
\hline
\end{tabular}

Note: $t$ test could not be calculated for mazes because means were zero. 
Table 15.

Mean friend ratings of language for clutterers and controls.

\begin{tabular}{lccccc}
\hline Friend Mean & $\mathrm{CL}$ & $\mathrm{CO}$ & $\mathrm{df}$ & $\mathrm{t}$ & $\mathrm{p}$ \\
\hline Pragmatic difficulty & 1.67 & 0.17 & 10 & 2.87 & $<.05$ \\
Syntactic errors & 0.83 & 0.33 & 10 & 1.86 & 0.09 \\
Semantic errors & 0.83 & 0.00 & 10 & 5.00 & $<.001$ \\
Word finding difficulty & 0.67 & 0.33 & 10 & 1.12 & 0.29 \\
Narrative difficulty & 1.17 & 0.00 & 10 & 1.78 & 0.10 \\
Mazes present & 0.83 & 0.17 & 10 & 0.99 & 0.35 \\
\hline
\end{tabular}

All participants were given the Peabody Picture Vocabulary Test, 4th Edition (Dunn \& Dunn, 2007), Form A, with the exception of CL6, who was given Form B due to the unavailability of Form A on the day of testing (Tables 1 and 2, columns 5 and 6). Language scores between groups were nearly identical. The experimental group's mean standard score was $106.17(S D=6.43$, range 97 to 114$)$. The control group's mean standard score was $105.83(S D=$ 7.76, range 95 to 115$)$. All participants' standard scores were within 1 standard deviation of the mean, according to the PPVT manual. Thus all participants in both groups were determined to have receptive vocabulary skills, as an indicator of receptive language, within normal limits. 
Figure 3. Mean perceptual rankings of all categories of language, as rated by each participant, the researcher, and a friend of the participant. Significant differences between clutterers and controls are marked with an asterisk (*).

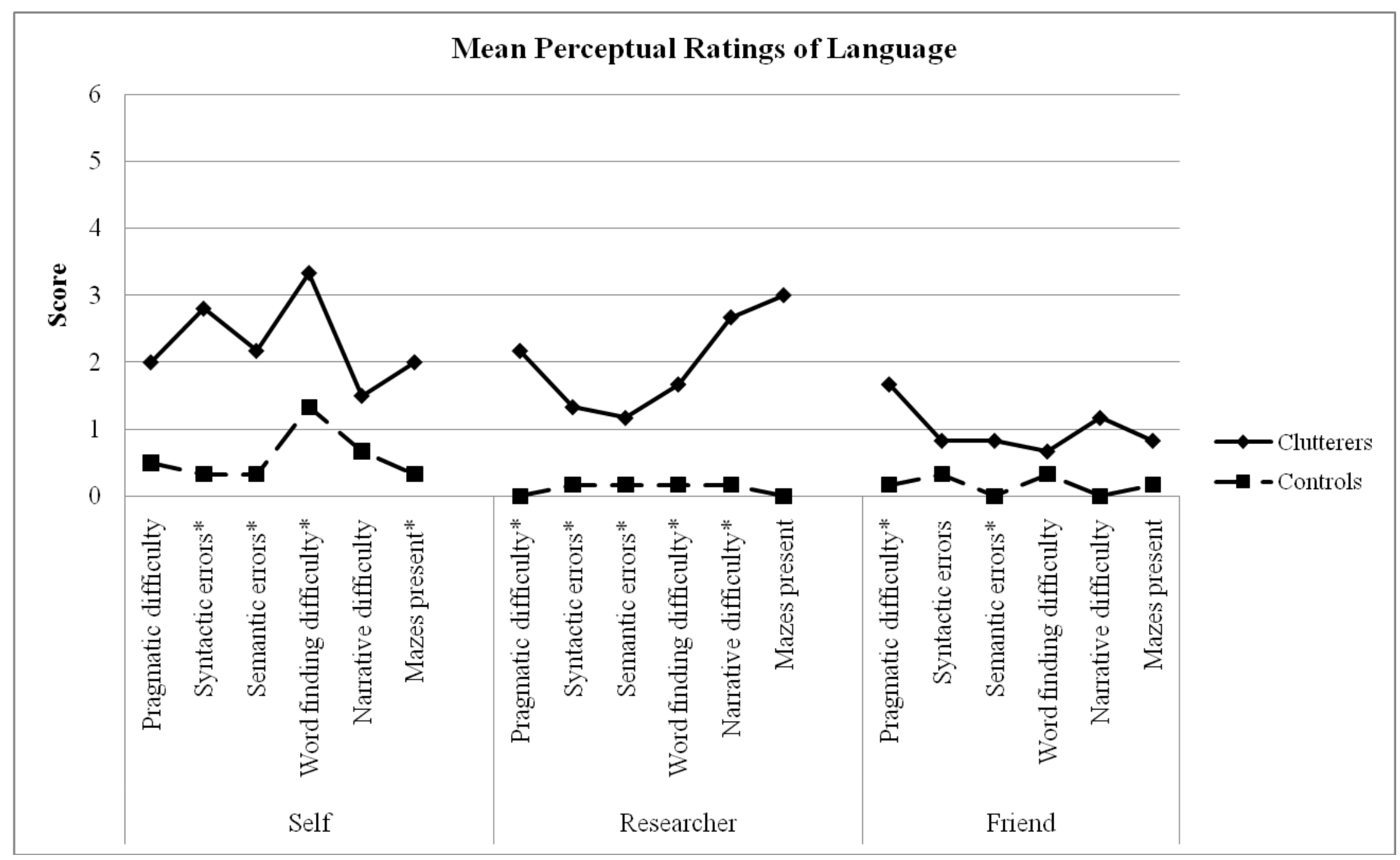


Fluency.

Disfluencies were also rated using the perceptual scales and were again rated by the same three persons as above on the same 7 point scale ranging from 0 (never) to 6 (always). Six fluency characteristics included: (a) unfinished words, (b) revisions, (c) interjections, (d) hesitations, (e) part-word repetitions, and (f) whole-word repetitions. Mean perceptual ratings of these fluency categories are provided in Table 16 (self), Table 17 (researcher), and Table 18 (friend), and Figure 4. Researcher ratings were significantly higher for clutterers versus controls in all categories of disfluencies. Clutterers' self-ratings were only significantly higher than those of controls in two areas, i.e., unfinished words and hesitations. Similarly, ratings completed by friends were only significantly higher for clutterers than controls in two areas, i.e., unfinished words and part-word repetitions.

Table 16.

Mean self-ratings of fluency for clutterers and controls.

\begin{tabular}{lccccc}
\hline Self Mean & $\mathrm{CL}$ & $\mathrm{CO}$ & $\mathrm{df}$ & $\mathrm{t}$ & $\mathrm{p}$ \\
\hline Unfinished Words & 3.33 & 0.67 & 10 & 6.76 & $<.001$ \\
Revisions & 2.50 & 1.00 & 10 & 1.96 & .08 \\
Interjections & 2.50 & 1.17 & 10 & 2.08 & .06 \\
Hesitations & 3.33 & 0.67 & 10 & 4.47 & $<.01$ \\
Part-word Repetitions & 1.50 & 0.33 & 10 & 1.66 & 0.13 \\
Whole-word Repetitions & 1.17 & 0.33 & 10 & 1.60 & 0.14 \\
Naturalness & 2.00 & 0.67 & 9 & 2.16 & 0.06 \\
\hline
\end{tabular}


Table 17.

Mean researcher ratings of fluency for clutterers and controls.

\begin{tabular}{lccccc}
\hline Researcher Mean & $\mathrm{CL}$ & $\mathrm{CO}$ & $\mathrm{df}$ & $\mathrm{t}$ & $\mathrm{P}$ \\
\hline Unfinished Words & 3.00 & 0.00 & 10 & 8.00 & $<.001$ \\
Revisions & 3.00 & 0.33 & 10 & 13.02 & $<.001$ \\
Interjections & 3.67 & 0.17 & 10 & 5.94 & $<.001$ \\
Hesitations & 3.00 & 0.17 & 10 & 5.43 & $<.001$ \\
Part-word Repetitions & 3.17 & 0.33 & 10 & 3.48 & $<.01$ \\
Whole-word Repetitions & 2.50 & 0.00 & 10 & 2.67 & $<.05$ \\
Naturalness & 3.33 & 0.50 & 10 & 4.71 & $<.001$ \\
\hline
\end{tabular}

Table 18.

Mean friend ratings of fluency for clutterers and controls.

\begin{tabular}{lccccc}
\hline Friend Mean & $\mathrm{CL}$ & $\mathrm{CO}$ & $\mathrm{df}$ & $\mathrm{t}$ & $\mathrm{p}$ \\
\hline Unfinished Words & 1.17 & 0.00 & 10 & 2.44 & $<.05$ \\
Revisions & 1.40 & 0.83 & 9 & 1.14 & 0.28 \\
Interjections & 1.50 & 1.00 & 10 & 1.00 & 0.34 \\
Hesitations & 1.67 & 0.50 & 10 & 2.15 & .06 \\
Part-word Repetitions & 1.50 & 0.17 & 10 & 2.27 & $<.05$ \\
Whole-word Repetitions & 0.83 & 0.17 & 10 & 1.53 & 0.16 \\
Naturalness & 1.33 & 0.33 & 10 & 2.12 & 0.06 \\
\hline
\end{tabular}


Figure 4. Mean perceptual rankings of all categories of disfluencies, as rated by each participant, the researcher, and a friend of the participant. Significant differences between clutterers and controls are marked with an asterisk (*).

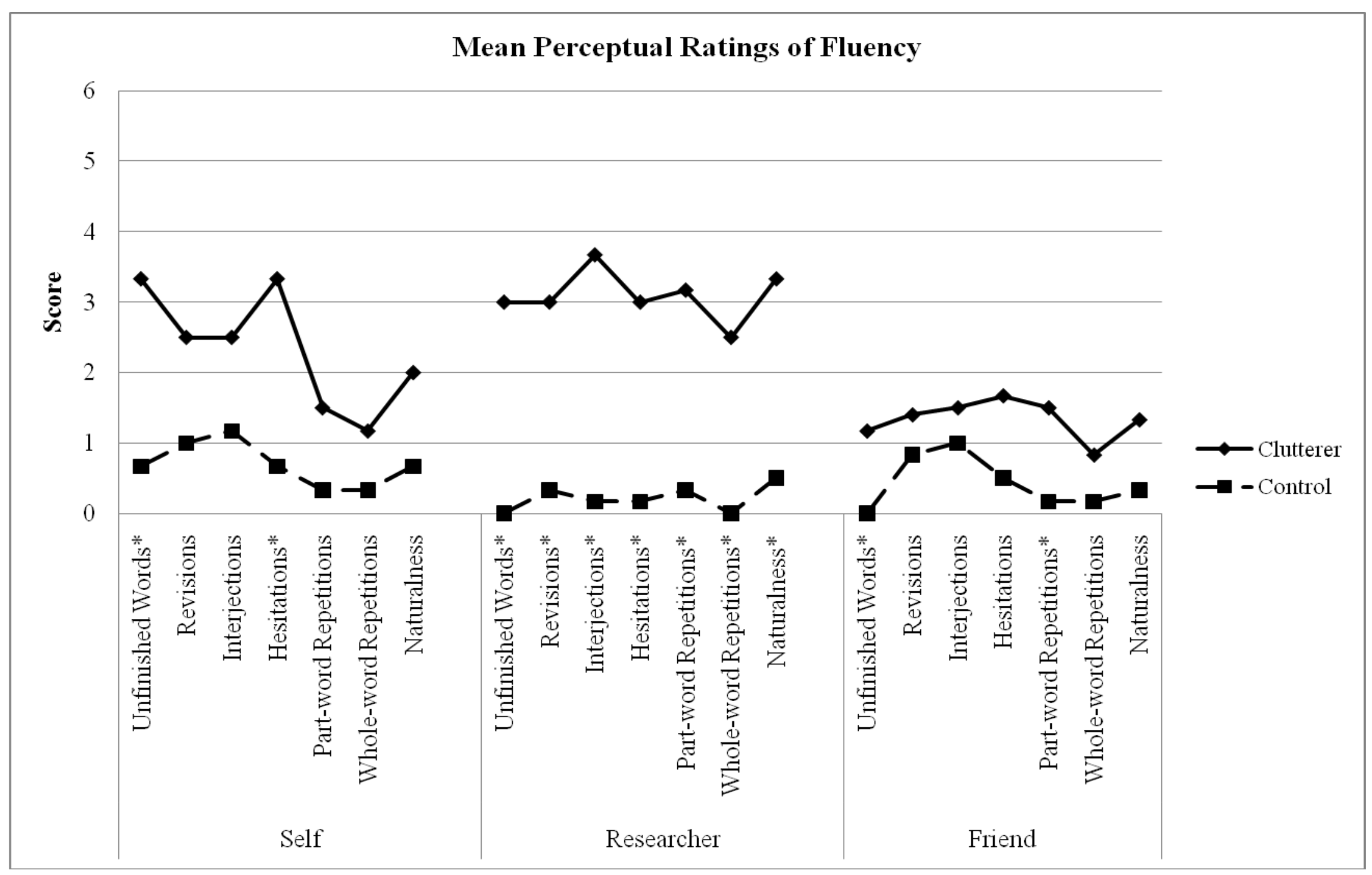


Separate disfluency analyses were conducted on the conversation samples and included eight strict disfluency categories: interjections, revisions, unfinished words, prolongations, phrase repetitions, word repetitions, syllable repetitions, and hesitations (Figure 5). In these samples, a slightly different dependent variable for disfluency was used, i.e., disfluencies per 100 syllables (D/100). This measurement has been used to assist in highlighting the frequency of disfluencies when all syllables, even those that occurred during mazes, were included in the analysis (Myers \& St. Louis, 1996; St. Louis, Myers, Faragasso, Townsend, \& Gallaher, 2004). As noted above, conversation samples were truncated to the first 420 syllables for each participant based on the fact that this was near the lowest number of spontaneous syllables produced by a participant. Independent sample t tests revealed that clutterers had significantly more revisions, hesitations, and total disfluencies than controls. Detailed results for each clutterer as well as overall means can be seen in Table 19 and Figure 6. Data for controls are in Table 20 and Figure 7.

Overall, clutterers were rated less fluent and less natural than controls on the perceptual scales completed by the participants, researcher, and friends of the participants. Even in instances of nonsignificant differences in the perceptual scales, the clutterers were still rated as less fluent and less natural than the controls. Additionally, clutterers were also less fluent than controls during conversation with respect to total number of disfluencies and each individual type of disfluency. 
Figure 5. Total disfluencies by clutterers and controls during the conversation sample. Significant differences are marked with an asterisk (*).

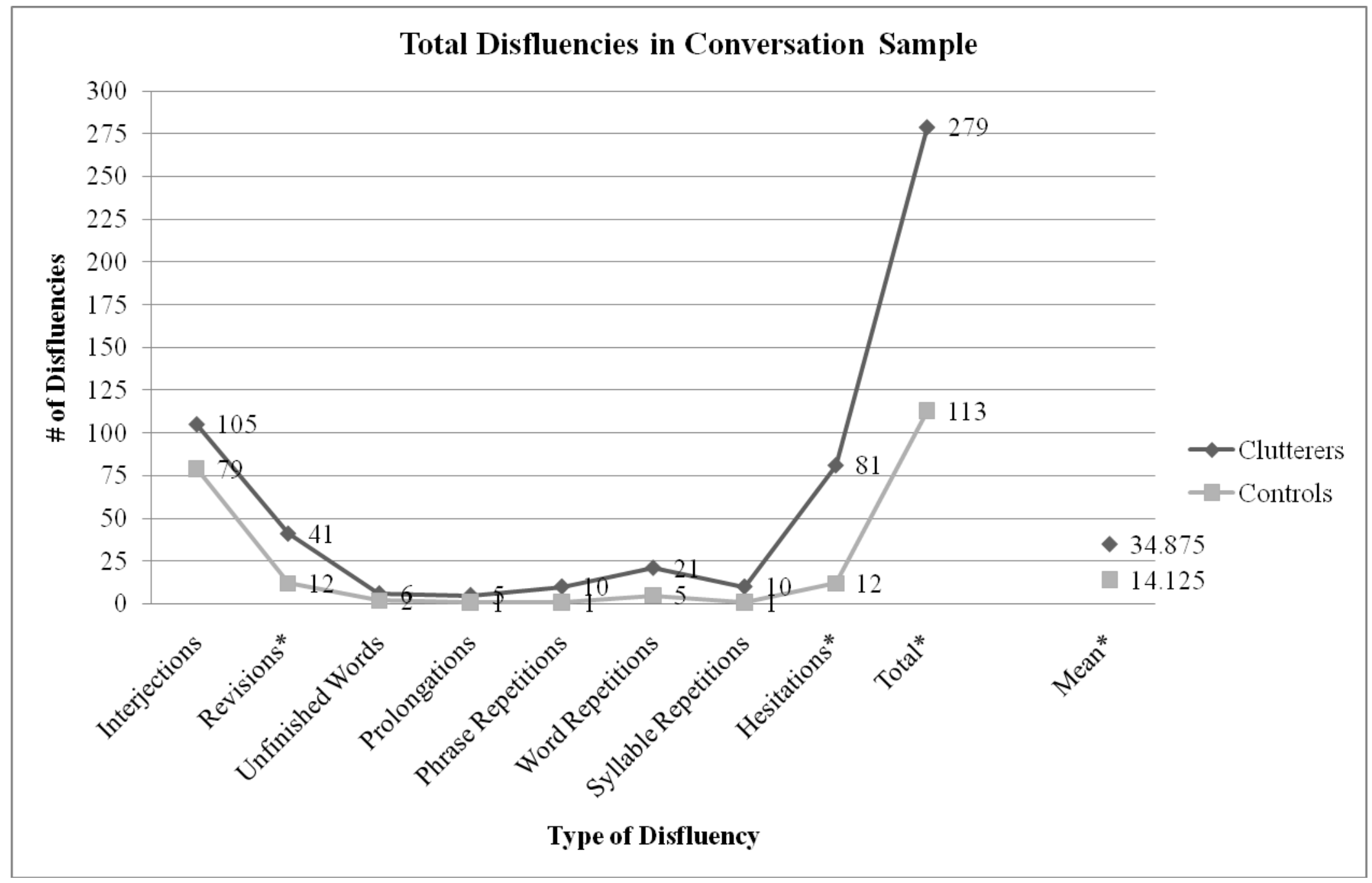


Table 19.

Disfluency analysis by type for clutterers.

\begin{tabular}{cccccccccccc}
\hline Subject & I & R & UW & P & PR & WR & SR & H & Total & Mean & D/100 \\
\hline CL1 & 15 & 5 & 0 & 0 & 1 & 0 & 0 & 12 & 33 & 4.13 & 7.86 \\
CL2 & 5 & 3 & 1 & 1 & 0 & 2 & 0 & 7 & 19 & 2.38 & 4.52 \\
CL3 & 9 & 13 & 3 & 0 & 0 & 8 & 1 & 12 & 46 & 5.75 & 10.95 \\
CL4 & 7 & 4 & 1 & 0 & 0 & 0 & 2 & 20 & 34 & 4.25 & 8.10 \\
CL5 & 21 & 8 & 0 & 0 & 5 & 4 & 4 & 8 & 50 & 6.25 & 11.90 \\
CL6 & 48 & 8 & 1 & 4 & 4 & 7 & 3 & 22 & 97 & 12.13 & 23.10 \\
Total & 105 & 41 & 6 & 5 & 10 & 21 & 10 & 81 & 279 & 34.88 & 66.43 \\
\hline Mean & 17.50 & $6.83 *$ & 1.00 & 0.83 & 1.67 & 3.50 & 1.67 & $13.50 * *$ & $46.50 *$ & 5.81 & 11.07 \\
STD & 16.05 & 3.66 & 1.10 & 1.60 & 2.25 & 3.45 & 1.63 & 6.19 & 27.05 & & \\
CV & 0.92 & 0.54 & 1.10 & 1.92 & 1.35 & 0.99 & 0.98 & 0.46 & 0.58 & & \\
Percent Total & $38 \%$ & $15 \%$ & $2 \%$ & $2 \%$ & $4 \%$ & $8 \%$ & $4 \%$ & $29 \%$ & & &
\end{tabular}

Note: $I=$ interjections, $R=$ revisions, $U W=$ unfinished words, $P=$ prolongations, $P R=$ phrase repetitions, $W R=$ word repetitions, $S R=$ syllable repetitions, $H=$ hesitations.

$* p<.05, * * p<.01$. (Compared with the data in Table 20). 
Figure 6. Distribution of disfluency by type for clutterers.

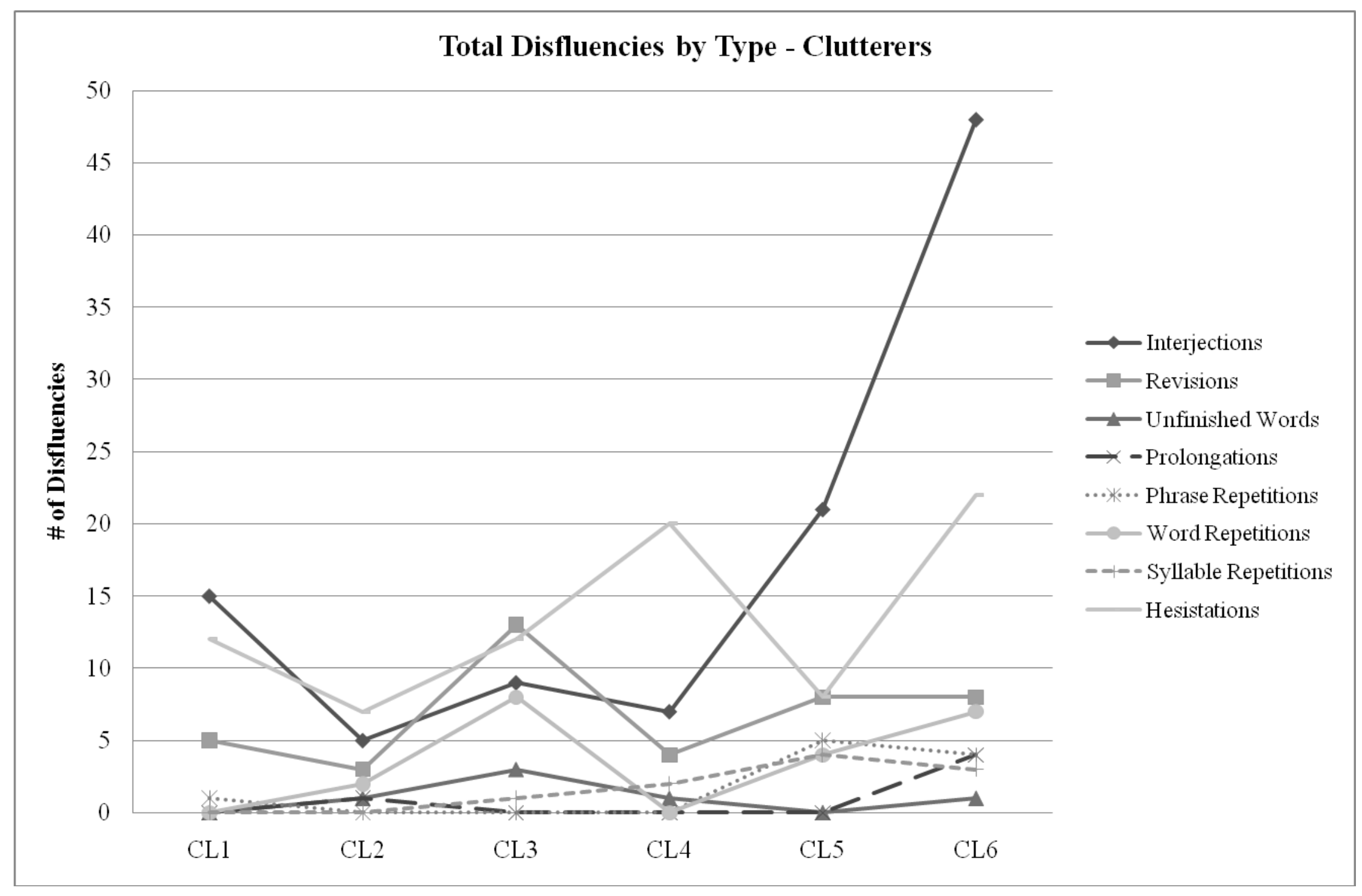


Table 20.

Disfluency analysis by type for controls.

\begin{tabular}{cccccccccccc}
\hline Subject & $\mathrm{I}$ & $\mathrm{R}$ & $\mathrm{UW}$ & $\mathrm{P}$ & $\mathrm{PR}$ & $\mathrm{WR}$ & $\mathrm{SR}$ & $\mathrm{H}$ & Total & Mean & D/100 \\
\hline CO1 & 4 & 2 & 0 & 0 & 0 & 3 & 0 & 1 & 10 & 1.25 & 2.38 \\
CO2 & 17 & 3 & 0 & 0 & 0 & 1 & 0 & 1 & 22 & 2.75 & 5.24 \\
CO3 & 20 & 4 & 1 & 0 & 1 & 0 & 0 & 3 & 29 & 3.63 & 6.90 \\
CO4 & 10 & 2 & 0 & 0 & 0 & 1 & 1 & 2 & 16 & 2.00 & 3.81 \\
CO5 & 18 & 0 & 0 & 0 & 0 & 0 & 0 & 1 & 19 & 2.38 & 4.52 \\
CO6 & 10 & 1 & 1 & 1 & 0 & 0 & 0 & 4 & 17 & 2.13 & 4.05 \\
Total & 79 & 12 & 2 & 1 & 1 & 5 & 1 & 12 & 113 & 14.13 & 26.90 \\
\hline Mean & 13.17 & $2.00 *$ & 0.33 & 0.17 & 0.17 & 0.83 & 0.17 & $2.00 * *$ & $18.83 *$ & 2.35 & 4.48 \\
STD & 6.15 & 1.41 & 0.52 & 0.41 & 0.41 & 1.17 & 0.41 & 1.26 & 6.37 & & \\
CV & 0.47 & 0.71 & 1.55 & 2.45 & 2.45 & 1.40 & 2.45 & 0.63 & 0.34 & & \\
Percent Total & $70 \%$ & $11 \%$ & $2 \%$ & $1 \%$ & $1 \%$ & $4 \%$ & $1 \%$ & $11 \%$ & &
\end{tabular}

Note: $I=$ interjections, $R=$ revisions, $U W=$ unfinished words, $P=$ prolongations, $P R=$ phrase repetitions, $W R=$ word repetitions, $S R=$ syllable repetitions, $H=$ hesitations.

$* p<.05,{ }^{* *} p<.01$. (Compared with the data in Table 19). 
Figure 7. Distribution of disfluency by type for controls.

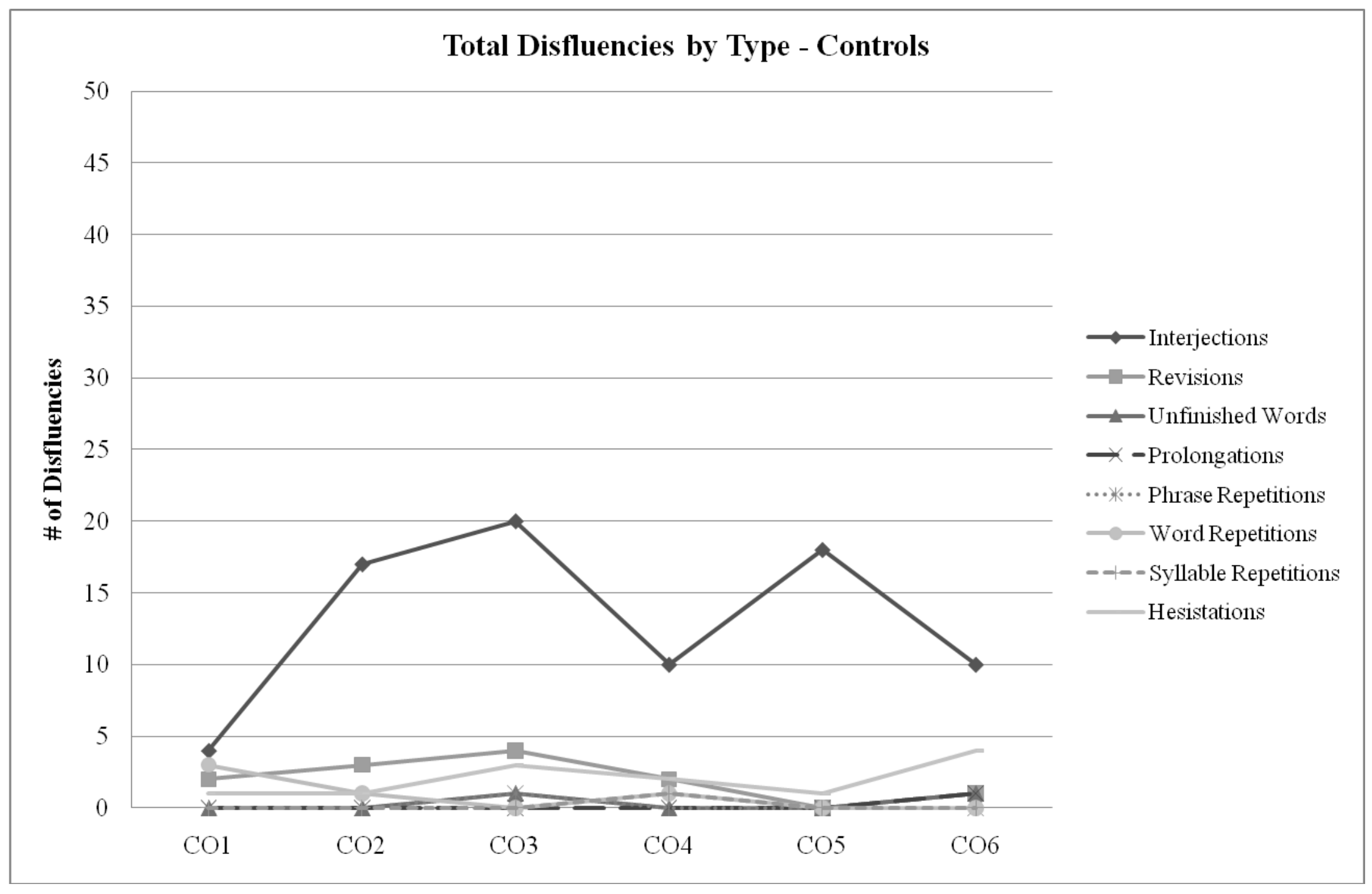


Awareness of Speech.

All participants completed the Predictive Cluttering Inventory (PCI; Daly, 2006), the Self-Awareness of Speech Index (St. Louis \& Atkins, 2005), and the St. Louis Inventory of Life Perspectives and Speech/Language Difficulty (SL $\bullet I L P-S / L$; St. Louis, 2005). Additionally, the researcher completed the $P C I$ on each participant. Individual results of the following test results are presented in Tables 1 and 2. Both participant-completed (column 7) and researchercompleted PCI (column 8) scores were higher for clutterers than controls. SASI means were nearly identical for clutterers (2.72) and controls (2.63) (column 9). SL $\bullet I L P-S / L$ scores were higher for clutterers than controls (column 10).

\section{Hearing Screening.}

All clutterers were deemed to have hearing within normal limits as a result of a screening performed by the researcher at the time of testing or previous hearing evaluation results, with two exceptions. No screening was performed on CL1 as no audiometer was available: however, she was able to understand and respond appropriately during conversation and reported no difficulties in hearing. CL4's screening resulted in a $65 \mathrm{~dB}$ monaural loss in the left ear as a result of years of noise exposure. All controls passed a pure tone screening consisting of tones at $1000 \mathrm{~Hz}, 2000 \mathrm{~Hz}, 3000 \mathrm{~Hz}$, and $4000 \mathrm{~Hz}$ at $20 \mathrm{~dB}$, with the following exceptions: (a) no screening was performed on $\mathrm{CO} 1$ as no audiometer was available, but participant reported normal hearing, (b) $\mathrm{CO} 2$ required $25 \mathrm{~dB}$ in the left ear at $1000 \mathrm{~Hz}$, and (c) $\mathrm{CO} 4$ required $25 \mathrm{~dB}$ in the right ear for all frequencies and $30 \mathrm{~dB}$ in the left ear for $1000 \mathrm{~Hz}$.

\section{Reliability}

As noted in Appendix Table I12, the researcher had listened and rated all conversation samples alone using the perceptual scales (represented below as ResA). It should be noted that 
the researcher was very familiar with the samples by this time as they had been transcribed orthographically before the ratings occurred. Reliability was estimated as follows. An independent rater, a recent master's level graduate in speech-language pathology with coursework in cluttering, received orientation and training with the researcher regarding the perceptual rating scales. This involved joint listening to a recording of a speech sample of a clutterer who was not part of the current study, independently rating him using the same scales, and discussing their results. This was repeated with a second external cluttering speech sample. Next, the researcher (represented as ResB) and independent rater (represented as ObservA) listened to all 12 conversation samples from the present experiment, without comparing ratings or discussing their results.

Results for both intra-rater and inter-rater reliability are shown in Tables 21 and 22. Column one shows the difference in ratings from 0 to \pm 4 . Column two lists mean intra-rater reliability from the first and second ratings completed by the researcher, followed by the ranges in column three. Column four shows inter-rater reliability from the researcher's first ratings compared to the independent rater's judgments, again followed by the ranges in column five. Column six shows inter-rater reliability from the simultaneous ratings of researcher and independent rater, with ranges in column seven.

As shown below, $84 \%$ of the researcher's first and second (ResA and ResB) ratings were identical (0) or within \pm 1 scale value for clutterers (Table 21) and 99\% for controls (Table 22). Additionally, $86 \%$ of the researcher's first ratings (ResA) were within \pm 2 scale value for clutterers and 100\% for controls when compared to the second rater's scores (ObservA). Finally, $89 \%$ of the researcher's second ratings (ResB) were within \pm 1 scale value for controls and $100 \%$ for the controls when compared to the second rater's scores (ObservA). Thus, Intra-rater 
reliability was satisfactory, even though some criteria were changed following training and discussion. The researcher's second ratings were primarily one to two ratings lower on several areas of the scale after training. Inter-rater reliability was also satisfactory, although somewhat lower when comparing the researcher's initial rating to the independent rater's judgments before reaching consensus on several items in the training. Agreement was better for controls than clutterers.

Table 21.

Mean inter- and intra-rater reliability for clutterers.

\section{Clutterers}

\begin{tabular}{ccccccc}
\hline & $\begin{array}{c}\text { ResA \& } \\
\text { ResB }\end{array}$ & Range & $\begin{array}{c}\text { ResA \& } \\
\text { ObservA }\end{array}$ & Range & $\begin{array}{c}\text { ResB \& } \\
\text { ObservA }\end{array}$ & Range \\
\cline { 2 - 7 } 0 & $34.2 \%$ & $14 \%-57 \%$ & $15.3 \%$ & $0 \%-29 \%$ & $28.5 \%$ & $19 \%-38 \%$ \\
$+/-1$ & $49.3 \%$ & $19 \%-81 \%$ & $34.3 \%$ & $19 \%-48 \%$ & $60.5 \%$ & $48 \%-81 \%$ \\
$+/-2$ & $15.0 \%$ & $0 \%-33 \%$ & $36.7 \%$ & $29 \%-48 \%$ & $9.7 \%$ & $0 \%-29 \%$ \\
$+/-3$ & $1.6 \%$ & $0 \%-5 \%$ & $9.5 \%$ & $0 \%-14 \%$ & $0.8 \%$ & $0 \%-5 \%$ \\
$+/-4$ & $0 \%$ & - & $4.8 \%$ & $0 \%-14 \%$ & $0 \%$ & - \\
\hline
\end{tabular}

Table 22.

Mean inter- and intra-rater reliability for controls.

Controls

\begin{tabular}{ccccccc}
\hline & $\begin{array}{c}\text { ResA \& } \\
\text { ResB }\end{array}$ & Range & $\begin{array}{c}\text { ResA \& } \\
\text { ObservA }\end{array}$ & Range & $\begin{array}{c}\text { ResB \& } \\
\text { ObservA }\end{array}$ & Range \\
\cline { 2 - 6 } 0 & $49.2 \%$ & $33 \%-71 \%$ & $60.1 \%$ & $52 \%-71 \%$ & $54.7 \%$ & $33 \%-76 \%$ \\
$+/-1$ & $50.3 \%$ & $29 \%-67 \%$ & $38.0 \%$ & $28 \%-48 \%$ & $45.3 \%$ & $24 \%-67 \%$ \\
$+/-2$ & $0.8 \%$ & $0 \%-5 \%$ & $1.7 \%$ & $0 \%-10 \%$ & $0 \%$ & - \\
$+/-3$ & $0 \%$ & - & $0 \%$ & - & $0 \%$ & - \\
$+/-4$ & $0 \%$ & - & $0 \%$ & - & $0 \%$ & - \\
\hline
\end{tabular}




\section{Experimental Task}

\section{Group Results}

Mean estimated, actual, and estimated minus actual (difference) times were calculated between subjects for clutterers and controls (Table 23). Clutterers' mean estimated time was 2.95 seconds (s), (range 1.20s to 5.33s), and was larger than controls' mean estimated time, which was $2.11 \mathrm{~s}$ (range $1.60 \mathrm{~s}$ to $3.46 \mathrm{~s}$ ). Clutterers' mean actual time was $2.43 \mathrm{~s}$, (range $1.62 \mathrm{~s}$ to $3.02 \mathrm{~s}$ ), and was also higher than controls' mean actual time, which was $1.93 \mathrm{~s}$ (range $1.37 \mathrm{~s}$ to 2.40s). Finally, the difference between estimated and actual times (i.e., estimated time minus actual time) of clutterers was $0.52 \mathrm{~s}$ (range $-0.40 \mathrm{~s}$ to $1.98 \mathrm{~s}$ ), and was, again, larger than the difference between estimated and actual times for controls, which was .18s (range -0.50 s to 0.62s). T tests for independent samples indicated that clutterers' mean estimated times in seconds $(M=2.95, S D=1.95)$ were not statistically different than controls' mean estimated times $(M=$ $2.11, S D=0.54), t(10)=1.40, p=.19)$. Clutterers' mean actual times $(M=2.43, S D=0.79)$ were also not statistically different than controls' mean actual times $(M=1.93, S D=0.44), t(10)$ $=1.36, p=.20)$. Finally, clutterers' mean difference between estimated and actual times $(M=$ $0.52, S D=0.59)$ were also not statistically different than controls mean difference between estimated times $(M=0.18, S D=0.10), t(10)=0.9, p=.39)$.

Additionally, within subject comparisons were made (also Table 23). No statistically significant differences were found between the estimated times $(M=2.95, S D=1.95)$ and actual times $(M=2.43, S D=0.79)$ of clutterers, $t(5)=1.51, p=.19$ (paired). Similarly, no statistically significant difference was found between the estimated times $(M=2.11, S D=0.54)$ and actual times $(M=1.93, S D=0.44)$ of controls, $t(5)=1.06, p=.34$ (paired). 
Table 23.

Group means, standard deviations (SD), and coefficient of variation (CV) for estimated, actual, and estimated minus actual times for clutterers and controls.

\begin{tabular}{|c|c|c|c|c|c|c|c|c|c|}
\hline & \multicolumn{3}{|c|}{ Clutterers } & \multicolumn{3}{|c|}{ Controls } & \multicolumn{3}{|c|}{ Differences } \\
\hline & Estimated & Actual & $\begin{array}{l}\text { Estimated } \\
\text {-Actual }\end{array}$ & Estimated & Actual & $\begin{array}{l}\text { Estimated } \\
\text { - Actual }\end{array}$ & Estimated & Actual & $\begin{array}{l}\text { Estimated - } \\
\text { Actual }\end{array}$ \\
\hline MEAN & 2.95 & 2.43 & 0.52 & 2.11 & 1.93 & 0.18 & 0.85 & 0.50 & 0.35 \\
\hline $\mathrm{SD}$ & 1.38 & 0.79 & 0.59 & 0.54 & 0.44 & 0.10 & 0.84 & 0.35 & 0.49 \\
\hline $\mathrm{CV}$ & 0.47 & 0.32 & 1.13 & 0.25 & 0.23 & 0.56 & 0.99 & 0.7 & 1.42 \\
\hline
\end{tabular}


Coefficient of variation $(\mathrm{CV})$ was used to evaluate variability. The $\mathrm{CV}$ is the ratio of the SD to the mean, and allows the variability to be reported in terms of the mean since larger means are often associated with larger SDs, and vice versa (Maxwell \& Satake, 1997). CVs were chosen in case there were large differences in the means between groups. As shown in Table 23, clutterers evidenced greater variability in all group comparisons. The CV for estimated times of clutterers $(0.47)$ is nearly double that for controls $(0.25)$. The $\mathrm{CV}$ for actual times is also higher for clutterers $(0.32)$ than for controls $(0.23)$. Finally, the CV for estimated minus actual times is twice as high for clutterers (1.13) compared to controls (0.56). Additionally, variability can be seen in Figures 8 and 9, which show estimated times of clutterers and controls, respectively, across all 50 experimental tasks, and Figures 10 and 11 which show actual times. 
Figure 8. Estimated times across all 50 experimental tasks for clutterers.

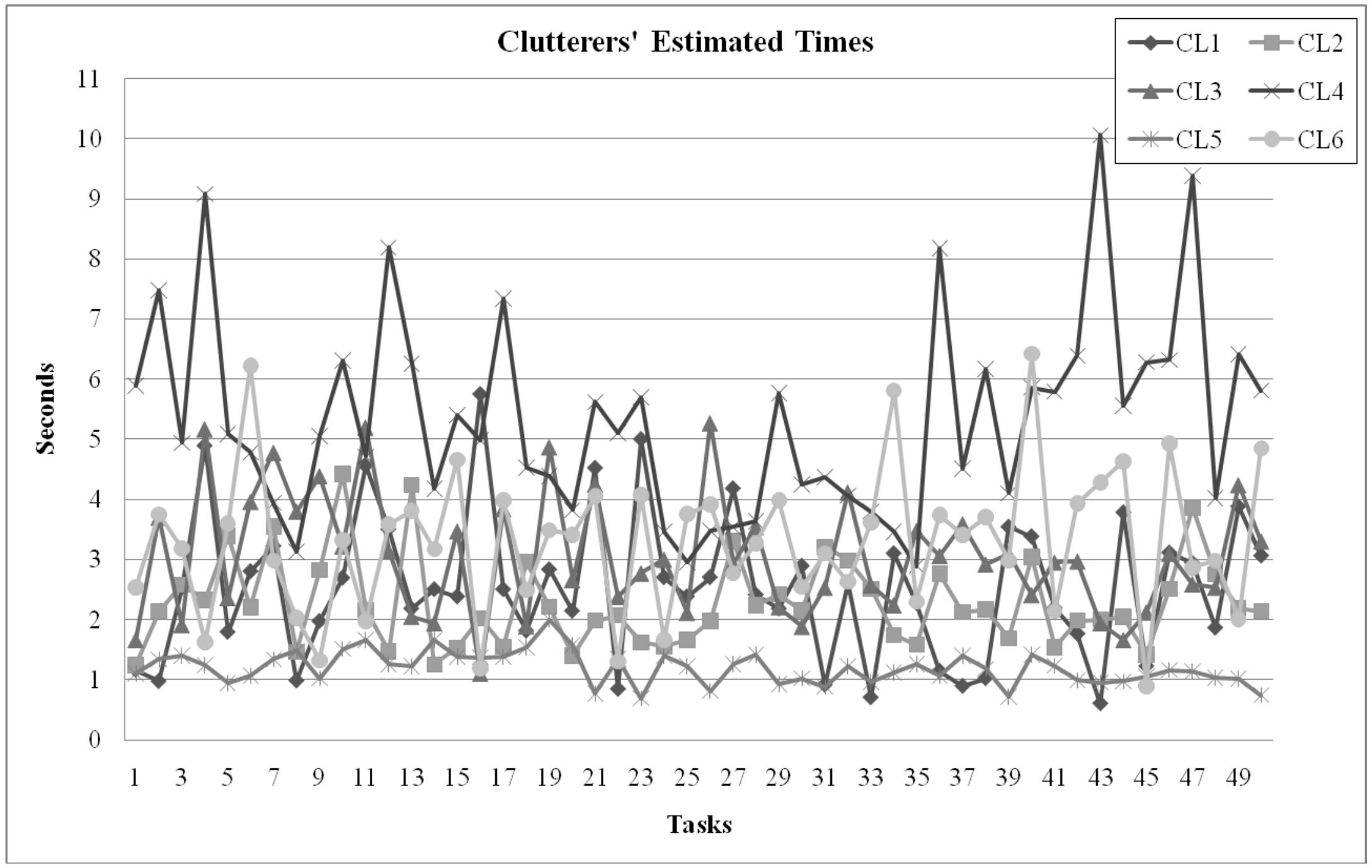


Figure 9. Estimated times across all 50 experimental tasks for controls.

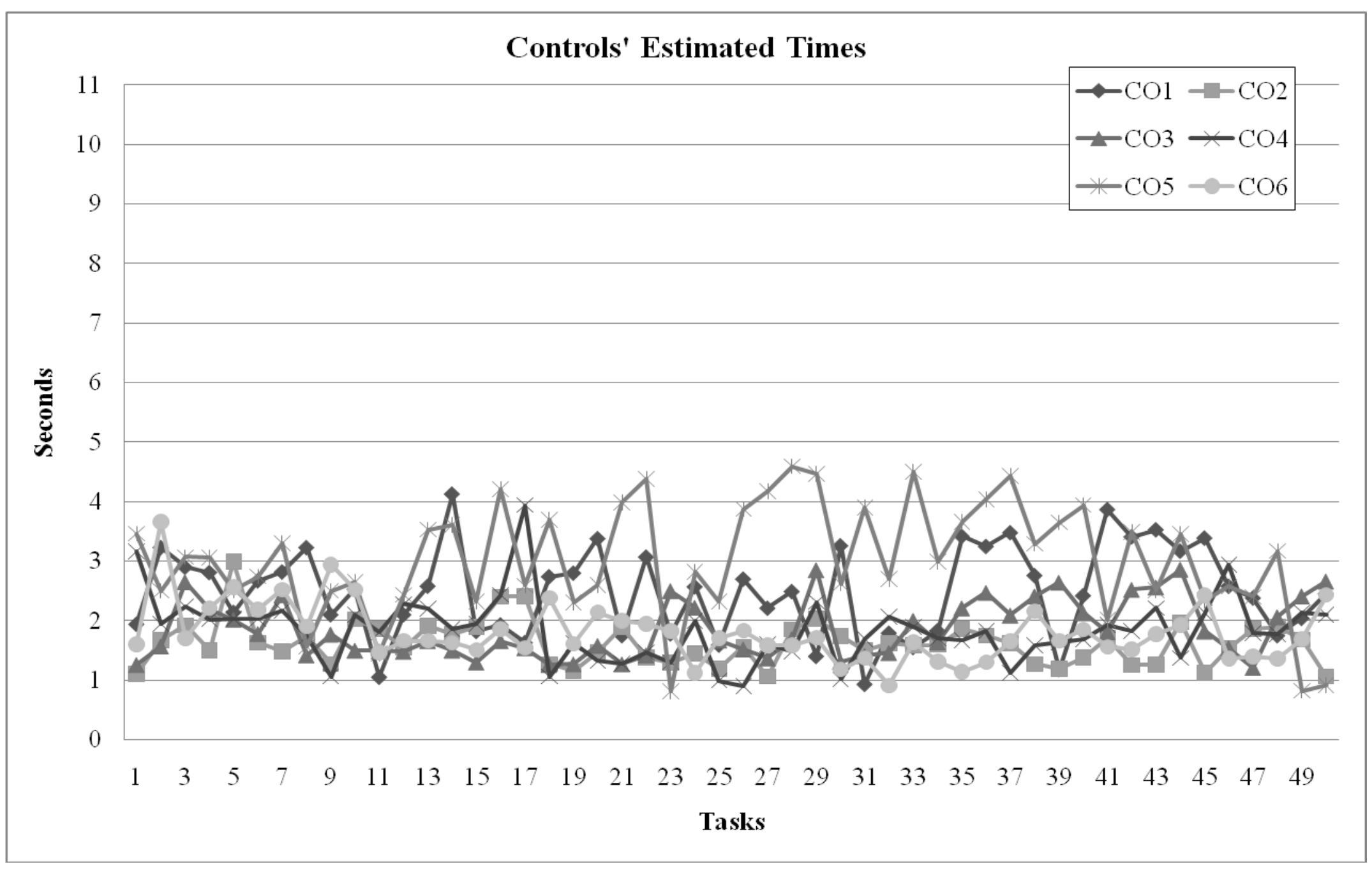


Figure 10. Actual times across all 50 experimental tasks for clutterers.

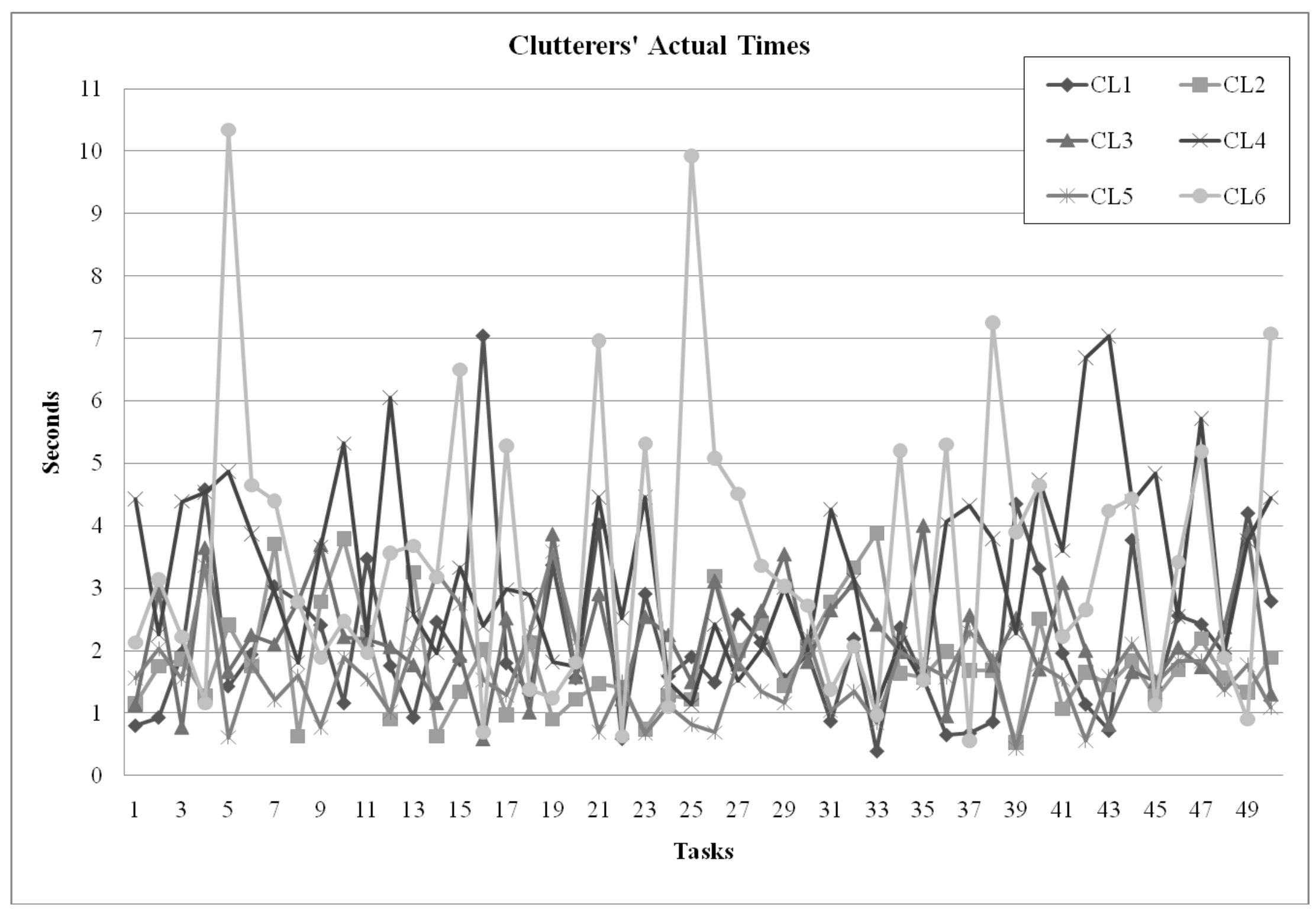


Figure 11. Actual times across all 50 experimental tasks for controls.

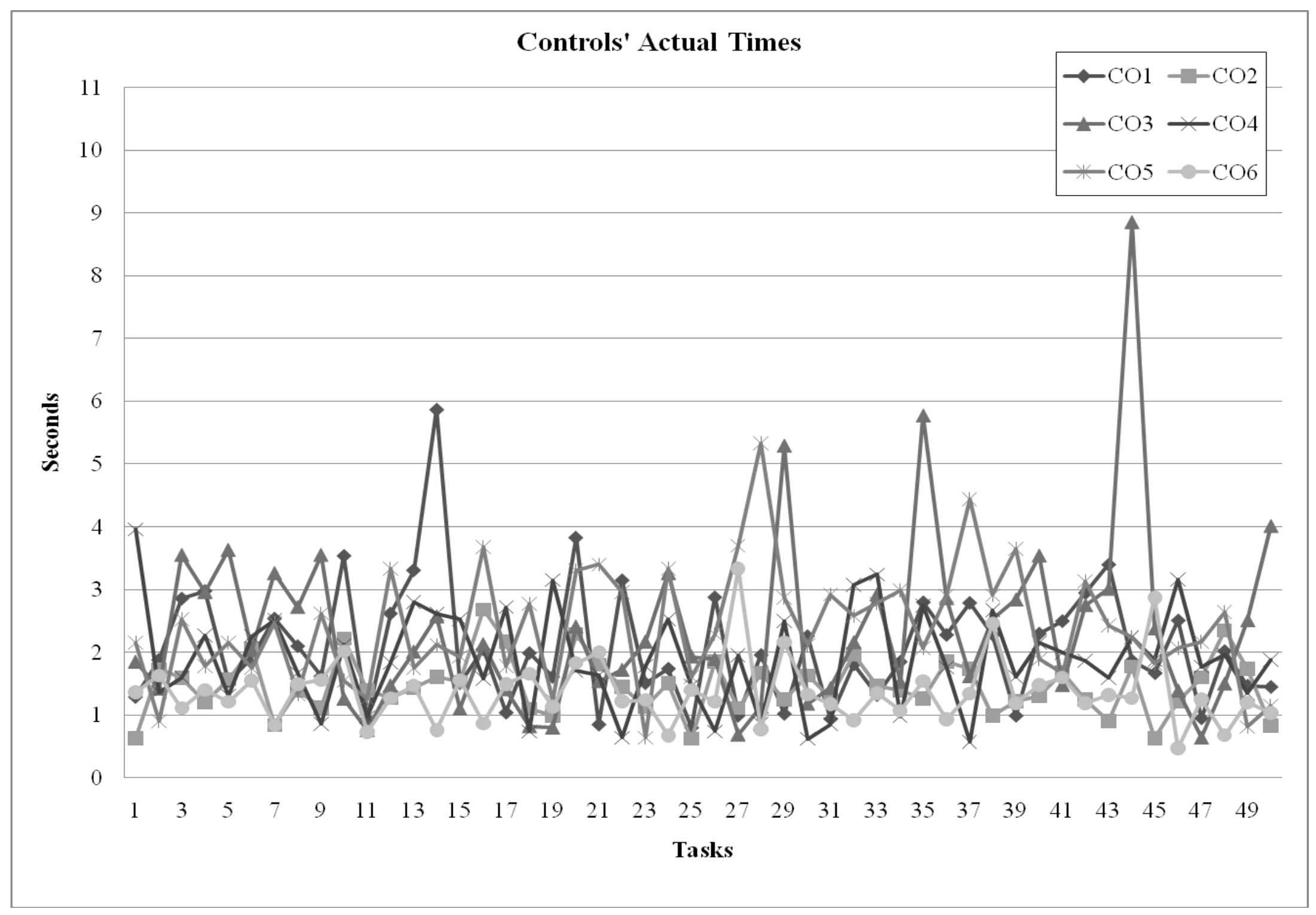




\section{Individual Clutterer-Control Pairs}

Although the main experimental question involved comparing clutterers and controls as groups, individual clutterer-control pair data were also analyzed for differences, and can be seen in Tables 24, 25, and 26. Five out of six clutterers evidenced statistically significant differences between their mean estimated and actual times (Table 24 and Figure 12). CL1, CL2, CL3, and CL4 had significantly longer estimated times than actual times. CL5 had significantly longer actual times than estimated times. For CL 6, there were no significant differences. Similarly, a different five out of six controls evidenced statistically significant differences between their mean estimated and actual times (Table 25 and Figure 13) with the same overall profiles. CO1, $\mathrm{CO} 2, \mathrm{CO} 5$, and $\mathrm{CO} 6$ had significantly longer estimated times than actual times, $\mathrm{CO} 3$ had a significantly longer mean actual time than mean estimated time, and CO4 had no significant difference between the two.

Comparing the differences between individual clutterer-control pairs (Table 26) with regard to the differences between estimated times (e.g., CL1 estimated versus CO1 estimated), five of the six pairs (pairs 2, 3, 4, 5, and 6) evidenced statistically significant differences between estimated times. In pairs 2, 3, 4 and 6, the clutterers had significantly higher estimated times than the controls. In pair 5 , the clutterer had a significantly lower estimated time than the control. Differences were not different for pair 1. Similarly, four out of the six pairs (pairs 2, 4, 5, and 6) showed statistically significant differences between actual times. Pairs 2, 4, and 6 showed clutterers had significantly higher actual times than their matched controls, while in pair 5, the clutterer had a significantly lower estimated time than the control. Actual times were not significantly different for pairs 1 and 3. Finally, five out of the six pairs also showed statistically 
Table 24.

Mean estimated times, actual times, and difference between estimated and actual times for clutterers.

\begin{tabular}{ccccccc}
\hline & CL1 & CL2 & CL3 & CL4 & CL5 & CL6 \\
\cline { 2 - 6 } Estimated & 2.54 & 2.28 & 3.06 & 5.33 & 1.20 & 3.30 \\
Actual & 2.15 & 1.83 & 2.19 & 3.35 & 1.60 & 3.46 \\
Est. - Act. & $0.39 * * *$ & $0.45 * * *$ & $0.87 * * *$ & $1.98 * * *$ & $-0.40 * * *$ & -0.16 \\
\hline
\end{tabular}

$* p<.05 . * * p<.01 . * * * p<.001$

Table 25.

Mean estimated times, actual times, and difference between estimated and actual times for controls.

\begin{tabular}{ccccccc}
\hline & $\mathrm{CO} 1$ & $\mathrm{CO} 2$ & $\mathrm{CO} 3$ & $\mathrm{CO} 4$ & $\mathrm{CO} 5$ & $\mathrm{CO6}$ \\
\cline { 2 - 7 } Estimated & 2.49 & 1.62 & 1.86 & 1.85 & 3.02 & 1.80 \\
Actual & 2.09 & 1.47 & 2.36 & 1.90 & 2.40 & 1.37 \\
Est. - Act. & $0.40 * * *$ & $0.15 * *$ & $-0.50 *$ & -0.05 & $0.62 * * *$ & $0.43 * * *$ \\
\hline$* p<.05 . * * p<.01 . * * * p<.001$ & & & &
\end{tabular}

Table 26.

Differences in estimated, actual, and estimated minus actual times for clutterer-control pairs.

\begin{tabular}{ccccccc}
\hline & Pair 1 & Pair 2 & Pair 3 & Pair 4 & Pair 5 & Pair 6 \\
\cline { 2 - 7 } Difference in Estimated & 0.05 & $0.66 * * *$ & $1.20 * * *$ & $3.48 * * *$ & $-1.82 * * *$ & $1.50 * * *$ \\
Difference in Actual & 0.06 & $0.36 * *$ & -0.17 & $1.45 * * *$ & $-0.80 * * *$ & $2.09 * * *$ \\
Difference in Est. - Act. & -0.01 & $0.30 * *$ & $1.37 * * *$ & $2.03 * * *$ & $-1.02 * * *$ & $-0.59 *$ \\
\hline
\end{tabular}

$* p<.05 . * * p<.01 . * * * p<.001$ 
Figure 12. Mean estimated times and actual times showing emerging trends in clutterers.

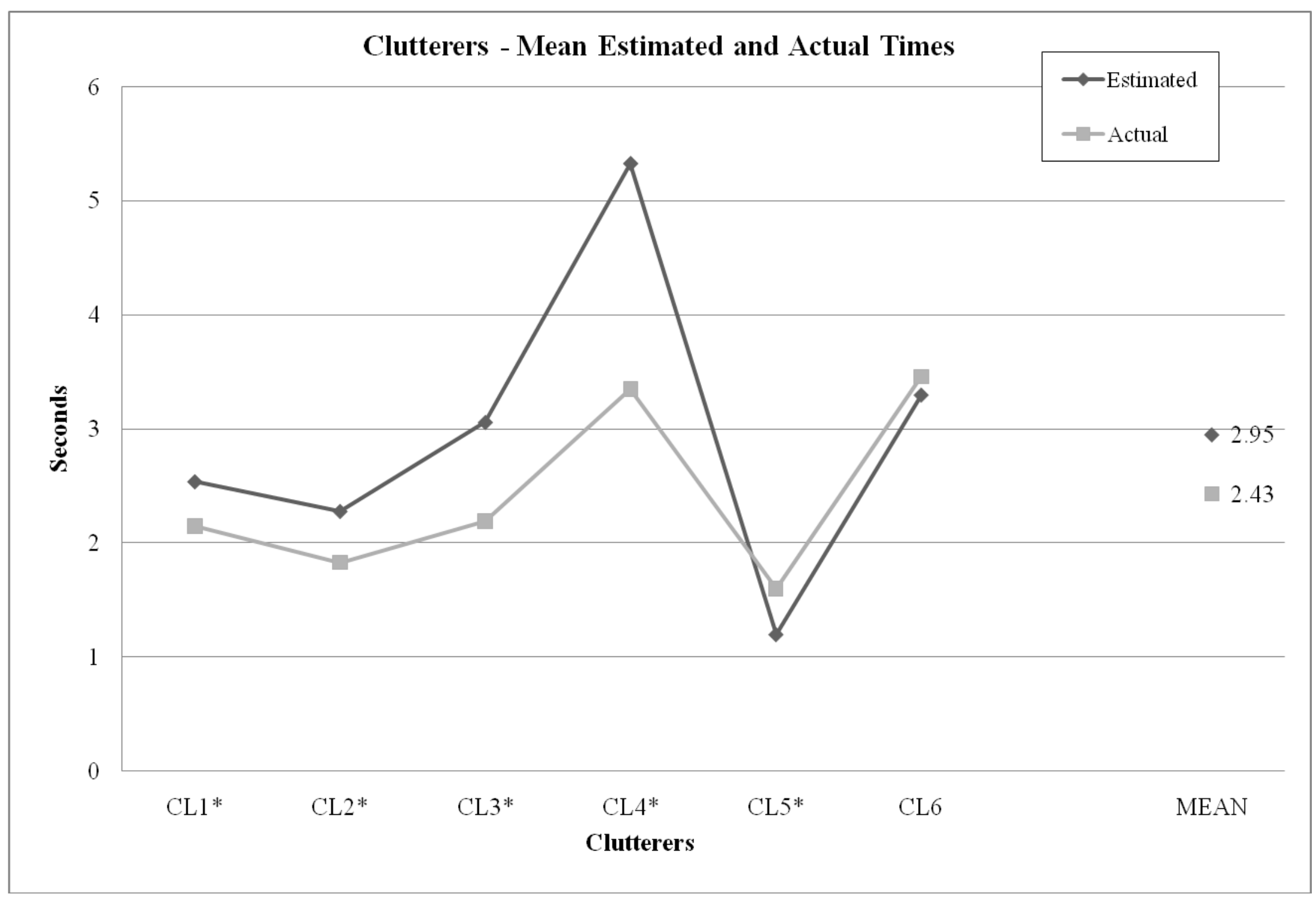


Figure 13. Mean estimated times and actual times showing emerging trends in controls.

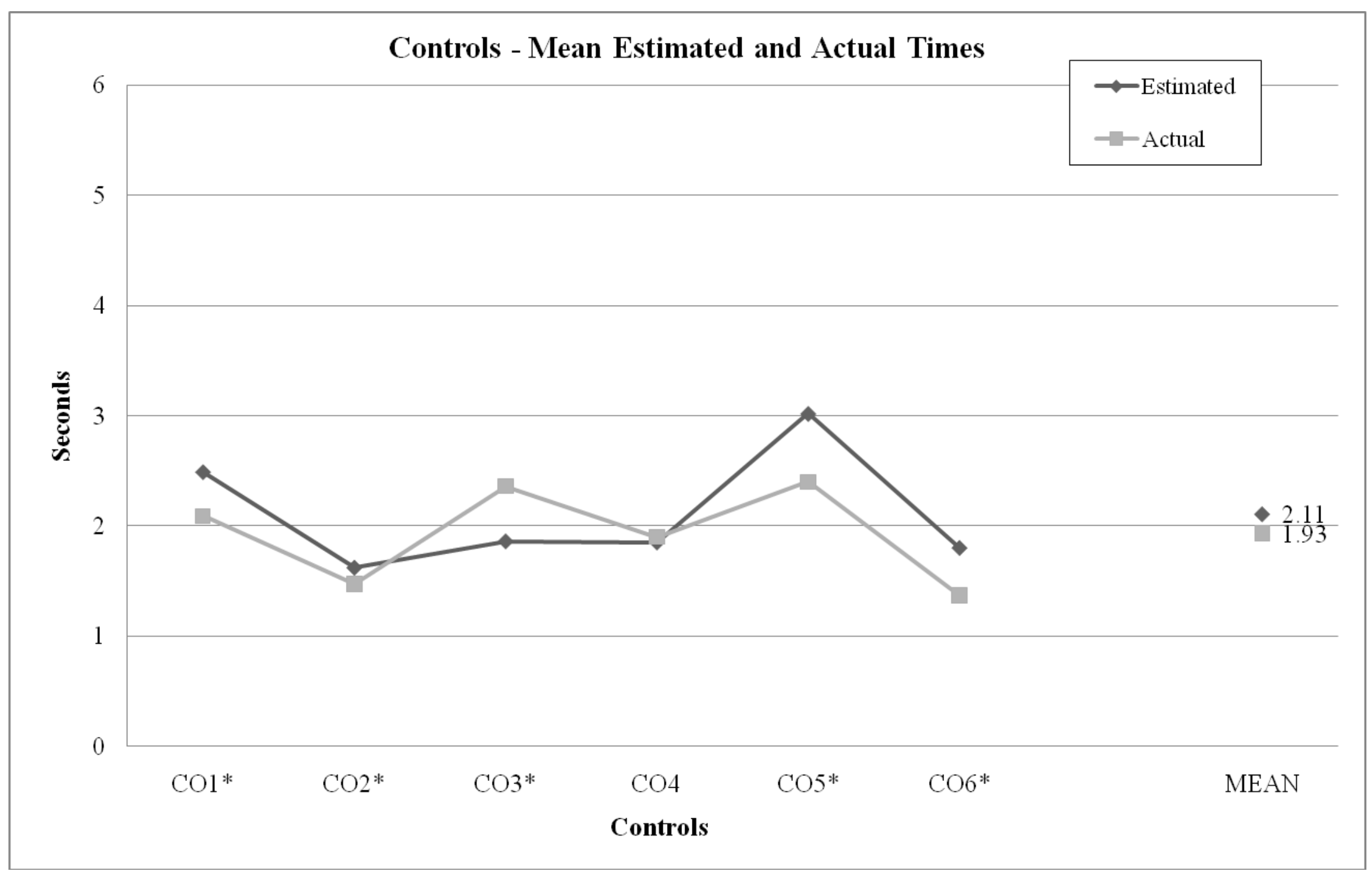


significant differences between estimated minus actual times (pairs 2, 3, 4, 5, and 6). In pairs 2, 3, and 4, the clutterers' difference between estimated minus actual time was significantly greater than that of their matched controls, while in pairs 5 and 6, the clutterers' difference between estimated minus actual times was significantly less than their matched controls. Pair one (CL1 versus CO1) did not show any statistically significant differences in any of the differences of estimated, actual, or estimated minus actual times.

\section{Prerecorded Sentences}

All participants were adequately able to start and stop a timer corresponding to the beginning and end of an utterance, respectively. Clutterers' mean estimations $(M=4.01$, $S D=1.65)$ were not significantly different that controls' $(M=4.00, S D=1.45), t(10)=0.01$, $p=.99$. Individual results are listed in Appendix K.

\section{Discussion}

The primary purpose of this study was to determine if clutterers, as a group, were poorer estimators of speech time than their matched controls. It was hypothesized that a difficulty in estimating speech time could be at least one of the factors that influence a person to produce cluttered speech. While differences in time-estimation did exist between the two groups, these differences were not significant. Nevertheless, the following group trends emerged. First, both clutterers and controls had longer estimated times than actual times. That is, it took all participants in the study less time to say their answers than they thought it would. This supports the results of Ringel and Minifie (1966), in which all participants (both stutterers and nonstutterers) overestimated time in all of the different conditions, but does not support Lass and Conn (1974), in which subjects underestimated time intervals in two-thirds of the conditions when combined. 
Second, clutterers had a greater difference between estimated and actual times (estimated time minus actual time) than controls, which supports Ezrati-Vinacour and Levin (2001) results, wherein stutterers were also poorer estimators of time than controls. Additionally, although the Brock (2008) master's thesis study was primarily concerned with the rate of covert versus overt speech, data from that study also indicated that the covert and overt timing (in actual seconds) of normal speakers are nearly identical. That is, there was no difference with regard to time between covert and overt speech. It should be noted, however, that since rate was of interest in the study, the participants were required to say the exact same words in their covert and overt utterances, so that rates could be compared. In the present study, this was not required, which would allow for the variability that occurred with the control subjects. Nevertheless, it suggests that, when saying the same words, normal speakers are able to accurately time their "inner speech" which can be likened to the "estimated time" of the present study.

Third, clutterers showed more variability in estimated, actual, and estimated minus actual times as evidenced by the coefficient of variation (CV). The CV for clutterers was approximately twice that of controls for estimated times and estimated minus actual times, and was higher for actual times as well. These results again suggest that clutterers were more variable than controls in all parts of the experiment, especially the estimation portion.

For the six clutterers and six controls in this study, quite consistent trends emerged for each group. These are apparent graphically in Figures 12 and 13. Two thirds of clutterers (CL1, CL2, CL3 and CL4; Figure 12) and two thirds of controls (CO1, CO 2, CO5, and CO6; Figure 13) had significantly longer estimated times than actual times. One-sixth of clutterers (CL5) and one sixth of controls (CO3) had significantly shorter estimated times than actual times. Finally, another one-sixth of clutterers (CL6) and one-sixth of controls (CO4) had virtually identical 
estimated and actual times. Thus, out of each group, four participants over estimated, one under estimated, and one estimated accurately. Note that it was not the same numbered participant in each group, nor should it have been, based on the fact that controls were matched only for sex and age, with limited attention to educational achievement. At least three tentative explanations might explain these trends.

First, there simply could have been no difference between the two groups, as evidenced by one-sixth of the participants in each group whose estimated and actual times were essentially the same. If the experimental participants were in fact not clutterers, this could account for the lack of a significant difference. Perhaps normal variability in the populations explains the similarities in time estimation results. This is not a trivial issue for the current investigation, especially given the similarities of the trends. The author submits, however, that the two groups sampled the populations intended. Before describing the two remaining possible explanations, substantial evidence of group differences will now be provided.

The six clutterers in this study can be clearly documented as such. It is important to reiterate that, as discussed in the introduction, clutterers are prone to normalization during testing situations (e.g., Daly, 2006; Daly \& Burnett, 1996). Revisiting the fact that a fast and/or irregular rate is central to a diagnosis of cluttering (St. Louis et al., 2007), inspection of the rates of clutterers and controls during conversation (205 SPM versus 186 SPM) and reading (209 SPM versus $218 \mathrm{SPM}$ ) were similar in speed. Although clutterers' rates were slightly higher than controls in conversation, both rates were within the range that is typically considered a normal rate of speech (Ingham, 1984). These results are not unexpected: numerous researchers have highlighted the difficulties inherent in accurately capturing a clutterer's true, natural, uninhibited speech during testing (e.g., Daly, 2006; Daly \& Burnett, 1996; Myers, in press). Perceptual data 
presented in Figure 1 however, suggest that clutterers were in fact perceived to have faster, more irregular rates by all three raters, i.e., trained examiners, friends, and even themselves. Thus, it is likely that clutterers normalized somewhat during conversation and reading. Additionally, although speaking rates during the experimental tasks were much faster ( $\sim 5-6$ SPS or 300-360 SPM), the means for clutterers and controls were again very similar (5.31SPS and 5.79SPS, respectively).

Comparing the clutterers with controls, several important similarities were observed. First, clutterers and controls, as a group, were virtually identical with regard to their mean standard scores on the PPVT-IV (106.17 versus 105.83, respectively). Even individual pairs were, probably by chance, extremely close, some being identical. In any case there were virtually no measured receptive language differences between the two groups. On the SASI which purports to measure self-awareness of speech-related variables, the mean results were also virtually identical. Additionally, with the exception of CL6 who had consistent misarticulation of /r/ (which is not related to cluttering), no differences in articulation were found between groups on a standardized articulation test. That is not to say that excessive coarticulation did not occur in the cluttering participants; it simply means that clutterers were able to say the target sounds correctly on a standardized test. (Further discussion of coarticulation differences will follow.) Similarly, there were no great differences in educational background that might have suggested general intellectual superiority of one group or the other. Attempts were made to match similar educational backgrounds, at least with respect to completion of post-high school education between individual pairs. For example, all clutterers and all controls had some college experience. 
How, then, did clutterers differ from controls in such a way as to ensure that the experimental group was in fact clutterers, and that the lack of difference in time estimation was not due to the groups being equal? The greatest difference can be seen by comparing the disfluency analyses conducted on the conversation samples of the two groups. Total disfluencies for both groups can be seen clearly in Figure 5. First, clutterers had more of each type of disfluency than controls. Overall, clutterers had significantly more total disfluencies (279 or 11.07/100S), which was nearly two and a half times more than controls (113 or 4.48/100S). When the eight individual disfluency types were analyzed, statistically significant differences existed for two important categories with regard to cluttering: revisions and hesitations. Clutterers had significantly more revisions and hesitations than controls. Both disfluency types probably contribute significantly to the perception of irregularity of rate. Hesitations, especially, can contribute to a perception of a choppy, jerky rate. So, while the clutterers' rate as a group was not significantly faster than the controls' rate with regard to absolute SPM, objective data from disfluency analysis, together with statistically significant differences in perceptual ratings of regularity by three different raters, suggest that clutterers did have an irregular rate of speech.

Upon inspection of the number of interjections during the analyzed conversation sample, one might initially be surprised to find that controls had, at least when looking at percentages, relatively more interjections $(70 \%)$ when compared with clutterers $(38 \%)$. Although the absolute mean difference was not statistically significant, it was rather large; however, distribution of disfluencies between clutterers and controls is worth mentioning here. Figures 6 and 7 show disfluency distribution by type for clutterers and controls, respectively. Over two thirds (79 out of a total of 113 disfluencies) of the controls' disfluencies were interjections (primarily “um”), leaving less frequent occurrences of the other types of disfluencies. Only two other disfluency 
types even reached over $10 \%$. By contrast, clutterers had a more widely distributed spread of the different types of disfluencies, thus yielding more varied disfluency types. Interestingly, clutterers, as a group, had 105 interjections, nearly matching the total number of disfluencies of controls, i.e., 113.

These data are somewhat at odds with previous and other reports (Myers \& St. Louis, 1996; Bakker, Myers, Raphael, \& St. Louis, in press; Myers, St. Louis, Bakker, Raphael \& Frangis, 2004) wherein, using SDA procedures, clutterers were observed to be very similar to controls and to non-cluttering but excessively rapid speakers. Moreover, all three groups manifested much higher levels of interjections and revisions than for any of the other disfluency categories; i.e., unfinished words, phrase repetitions, word repetitions, syllable repetitions, sound repetitions, or prolongations. Interestingly, hesitations were virtually absent from all three groups, perhaps related to criteria listed in the SDA guidelines as a pause of one second or greater. For reasons that cannot be determined, the disfluency data from this study show much greater differences in disfluency, however determined or calculated, than the aforementioned studies.

Finally, perceptual ratings of naturalness by both the researcher and a friend of each participant were significantly lower in clutterers when compared with controls, suggesting that listeners perceive clutterers' speech to be unnatural, while clutterers seem not to be as aware of this. Perceptual ratings of all disfluency data are presented in Figure 4.

As noted, clutterers and controls were virtually identical with regard to their performance on the PPVT-IV, a measure of receptive language. No formal expressive language test was given, but subjective perceptual ratings provide some insight into expressive language abilities. Six areas of expressive language were assessed on the perceptual rating scale developed by the 
researcher: pragmatics, syntax, semantics, word finding, narratives, and mazes. Again, this scale was completed by each participant, the researcher, and a friend of each participant. Figure 3 shows the perceptual ratings of language by all three raters. Statistically significant differences between clutterers and controls (with clutterers rated higher than controls) for pragmatics were observed by the researcher and friend, syntax and semantics by all three raters, word finding and mazes by the participants and the researcher, and narratives only by the researcher. Overall, the researcher perceived differences that proved to be significant for all aspects of expressive language, two-thirds for participants' self ratings, and half for friends of the participants. While some authors (St. Louis, Raphael, Myers, \& Bakker, 2003, St. Louis, et al., 2007) do not consider cluttering to be a language disorder, they clearly recognize language disorders frequently coexist with cluttering, and other authors do recognize or suggest an essential language component (e.g., Daly \& Burnett, 1996; Myers, 1996; \& Weiss, 1964). Whether or not these language differences cause cluttering or simply coexist with cluttering (or, that cluttering symptoms tend to be perceived as language difficulties when in fact they are cluttering) cannot be determined.

Although no significant differences were observed on a standardized articulation test, perceptual differences in articulation between clutterers and controls occurred on the perceptual rating scale developed by the researcher. Figure 2 shows perceptual rating data for articulation for all three raters. Statistically significant differences characterized the results from all three raters (participant, researcher, and friend of the participant) for collapsed syllables, compressed clusters, and shortened vowels, with clutterers having more of these symptoms than controls. Traditional articulation error differences were rated statistically significantly different by the participants and the researcher but not by friends. Additionally, intelligibility was rated 
significantly lower for clutterers by the researcher and friends of the participants. Clutterers' self ratings were not significantly different than controls with regard to intelligibility, which also could suggest some unawareness of their own speech, though clutterers did rate themselves as less natural than controls.

Assuming, then, that the clutterers in this study were correctly labeled as such, there are two remaining possible scenarios to explain the similar profiles between the two groups: those who overestimated time and those who underestimated time. Again, clutterers could have longer estimated times than actual times. That is, it could take clutterers less time to say something than they think it will take. Conversely, clutterers could have longer actual times than estimated times. That is, it could take clutterers longer to say something than they think it will. The weight of the evidence suggests that in general overestimation of time is more prevalent in the present study.

While clutterers did not overestimate time statistically significantly more often than controls, their estimations were higher. Clutterers as a whole had a mean estimated time of 2.95 seconds compared to controls who had a mean estimated time of 2.11 seconds. Therefore, clutterers' estimated times, as a group, were nearly one second (0.85) longer than controls', while clutterers' actual times were only one half of a second longer than controls'. So the important difference seems to lie more in the estimated times, rather than the actual times. Interestingly, the same 4/1/1 (longer estimations/shorter estimations/correct estimations) trend described above emerges in the difference in estimated times between clutterers and controls: four clutterers had larger differences in estimated times than their paired controls $(2,3,4$, and 6); one clutterer had no difference in estimated time when compared with the matched control (1); and one clutterer underestimated time when compared with the matched control (5). Given the 
limited sample of this study, these differences must be treated only as trends at this time rather than significant differences. Nevertheless, they are interesting.

Other unexpected but interesting trends also emerged, and are apparent in Figures 8, 9, 10 and 11, which graph individual participants' estimated and actual times across all 50 tasks. When inspected visually, clutterers showed greater variability in both their estimated (Figure 8) and actual times (Figure 9) in comparison to controls (Figures 10 and 11), especially in their estimated times. Most controls' estimated times remained at or below 4.5 seconds, many under 3 seconds. This was not true for clutterers. Their estimated times varied much more, with comparable durations of 1 to 6 seconds. The same was true for actual times, although the trend was less pronounced. These differences are also reflected numerically in the $\mathrm{CV}$, as the most variability was found in the estimated times. Again, the important difference between cluttering and non-cluttering participants seems to lie in their estimated times. Interestingly, the Brock (2008) study also found more variability in the covert speech compared to overt speech in normal speakers.

Several possible explanations for the general overestimation of time for all participants are possible. Participants were instructed to first think about the answer to the question, then press and hold the mouse button for the amount of time they thought it would take them to say it. They were not to include the time it took them to formulate their responses, but it is possible that such formulation times were included. If this occurred, however, it would seem that it occurred for both clutterers and controls, as both groups had longer estimated times. Nevertheless and importantly, clutterers' times were longer. Perhaps clutterers needed longer to formulate their answers and this was included in their estimated times. 
Alternatively, perhaps clutterers' "internal clock" with regard to speech timing functions correctly. If so, their estimated speech time could in fact be fairly accurate. Yet, when they speak their answers aloud, their rapid rate is evidenced in the fact that their actual times were shorter. They were shorter because they spoke too fast. In the present study, however, rates in SPS during experimental tasks were actually slightly $(\sim 0.5 \mathrm{~s})$ faster in controls. Some support for this alternative notion is found in the fact that controls' estimated and actual times were closer, although not significantly so. It is important to note that it appears from the results of the timing of the six prerecorded sentences that clutterers are no different than controls with respect to their ability to time something "external." This task, however, did not involve any speech or language, at least on the part of the participants, nor was it a task of time estimation.

Considering both potential explanations, the author submits that the first, i.e., that clutterers require more formulation time, is more plausible than the second. As speaking rates for both groups during the experimental tasks were comparable, it does not appear that clutterers spoke much faster during their answering, causing their actual times to be shorter. Additionally, most of the variability lies in the estimated times, not the actual times, suggesting that whatever occurred, occurred during the estimation portion of the experiment rather than the actual speaking portion.

\section{Conclusions and Suggestions for Future Research}

The purpose of this study was to investigate and test a possible explanation for clutterers' rapid and/or irregular rate of speech. Stemming from previous research that suggested that persons with fluency disorders (i.e. stutterers) have some general difficulties with temporal organization and timing, a time estimation task was used. The decision to use a verbal time estimation task was made in light of the fact that if clutterers were unaware of the time required 
to say something, they may speak too fast. It is speech time that was of interest, not timing ability in general. A control procedure of starting and stopping a timer was used to ensure participants were able to adequately time a segment; however this task did have some unavoidable language component to it, as they were timing verbal material (sentences). While their timing was accurate, it was not an estimation of any future event. Estimation of nonverbal tasks, and comparing that with estimation of verbal tasks, is an area that was not addressed in this study. It remains to be discovered if clutterers' overall estimation ability is impaired. Clearly, increasing the sample size might result in clearer, more distinct results.

Although the differences in estimated time, actual time, and estimated minus actual times between clutterers and controls, as groups, were not statistically significant, the trends that emerged suggested that clutterers' perception of time was "off” in some manner. This is especially true when inspecting the individual participant pairs. Many of those comparisons were significant; however the limited statistical power of six participants per group is most certainly a factor. If maintained, these trends would become statistically significant with the addition of more participants, which is the primary suggestion for a follow-up investigation. Additionally, many previous studies group stutterers by severity, and when doing so, found differences between moderate to severe stutterers and controls, but less or no difference between mild stutterers and controls. Although not feasible in a study of six clutterers, adding consideration of the severity of cluttering to time estimation might prove useful.

While the present study suggests that clutterers may have some differences with regard to their estimation of speech time, it is not clear at this time why these differences exist. Clutterers and controls, as groups, but not consistently so as individuals, both tended to overestimate their times. If this finding were to be replicated in future investigations, the implication to be drawn is 
that clutterers very likely do not talk fast because they cannot estimate their own speaking time. If controls had shown entirely different patterns than clutterers, then perhaps such a conclusion might be warranted. That, clearly, was not the case. Yet, time estimation is only one of many abilities or areas that could be included in measurement of awareness, meta-awareness, or speech monitoring. The author maintains that one possible explanation for cluttering symptoms is some inability to monitor one's own speech, as many of the treatment goals for clutterers involve heightening clutterers' awareness of their speech, and, many of these are successful. Future research should continue to delve into this area of awareness and monitoring. 


\section{References}

American Speech-Language-Hearing Association Audiological Assessment Panel 1996. (1997). Guidelines for audiological screening. Rockville, MD: Author.

American Speech-Language-Hearing Association. (1999). Terminology pertaining to fluency and fluency disorders: Guidelines. Retrieved July 1, 2009 from www.asha.org/policy.

Bakker, K., Myers, F. L., Raphael, L. J., \& St. Louis, K. O. (in press). People who clutter or speak exceptionally fast: Comparing the evidence. In D. Ward \& K. S. Scott (Eds.). Cluttering: Research, intervention, education. East Sussex, UK: Psychology Press.

Bakker, K., St. Louis, K. O., Myers, F. L., \& Raphael, L. J. (2005). Computer aided assessment of cluttering severity. Paper presented at the $8^{\text {th }}$ International Stuttering Awareness Day OnLine Conference. October, 2005. Retrieved July 1, 2009 from http://www.mnsu.edu/comdis/isad8/papers/bakker8/bakker8.html.

Barasch, C. T., Guitar, B., McCauley, R. J., \& Absher, R. G. (2000). Disfluency and time perception. Journal of Speech, Language, and Hearing Research, 43, 1429-1439.

Brock, M. A. (2008). The rate of inner speech. Unpublished master's thesis, Missouri State University, Springfield.

Campbell, J. G., \& Hill, D. G. (1994). Systematic Dysfluency Analysis. Evanston, IL: Northwestern University.

Dalton, P., \& Hardcastle, W. (1989). Disorders of fluency and their effects on communication, $\left(2^{\text {nd }}\right.$ ed). London: Elsevier-North Holland.

Daly, D. A. (2006). Predictive Cluttering Inventory. Author.

Daly, D. A. \& Burnett, M. L. (1996). Cluttering: Assessment, treatment planning, and case study illustration. Journal of Fluency Disorders, 21, 239-248. 
Daly, D. A. \& Burnett, M. (1999). Cluttering: Traditional views and new perspectives. In R. F. Curlee (Ed.), Stuttering and related disorders of fluency ( $2^{\text {nd }}$ ed.). (pp. 222-254). New York: Thieme.

Daly, D. A., \& St. Louis, K. O. (1998). Videotaping clutterers: How to do it and what to look for. In E. C. Healey \& H. F. M. Peters (Eds.). 2nd World Congress on Fluency Disorders Proceedings (pp. 233-235). International Fluency Association.

Darley, F., Aronson, A., and Brown, J. (1975). Motor speech disorders. Philadelphia: W. B. Saunders, Inc.

Dunn, L. M. \& Dunn, D. M. (2007). Peabody Picture Vocabulary Test-Fourth Edition (PPVT4). Bloomington, MN: NCS Pearson.

Ezrati-Vinacour, R. \& Levin, I. (2001). Time estimation by adults who stutter. Journal of Speech, Language, and Hearing Research, 44, 144-155.

Guitar, B. (2006). Stuttering: An integrated approach to its nature and treatment $\left(3^{\mathrm{rd}} \mathrm{ed}.\right)$. Philadelphia: Lippincott, Williams \& Wilkins.

Ingham, R. J. (1984). Stuttering and behavior therapy: Current status and experimental foundations. San Diego: College-Hill Press.

Kent, R. D. (1984). Stuttering as a temporal programming disorder. In R. F. Curlee \& W. H. Perkins (Eds), Nature and treatment of stuttering: New directions (pp. 283-301). San Diego: College-Hill Press.

Lass, N. J. \& Conn, W. H. (1974). Time perception: a comparative study of time estimations in empty passive, speech-filled passive, and speech-filled active conditions. Journal of Auditory Research, 14, 117-120.

Lees, R. M., Boyle, B. E., \& Woolfson, L. (1996). Is cluttering a motor disorder? Journal of 
Fluency Disorders, 21, 281-287.

Loban, W.D. (1963). The language of elementary school children. Champaign, IL: National Council of Teachers of English.

Maxwell, D. L. \& Satake, E. (1997). Research and statistical methods in communication disorders. Boston: Lippincott, Williams, \& Wilkins.

Myers, F. L. (1992). Cluttering: A synergistic framework. In F. L. Myers \& K. O. St. Louis (Eds.) Cluttering: A clinical perspective (pp. 71-84). Kibworth, England: Far Communications. (Reissued in 1996 by Singular, San Diego, CA).

Myers, F. L. (1996). Cluttering: A matter of perspective. Journal of Fluency Disorders, 21, 175185.

Myers, F. L. (In press). Treatment of cluttering: A cognitive-behavioral approach centered on rate control. In D. Ward \& K. S. Scott (Eds.). Cluttering: Research, intervention, education. East Sussex, UK: Psychology Press.

Myers, F. L. \& St. Louis, K. O. (1992). Cluttering: Issues and controversies. In F. L. Myers \& K. O. St. Louis (Eds.) Cluttering: A clinical perspective (pp 11-12). Leicester: FAR Communications. (Reissued in 1996 by Singular, San Diego, CA).

Myers, F. L. \& St. Louis, K. O. (1996). Two youths who clutter, but is that the only similarity? Journal of Fluency Disorders, 21, 297-304.

Myers, F. L., St. Louis, K. O., Bakker, K., Raphael, L. J., \& Frangis, G. (2004). Disfluencies of cluttered and excessively rapid speech. Poster submitted to the Annual Convention of the American Speech-Language-Hearing Association. Philadelphia, PA.

Myers, F. L., St. Louis, K. O., \& Faragasso, K. A. (2008) Disfluency clusters associated with cluttering. Bulgarian Journal of Communication Disorders, 2, 10-19. 
Ringel, R. L. \& Minifie, F. D. (1966). Protensity estimates of stutterers and nonstutterers. Journal of Speech and Hearing Research, 9, 289-296.

Scott, K. S., \& St. Louis, K. O. (In press). A perspective on improving evidence and practice in cluttering. Perspectives on Fluency and Fluency Disorders.

Semel, E., Wiig, E. H., \& Secord, W. (1987). Clinical Evaluation of Language Fundamentals Revised. San Antonio, TX: The Psychological Corporation.

Starkweather, C. W. (1987). Fluency and stuttering. Englewood Cliffs, NJ: Prentice-Hall.

St. Louis, K. O. (1996). A tabular summary of cluttering subjects in the special edition. Journal of Fluency Disorders, 21, 337-343.

St. Louis, K. O. (1998). Cluttering: Some guidelines. Memphis, TN: Stuttering Foundation of America.

St. Louis, K. O. (2005). St. Louis Inventory of Life Perspectives and Speech/Language Difficulty. Morgantown, WV: Populore.

St. Louis, K. O. \& Atkins, C. P. (2005). Self-awareness of Speech Index. Morgantown, WV: Populore.

St. Louis, K. O. \& Hinzman, A. R. (1986). Studies of cluttering: Perceptions of speech-language pathologists and educators of cluttering. Journal of Fluency Disorders, 11, 131-149.

St. Louis, K. O., \& Myers, F. L. (1997). Management of cluttering and related fluency disorders. In R. F. Curlee and G. M. Siegel (Eds.), Nature and treatment of stuttering: New directions (pp. 313-332). NY: Allyn and Bacon.

St. Louis, K. O. \& Myers, F. L. (1998). A synopsis of cluttering and its treatment. Paper presented at the $1^{\text {st }}$ annual International Stuttering Awareness Day Online Conference, October 22, 1998. 
St. Louis, K. O., Myers, F. L., Bakker, K., \& Raphael, L. J. (2007). Understanding and treating cluttering. In E. G. Conture \& R. F. Curlee (Eds.), Stuttering and related disorders of fluency, (3rd ed.) (pp. 297-325). New York: Thieme.

St. Louis, K. O., Myers, F. L., Faragasso, K., Townsend, P. S., \& Gallaher, A. J. (2004). Perceptual aspects of cluttered speech. Journal of Fluency Disorders, 29, 213-235.

St. Louis, K. O., Raphael, L. J., Myers, F. L., \& Bakker, K. (2003, November). Cluttering updated. The Asha Leader, 8(21), 4-5, 20-23.

St. Louis, K. O., Ruscello, D. M., \& Lundeen, C. (1992). Coexistence of communication disorders in schoolchildren. ASHA Monographs, No. 27.

St. Louis, K. O. \& Schulte, K. (In press). Defining cluttering: The lowest common denominator. In D. Ward \& K. S. Scott (Eds.). Cluttering: Research, intervention, education. East Sussex, UK: Psychology Press.

Teigland, A. (1996). A study of pragmatic skills of clutterers and normal speakers. Journal of Fluency Disorders, 21, 201-214.

Templin, M. \& Darley, F. (1969). The Templin-Darley Tests of Articulation (2nd Ed.). Iowa City: University of Iowa Bureau of Educational Research \& Service.

Van Riper, C. (1971). The nature of stuttering. Englewood Cliffs, NJ: Prentice-Hall.

Weiss, D. A. (1964). Cluttering. Englewood Cliffs, NJ: Prentice-Hall.

Zakay, D. (1990). The evasive art of subjective time measurement: Some methodological dilemmas. In R. A. Block (Ed.), Cognitive models of psychological time, (pp. 59-84). Mahwah, NJ: Lawrence Erlbaum.

Zakay, D. (1993). Timing and method of subjective time estimation: Do they influence time estimation? Perception, 22, 91-101. 


\section{Appendix A}

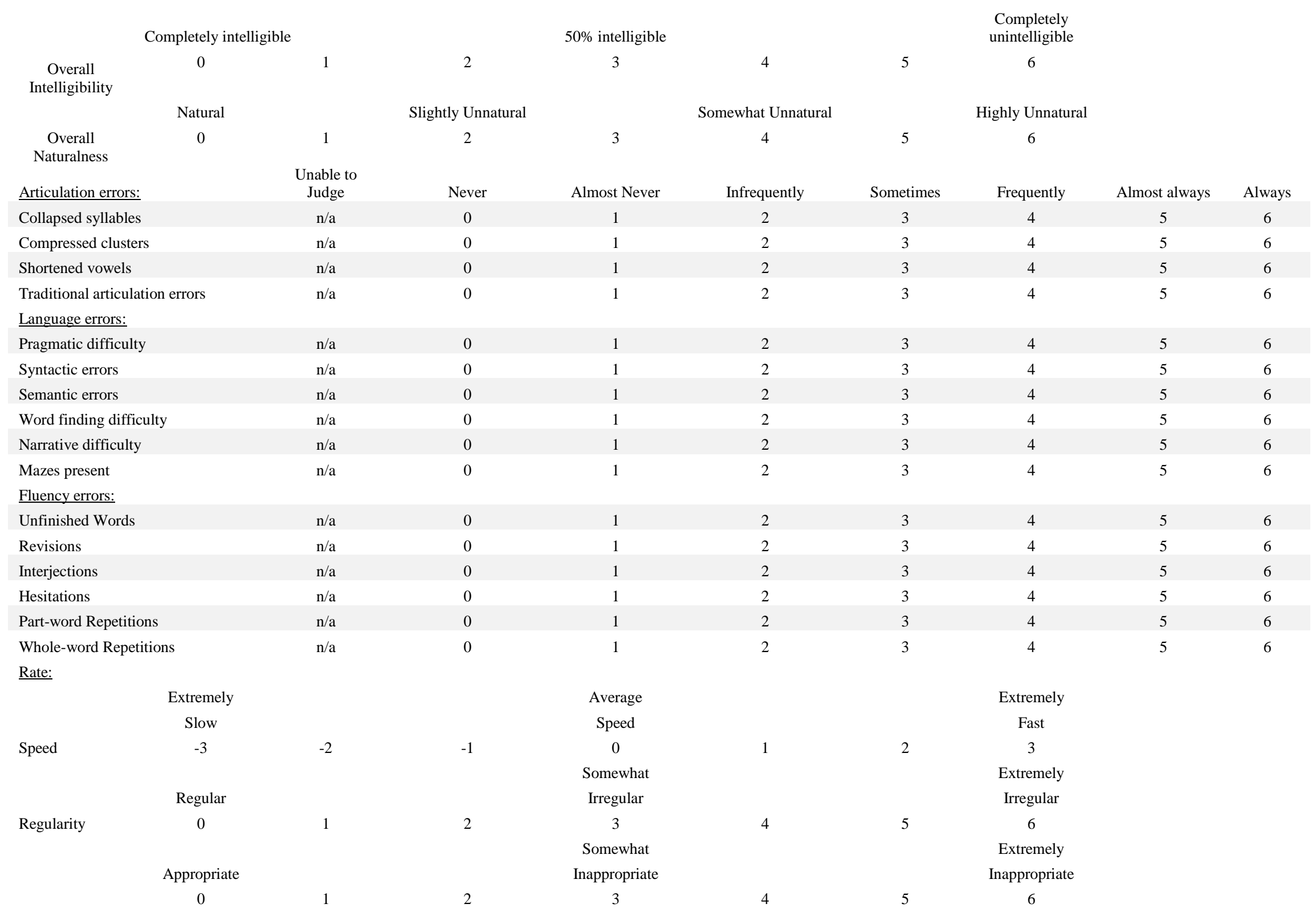




\section{Appendix B}

\section{PREDICTIVE CLUTTERING INVENTORY (PCI) David A. Daly (2006)}

\section{INSTRUCTIONS: Please respond to each description section below. Circle the number you believe is most descriptive of this person's cluttering.}

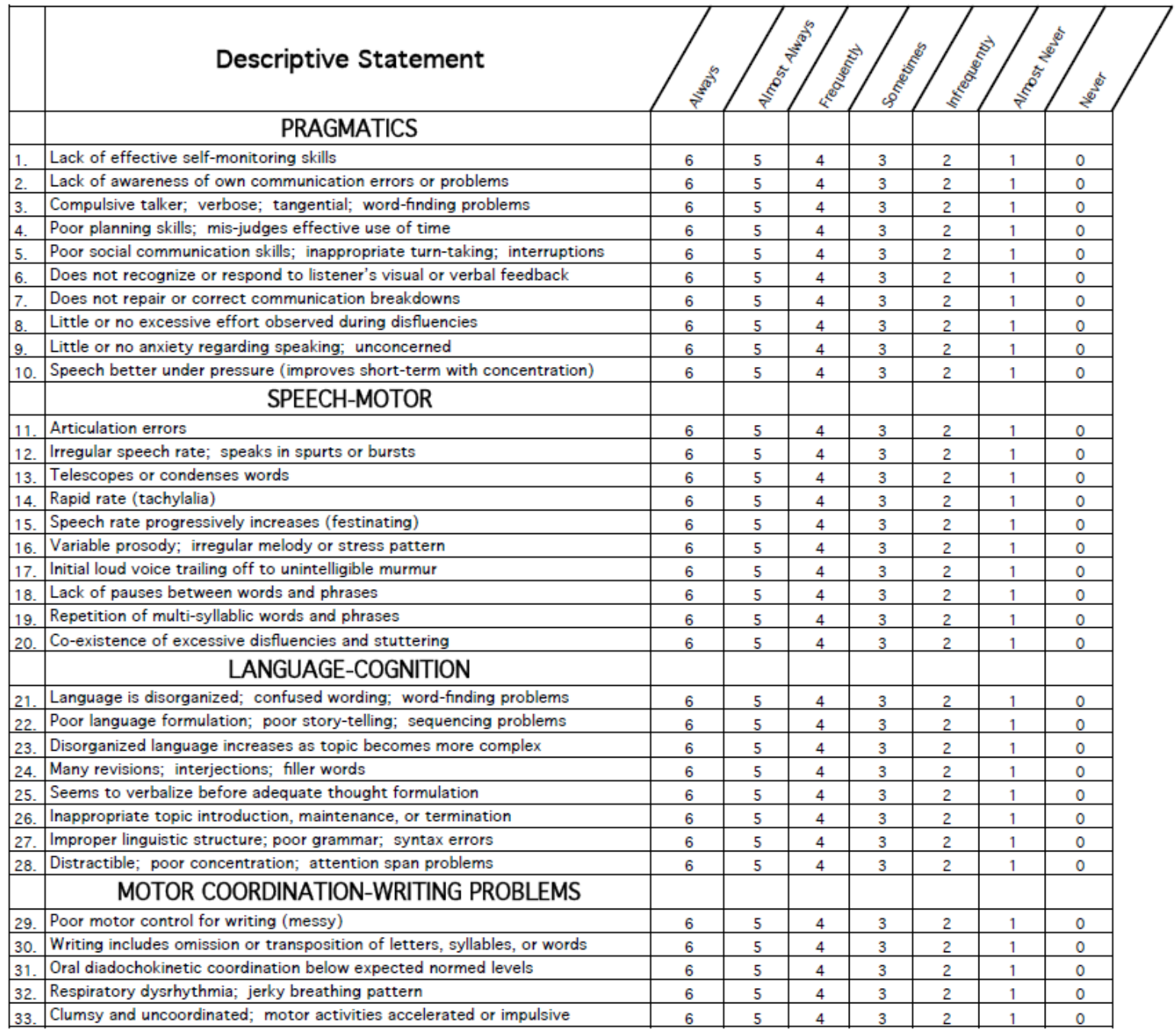

TOTAL SCORE:

\section{COMMENTS:}


Appendix C

\title{
Self-Awareness of Speech Index (SASI)
}

\author{
Kenneth O. St. Louis \& Carolyn P. Atkins
}

West Virginia University, Morgantown, WV

Name:

Date:

Instructions: Please check $(\sqrt{ })$ the appropriate box for each question. Work rapidly and do not look back or change your answers.

\begin{tabular}{|c|c|c|c|c|c|}
\hline \multicolumn{2}{|r|}{$\begin{array}{l}\text { Instructions: Please check }(\sqrt{ }) \text { the appropriate box for } \\
\text { each question. Work rapidly and do not look back or } \\
\text { change your answers. }\end{array}$} & \multirow{2}{*}{ 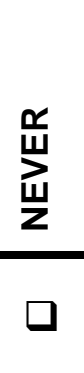 } & \multirow{2}{*}{ 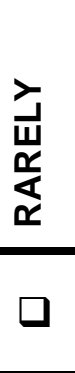 } & \multirow{2}{*}{ 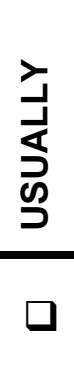 } & \multirow{2}{*}{ 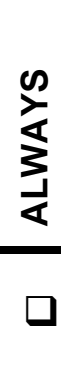 } \\
\hline 1. & $\begin{array}{l}\text { I notice differences in the way I say words as } \\
\text { compared to the way other people say words. }\end{array}$ & & & & \\
\hline 2. & $\begin{array}{l}\text { I notice when other people use fillers when they } \\
\text { talk, such as "uh," "ya know," and "um." }\end{array}$ & $\square$ & $\square$ & $\square$ & a \\
\hline 3. & I try to copy the way other people say certain words. & $\square$ & $\square$ & $\square$ & $\square$ \\
\hline 4. & $\begin{array}{l}\text { I listen to whether someone else's voice is high- } \\
\text { pitched or low-pitched. }\end{array}$ & $\square$ & a & a & ] \\
\hline 5. & I am aware of other people's accents as they talk. & $\square$ & $\square$ & $\square$ & $\square$ \\
\hline 6. & I know when I repeat a sound, word, or phrase. & $\square$ & $\square$ & $\square$ & $\square$ \\
\hline 7. & I notice pitch changes in my own voice. & $\square$ & $\square$ & $\square$ & $\square$ \\
\hline 8. & I pay attention to how fast other people talk. & $\square$ & $\square$ & $\square$ & $\square$ \\
\hline 9. & $\begin{array}{l}\text { I notice repetitions of sounds, words, or phrases } \\
\text { when other people talk. }\end{array}$ & $\square$ & $\square$ & $\square$ & a \\
\hline 10. & I am aware of how other people say words. & $\square$ & $\square$ & $\square$ & $\square$ \\
\hline 11. & I pay attention to how fast I talk. & $\square$ & $\square$ & $\square$ & $\square$ \\
\hline 12. & I notice when I stumble over words. & $\square$ & $\square$ & $\square$ & $\square$ \\
\hline 13. & I notice my own accent. & $\square$ & $\square$ & $\square$ & $\square$ \\
\hline 14. & $\begin{array}{l}\text { I am aware when I use fillers when I talk, such as } \\
\text { "uh," "ya know," and "um." }\end{array}$ & $\square$ & $\square$ & a & a \\
\hline
\end{tabular}




\title{
Self-Awareness of Speech Index (SASI) Summary Form
}

\author{
Kenneth O. St. Louis \& Carolyn P. Atkins \\ West Virginia University, Morgantown, WV
}

Name:

Date:

Instructions: Count the number of checks in each of the 4 columns of the completed SASI form. Write the totals in the boxes in the $1^{\text {st }}$ row. Multiply these numbers by the weights provided in the $2^{\text {nd }}$ row and write Weighted Totals in the boxes in the $3^{\text {rd }}$ row. Write the sum of these four numbers in the Grand Total box in the $4^{\text {th }}$ row and on the line below. Divide the Grand Total by 14 to determine the Average SASI Score. Round the Average SASI Score to tenths, e.g., 2.4.

Total Checks In Each Category

\begin{tabular}{|l|c|c|c|c|}
\hline Weights (Multipliers) & x 1 & $\times 2$ & $\times 3$ & $\times 4$ \\
\hline Weighted Totals & $\square$ & $\square$ & $\square$ & $\square$ \\
\hline Grand Total & \multicolumn{3}{|c|}{$\mid$} \\
\hline
\end{tabular}

Average SASI Score:

Grand Total

$/ 14=$

Notes:

1. Attach this Summary Form to the completed SASI form after scoring.

2. Average SASI Scores can range from 1.0 (completely unaware of speech in oneself and others) to 4.0 (extremely aware of speech in oneself and others).

3. The Average SASI Score for 171 unselected college students (34\% males and $66 \%$ females, with a mean age of 21 years [range $=18-44$ years]) was 2.7, with individual SASI items ranging from 1.7 to 3.4 (Atkins \& St. Louis, 1988). 
Appendix D

\section{St. Louis Inventory of Life Perspectives and Speech/Language Difficulty $(S L \diamond$ ILP-S/L) \\ A Taking Stock Self-Study Exercise • Kenneth O. St. Louis, Ph.D.}

Name:

Age:

Date:

1. Overall, how much difficulty, handicap, or suffering do you experience from your speech or language difficulty at this time?

\begin{tabular}{c|c|c|c|c|c|c|c|c|c|}
$\begin{array}{c}\text { I Don't } \\
\text { Know }\end{array}$ & None & \multicolumn{1}{c|}{$\begin{array}{c}\text { Very } \\
\text { Much }\end{array}$} \\
\hline 0 & 1 & 2 & 3 & 4 & 5 & 6 & 7 & 8 & 9 \\
\hline
\end{tabular}

2. Overall, how much does your speech or language difficulty negatively affect your ability to interact with other people at this time?

\begin{tabular}{c|c|c|c|c|c|c|c|c|c|}
$\begin{array}{c}\text { I } \\
\text { I Don't } \\
\text { Know }\end{array}$ & $\begin{array}{c}\text { No } \\
\text { Negative } \\
\text { Effect }\end{array}$ & $\begin{array}{c}\text { Moderate } \\
\text { Negative } \\
\text { Effect }\end{array}$ \\
\hline 0 & 1 & 2 & 3 & 4 & 5 & 6 & 7 & 8 & 9 \\
\hline
\end{tabular}

3. Overall, how much do you feel able or unable to control your speech or language difficulty at this time?

\begin{tabular}{|c|c|c|c|c|c|c|c|c|}
$\begin{array}{c}\text { I Don't } \\
\text { Know }\end{array}$ & $\begin{array}{l}\text { Completely } \\
\text { Able to } \\
\text { Control }\end{array}$ & \multicolumn{3}{c}{$\begin{array}{c}\text { Equally Able } \\
\text { or Unable to } \\
\text { Control }\end{array}$} \\
\hline 0 & 1 & 2 & 3 & 4 & 5 & 6 & 7 & 8 \\
\hline
\end{tabular}

4. Overall, how severe is your speech or language difficulty at this time?

\begin{tabular}{|c|c|c|c|c|c|c|c|c|c|}
\hline $\begin{array}{l}\text { I Don't } \\
\text { Know }\end{array}$ & $\begin{array}{c}\text { No } \\
\text { Difficulty }\end{array}$ & Very Mild & & & der & & & & $\begin{array}{l}\text { Very } \\
\text { Severe }\end{array}$ \\
\hline 0 & 1 & 2 & 3 & 4 & 5 & 6 & 7 & 8 & 9 \\
\hline
\end{tabular}

5. Overall, how much do you feel a need or desire to get help for your speech or language difficulty at this time?

\begin{tabular}{|c|c|c|c|c|c|c|c|c|c|}
\hline $\begin{array}{l}\text { I Don't } \\
\text { Know }\end{array}$ & None & & & & der & & & & $\begin{array}{l}\text { Very } \\
\text { Much }\end{array}$ \\
\hline 0 & 1 & 2 & 3 & 4 & 5 & 6 & 7 & 8 & 9 \\
\hline
\end{tabular}

6. How important a problem is your speech or language difficulty in your life at this time?

\begin{tabular}{c|c|c|c|c|c|c|c|c|c|}
$\begin{array}{c}\text { Not } \\
\text { I Don't } \\
\text { Know }\end{array}$ & $\begin{array}{c}\text { Moderate } \\
\text { Important } \\
\text { At All }\end{array}$ \\
\hline 0 & 1 & 2 & 3 & 4 & 5 & 6 & 7 & 8 & 9 \\
\hline
\end{tabular}


7. How important a problem is your speech or language difficulty in the lives of the people you live with at this time?

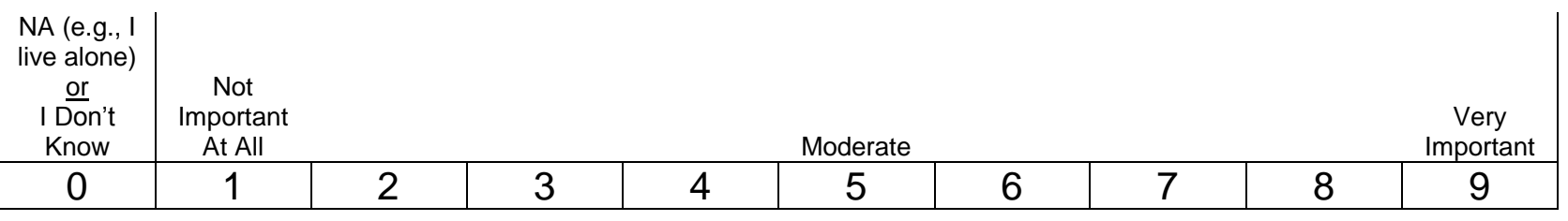

8. Overall, how much do you feel inclined to associate with other people with speech or language difficulties at this time?

\begin{tabular}{|c|c|c|c|c|c|c|c|c|c|}
\hline $\begin{array}{l}\text { I Don't } \\
\text { Know }\end{array}$ & Not At Al & & & & Modera & & & & $\begin{array}{l}\text { Very } \\
\text { Much }\end{array}$ \\
\hline 0 & 1 & 2 & 3 & 4 & 5 & 6 & 7 & 8 & 9 \\
\hline
\end{tabular}

9. Overall, how much do you feel inclined to help other people with speech or language difficulties at this time?

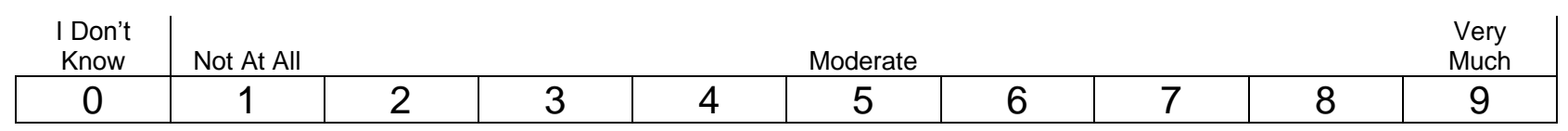

10. Overall, how is your physical health at this time?

\begin{tabular}{|c|c|c|c|c|c|c|c|c|c|}
\hline $\begin{array}{l}\text { I Don't } \\
\text { Know }\end{array}$ & \multicolumn{9}{|c|}{$\begin{array}{l}\text { Not Poor but } \\
\text { Not Good }\end{array}$} \\
\hline 0 & 1 & 2 & 3 & 4 & 5 & 6 & 7 & 8 & 9 \\
\hline
\end{tabular}

11. Overall, how is your mental health at this time?

\begin{tabular}{c|c|c|c|c|c|c|c|c|c|}
$\begin{array}{c}\text { I } \begin{array}{c}\text { Not Poor but } \\
\text { Know }\end{array} \\
\text { Knot Good }\end{array}$ \\
\hline 0 & 1 & 2 & 3 & 4 & 5 & 6 & 7 & 8 & 9 \\
\hline
\end{tabular}

12. Overall, how satisfied with your life are you at this time?

\begin{tabular}{c|c|c|c|c|c|c|c|c|c|}
$\begin{array}{c}\text { I Don't } \\
\text { Know }\end{array}$ & $\begin{array}{c}\text { Highly } \\
\text { Unsatisfied }\end{array}$ & $\begin{array}{c}\text { Not Unsatisfied } \\
\text { but Not Satisfied }\end{array}$ & $\begin{array}{c}\text { Highly } \\
\text { Satisfied }\end{array}$ \\
\hline 0 & 1 & 2 & 3 & 4 & 5 & 6 & 7 & 8 & 9 \\
\hline
\end{tabular}

13. How much did your speech or language difficulty affect your answer on the previous question, No. 12. above?

\begin{tabular}{|c|c|c|c|c|c|c|c|c|c|}
\hline $\begin{array}{l}\text { I Don't } \\
\text { Know }\end{array}$ & $\begin{array}{c}\text { No Effect } \\
\text { on \#12 }\end{array}$ & & & & $\begin{array}{r}\text { loder } \\
\text { Effect } \\
\# 12 \\
\end{array}$ & & & & $\begin{array}{c}\text { Completely } \\
\text { Determined } \\
\# 12\end{array}$ \\
\hline 0 & 1 & 2 & 3 & 4 & 5 & 6 & 7 & 8 & 9 \\
\hline
\end{tabular}




\section{Appendix E}

Please read the following words aloud:

Apply

Application

Applicable

Captive

Captivation

Captivity

Graphically

Geography

Geographically

Psyche

Psychology

Psychological
Fundamental

Hibernation

Appropriate

Biographical

Perturbation

Statistics

Characteristic

Appropriation

Chrysanthemum

Appropriately

Character

Philadelphia

Honolulu

Stuttering

Characterization

Recommendation

Glandular

Biography 
Appendix F

\section{The Grandfather Passage}

You wished to know all about my grandfather. Well, he is nearly ninety-three years old; he dresses himself in an ancient black frock coat, usually minus several buttons; yet he still thinks as swiftly as ever. A long, flowing beard clings to his chin, giving those who observe him a pronounced feeling of the utmost respect. When he speaks, his voice is just a bit cracked and quivers a trifle. Twice each day he plays skilfully and with zest upon our small organ. Except in the winter when the ooze or snow or ice prevents, he slowly takes a short walk in the open air each day. We have often urged him to walk more and smoke less, but he always answers, "Banana oil!" Grandfather likes to be modern in his language. 


\title{
Appendix G
}

\author{
Speech tasks
}

\section{Training Stimuli}

1. You're driving and the person in the car in front of you puts on the brakes, what do you do?

2. Do you prefer cats or dogs and why?

3. You're at a restaurant and the waiter brings your order and it's not correct, what do you do?

4. Do you prefer driving or being a passenger and why?

5. You're driving and the sun is suddenly in your eyes, what do you do?

6. Do you prefer overhead lights or lamps and why?

7. Someone knocks on your door and you are in the restroom, what do you do?

8. Do you prefer taking showers or baths and why?

9. A person comes out of the bathroom with toilet paper stuck to her shoe, what do you do?

10. Do you prefer to read or watch movies and why?

11. You've just finished loading your groceries onto the scanner and realize you forgot your wallet, what do you do?

12. Do you prefer rock or country and why?

13. A friend calls you at 1:00 a.m. needing a ride home from a bar, what do you do?

14. Do you prefer Coke or Pepsi and why?

15. You are driving and you think you have a flat tire, what do you do?

16. Do you prefer tea or coffee and why?

17. You come out of the mall and cannot find your car, what do you do?

18. Do you prefer gum or mints and why?

19. You are driving in the rain and your windshield wipers break, what do you do?

20. Do you prefer spring or fall and why?

\section{Experimental Stimuli}

1. Someone comes to your door selling something, what do you do?

2. Do you prefer to look at a clock or a watch and why?

3. You try to start your car on a cold morning. It doesn't start on the first try. What do you do?

4. Do you prefer light sheets or heavy blankets and why?

5. You hit your foot very hard on your couch and it begins to bleed, what do you do?

6. Do you prefer to use a fireplace or heater why?

7. You are on a first date and you realize it is not going to work out. What do you do?

8. Do you prefer to wear tennis shoes or sandals and why?

9. You are out with a new friend and realize you don't have your wallet when it is time to pay for dinner. What do you say to your friend?

10. Do you prefer to go out to the movies or rent movies and why? 
11. You need to find a phone number for a business but it is not listed in the phone book. What do you do?

12. Do you prefer chicken or pork and why?

13. You lose a DVD that you borrowed from a friend. What do you do?

14. Do you prefer to stay home or go out and why?

15. You notice that someone you're acquainted with has food in their teeth, what do you do?

16. Do you prefer socks or bare feet and why?

17. You're in the shower and you hear a knock on your door, what do you do?

18. Do you prefer a car or a truck and why?

19. A stranger asks you for directions to a place you've never heard of, what do you say?

20. Do you prefer to watch TV or listen to the radio and why?

21. Your remote control doesn't work, what do you do?

22. Do you prefer a landline or cell phone and why?

23. Someone calls and asks for someone you don't know, what do you say?

24. Do you prefer McDonald's or Burger King and why?

25. Your apartment is very cold, what do you do?

26. Do you prefer sweet or salty and why?

27. Someone cuts in front of you in line, what do you say?

28. Do you prefer chocolate or peanut butter and why?

29. Your clock is blinking 12:00 over and over, what do you do?

30. Do you prefer chicken or steak and why?

31. Someone is walking in your direction on the same side of the sidewalk as you, what do you do?

32. Do you prefer winter or summer and why?

33. Someone walking front of you slips on the ice, what do you do?

34. Do you prefer bacon or sausage and why?

35. You are in line to checkout with a cart full of groceries when you realize you left your wallet and cash at home, what do you do?

36. Do you prefer turkey or ham and why?

37. You get to the gym and realize you have everything you need, except your socks, what do you do?

38. Do you prefer sleeping in or getting up early and why?

39. Someone calls you accidentally. What do you say to them?

40. Do you prefer to go through the drive through or go in and why?

41. A stranger on the sidewalk keeps engaging you in conversation, and you want to leave. What do you do?

42. Do you prefer to use a desktop or laptop and why?

43. You're at the grocery store and you accidentally drop a jar of pickles and it breaks. What do you do?

44. Do you prefer to use a Mac or a PC and why?

45. You're in the middle of following a recipe for dinner and the phone rings. What do you do?

46. Do you prefer to use Email or talk on the phone and why?

47. An old acquaintance asks you if you and your ex are still dating. What do you say?

48. Do you prefer comedies or drama and why?

49. Someone asks you if you've lost weight, and you haven't, what do you say? 
50. Do you prefer working out at home or the gym and why?

51. You're standing in line and the cashier is having a leisurely conversation with the customer in front of you. What do you do?

52. Do you prefer salad or soup and why?

53. Somebody cuts in front of you while you're driving. What do you do?

54 . Do you prefer to use an umbrella or a rain coat and why?

55. A friend asks you how you like his/her outfit. You don't like it. What do you say?

56. Do you prefer to shop online or shop in the store?

57. Someone is talking very loudly about private topics on a cell phone in a public area. What do you do?

58. Do you prefer to wear boots or tennis shoes and why?

59. Your friend gives you the same gift for Christmas that you gave her last year. What do you say?

60. Do you prefer to drink your water with or without lemon and why?

61. You get to the grocery/other store checkout area and decide against purchasing one of your items. What do you do?

62. Do you prefer to wear glasses or contacts and why?

63. You are outside waiting for a parking spot, and another car swoops in and takes it. What do you do?

64. Do you prefer to study arts or science and why?

65 . You are walking to the store and a homeless person asks you for spare change. What do you do?

66. Do you prefer Gatorade or water and why?

67. The person you are interested in just asked for your friend's phone number, what do you say?

68. Do you prefer to watch football or basketball and why?

69. You see an employee drop a piece of bread on the floor in a restaurant, pick it up, put it in a bag and give it to a customer that didn't see it happen, what do you do?

70. Do you prefer paper or plastic bags and why?

71. You're in the shower and the fire alarm goes off, what do you do?

72. Do you prefer hard or soft tacos and why?

73. You are invited over to a friend's house for dinner and you don't like the food that he/she cooked. What do you do?

74. Do you prefer to swim in the ocean or a pool and why?

75. Your neighbor's mail was delivered to your house. What do you do?

76. Do you prefer to read fiction or non-fiction and why?

77. You arrive at work/class and realize that you have a large, embarrassing rip in your pants. What do you do?

78. Do you prefer to listen eat French fries or baked potatoes and why?

79. You go to pick your pictures up from being developed and realize that you were given another person's pictures. What do you do?

80. Do you prefer ketchup or mustard and why? 


\section{Appendix $\mathrm{H}$}

Thesis experiment procedure (check off as completed):

- Training

- Experimental tasks

- Pre-recorded sentences

- Conversational speech sample

- Perceptual rating scales

- Predictive Cluttering Inventory

- SASI

- SL-ILP-S/L

- Peabody

- Templin Darley

— Hearing screening

First we will do the experimental tasks. I'd again like to ask to make sure it's ok that I record our session together.

\section{Instructions to Participants}

I am going to ask you to answer some questions. Please answer the questions however you choose. Your answers to the questions are not important, and there are no right or wrong answers. Please answer as completely as possible. It is ok to use more than one sentence.

I will ask you a question. You are to think about what you would say, press and hold the mouse button for the exact time you think it would take you to say your answer, release the mouse button, and then say your answer aloud.

After each utterance, please rate on a scale of 1 to 5 how well what you said out loud matched what you thought you thought you would say. A rating of 1 means they did not match at all, 3 means they matched about half, and 5 means they matched perfectly.

First we will practice so that you get the hang of it. At the end I will then have you time some pre-recorded speech samples.

Practice items:

What is your full name?

What is your address?

Please count from 10 to 20.

Please tell me what you did in the last 30 minutes.

Now we will begin.

1. Training items 
2. Experimental items

3. Pre-recorded sentences

Now we are just going to talk for a few minutes to get a conversation sample.

Conversation topics:

Tell me about your family.

Prompts - ages, where they live, if they have children

Tell me about your major/occupation.

Prompts - Have you always done this, have you worked in other settings, what is your

degree in, where do you want to work when you graduate, how did you learn about this field

Tell me about a recent trip you took.

Prompts - when was it, who did you go with, how long did you stay, what places did you visit, what was the best part, worst part

Tell me about the city you grew up in.

Prompts - population, terrain, temp, weather, employers, fun things to do

Tell me about your favorite book/tv show/movie.

Prompts - how many times have you read it, how did you learn about it, is there a book/movie about it, who stars in it, what's your favorite part, who is your favorite character

Next I'd like to have you read some things to me.

1. Word lists

2. Grandfather/Rainbow passage

Now I'd like you to fill out some questionnaires for me.

1. Perceptual rating scales

2. PCI

3. SASI

4. SL-ILP-S/L

Now I'm going to give you 2 standardized tests that measure speech and language

1. Peabody

2. Templin Darley

Now I'm going to perform a quick hearing screening.

1. Audiometry

2. Tympanometry 
Table I1.

Appendix I

Self-ratings of clutterers and controls using researcher-created perceptual rating scales.

\begin{tabular}{lcccccccccccccc}
\hline & \multicolumn{1}{c}{ Clutterers } \\
\hline \multicolumn{1}{c}{ Measure } & CL1 & CL2 & CL3 & CL4 & CL5 & CL6 & Mean & CO1 & CO2 & CO3 & CO4 & C5O & CO6 & Mean \\
\hline Intelligibility & 1 & 2 & - & 1 & 1 & 3 & 1.60 & 0 & 0 & 2 & 0 & 0 & 1 & 0.50 \\
Naturalness & 2 & 3 & - & 2 & 0 & 3 & 2.00 & 0 & 0 & 1 & 0 & 1 & 2 & 0.67 \\
Collapsed Syllables & 4 & 4 & 4 & 3 & 4 & 2 & 3.50 & 0 & 0 & 1 & 0 & 1 & 1 & 0.50 \\
Compressed Clusters & 3 & 4 & 3 & 4 & 4 & 4 & 3.67 & 0 & 0 & 1 & 0 & 1 & 0 & 0.33 \\
Shortened Vowels & 2 & 4 & 3 & 4 & 3 & 3 & 3.17 & 0 & 0 & 0 & 0 & 1 & 1 & 0.33 \\
Articulation Errors & 1 & 3 & 0 & 3 & 1 & 3 & 1.83 & 0 & 0 & 1 & 0 & 1 & 0 & 0.33 \\
Pragmatic difficulty & 1 & - & 0 & 5 & - & 2 & 2.00 & 0 & 0 & 2 & 0 & 1 & 0 & 0.50 \\
Syntactic errors & 5 & - & 3 & 3 & 1 & 2 & 2.80 & 0 & 0 & 1 & 0 & 1 & 0 & 0.33 \\
Semantic errors & 4 & 2 & 0 & 3 & 3 & 1 & 2.17 & 0 & 0 & 1 & 0 & 1 & 0 & 0.33 \\
Word finding difficulty & 4 & 4 & 4 & 3 & 2 & 3 & 3.33 & 3 & 0 & 2 & 0 & 1 & 2 & 1.33 \\
Narrative difficulty & 2 & 0 & 3 & 1 & 1 & 2 & 1.50 & 0 & 0 & 2 & 0 & 2 & 0 & 0.67 \\
Mazes present & 3 & 0 & 3 & 4 & 0 & 2 & 2.00 & 0 & 0 & 1 & 0 & 1 & 0 & 0.33 \\
Unfinished Words & 3 & 4 & 4 & 3 & 3 & 3 & 3.33 & 0 & 1 & 2 & 0 & 0 & 1 & 0.67 \\
Revisions & 3 & 4 & 4 & 2 & 0 & 2 & 2.50 & 0 & 1 & 1 & 0 & 1 & 3 & 1.00 \\
Interjections & 3 & 1 & 4 & 2 & 3 & 2 & 2.50 & 0 & 1 & 2 & 0 & 1 & 3 & 1.17 \\
Hesitations & 4 & 4 & 4 & 1 & 4 & 3 & 3.33 & 0 & 0 & 1 & 0 & 2 & 1 & 0.67 \\
Part-word Repetitions & 1 & 0 & 4 & 1 & 0 & 3 & 1.50 & 0 & 0 & 1 & 0 & 1 & 0 & 0.33 \\
Whole-word Repetitions & 0 & 0 & 3 & 1 & 1 & 2 & 1.17 & 0 & 0 & 1 & 0 & 1 & 0 & 0.33 \\
Speed & 4 & 4 & 6 & 4 & 4 & 4 & 4.33 & 5 & 2 & 3 & 4 & 3 & 3 & 3.33 \\
Regularity & 5 & 2 & 5 & 3 & 3 & 3 & 3.50 & 0 & 0 & 2 & 1 & 1 & 0 & 0.67 \\
Pausing & 3 & 2 & 5 & 4 & 2 & 3 & 3.17 & 0 & 0 & 1 & 0 & 1 & 1 & 0.50 \\
\hline
\end{tabular}


Table I2.

Researcher ratings of clutterers and controls using researcher-created perceptual rating scales.

\begin{tabular}{lcccccccccccccc}
\hline & \multicolumn{1}{c}{ Clutterers } \\
\hline \multicolumn{1}{c}{ Measure } & CL1 & CL2 & CL3 & CL4 & CL5 & CL6 & Mean & CO1 & CO2 & CO3 & CO4 & C5O & CO6 & Mean \\
\hline Intelligibility & 2 & 1 & 3 & 2 & 2 & 4 & 2.33 & 0 & 0 & 0 & 0 & 1 & 0 & 0.17 \\
Naturalness & 2 & 2 & 4 & 3 & 4 & 5 & 3.33 & 0 & 2 & 0 & 1 & 0 & 0 & 0.50 \\
Collapsed Syllables & 2 & 4 & 4 & 3 & 4 & 5 & 3.67 & 0 & 0 & 0 & 1 & 1 & 0 & 0.33 \\
Compressed Clusters & 2 & 4 & 3 & 3 & 4 & 5 & 3.50 & 0 & 0 & 0 & 1 & 1 & 0 & 0.33 \\
Shortened Vowels & 3 & 4 & 4 & 4 & 4 & 4 & 3.83 & 0 & 1 & 0 & 0 & 0 & 0 & 0.17 \\
Articulation Errors & 0 & 2 & 1 & 3 & 3 & 4 & 2.17 & 0 & 0 & 0 & 0 & 0 & 0 & 0.00 \\
Pragmatic difficulty & 3 & 1 & 2 & 3 & 2 & 2 & 2.17 & 0 & 0 & 0 & 0 & 0 & 0 & 0.00 \\
Syntactic errors & 0 & 2 & 2 & 1 & 1 & 2 & 1.33 & 0 & 0 & 0 & 1 & 0 & 0 & 0.17 \\
Semantic errors & 1 & 1 & 1 & 1 & 1 & 2 & 1.17 & 0 & 0 & 0 & 0 & 1 & 0 & 0.17 \\
Word finding difficulty & 2 & 1 & 1 & 2 & 1 & 3 & 1.67 & 0 & 0 & 0 & 0 & 1 & 0 & 0.17 \\
Narrative difficulty & 3 & 3 & 2 & 2 & 3 & 3 & 2.67 & 0 & 0 & 0 & 0 & 1 & 0 & 0.17 \\
Mazes present & 3 & 3 & 3 & 3 & 3 & 3 & 3.00 & 0 & 0 & 0 & 0 & 0 & 0 & 0.00 \\
Unfinished Words & 2 & 3 & 3 & 3 & 3 & 4 & 3.00 & 0 & 0 & 1 & 0 & 1 & 0 & 0.33 \\
Revisions & 4 & 3 & 4 & 4 & 3 & 4 & 3.67 & 0 & 0 & 0 & 0 & 1 & 0 & 0.17 \\
Interjections & 3 & 2 & 3 & 5 & 2 & 3 & 3.00 & 0 & 0 & 0 & 0 & 1 & 0 & 0.17 \\
Hesitations & 2 & 2 & 3 & 5 & 3 & 4 & 3.17 & 0 & 0 & 0 & 1 & 1 & 0 & 0.33 \\
Part-word Repetitions & 1 & 1 & 1 & 3 & 4 & 5 & 2.50 & 0 & 0 & 0 & 0 & 0 & 0 & 0.00 \\
Whole-word Repetitions & 0 & 1 & 1 & 1 & 2 & 4 & 1.50 & 0 & 0 & 0 & 0 & 0 & 0 & 0.00 \\
Speed & 4 & 5 & 5 & 5 & 5 & 6 & 5.00 & 3 & 2 & 3 & 4 & 3 & 3 & 3.00 \\
Regularity & 4 & 3 & 3 & 3 & 4 & 5 & 3.67 & 0 & 0 & 0 & 0 & 0 & 0 & 0.00 \\
Pausing & 3 & 3 & 2 & 1 & 2 & 5 & 2.67 & 0 & 0 & 0 & 0 & 0 & 0 & 0.00 \\
\hline
\end{tabular}


Table I3.

Friend ratings of clutterers and controls using researcher-created perceptual rating scales.

\begin{tabular}{lcccccccccccccc}
\hline & \multicolumn{1}{c}{ Clutterers } \\
\hline \multicolumn{1}{c}{ Measure } & CL1 & CL2 & CL3 & CL4 & CL5 & CL6 & Mean & CO1 & CO2 & CO3 & CO4 & C5O & CO6 & Mean \\
\hline Intelligibility & 1 & 1 & 0 & 2 & 1 & 2 & 1.17 & 0 & 0 & 0 & 1 & 1 & 0 & 0.33 \\
Naturalness & 0 & 1 & 1 & 3 & 1 & 2 & 1.33 & 0 & 0 & 0 & 1 & 1 & 0 & 0.33 \\
Collapsed Syllables & 3 & 2 & 1 & 2 & 1 & 3 & 2.00 & 0 & 1 & 1 & 0 & 1 & 0 & 0.50 \\
Compressed Clusters & 3 & 2 & 0 & 4 & 3 & 4 & 2.67 & 0 & 0 & 0 & 0 & 1 & 0 & 0.17 \\
Shortened Vowels & 2 & 2 & 0 & 4 & 2 & 5 & 2.50 & 0 & 0 & 1 & 0 & 1 & 0 & 0.33 \\
Articulation Errors & 0 & 1 & 0 & 1 & 1 & 6 & 1.50 & 0 & 0 & 0 & 0 & 1 & 0 & 0.17 \\
Pragmatic difficulty & 1 & 0 & 2 & 3 & 3 & 1 & 1.67 & 0 & 0 & 1 & 0 & 0 & 0 & 0.17 \\
Syntactic errors & 0 & 1 & 1 & 1 & 1 & 1 & 0.83 & 0 & 0 & 0 & 1 & 1 & 0 & 0.33 \\
Semantic errors & 1 & 1 & 1 & 1 & 1 & 0 & 0.83 & 0 & 0 & 0 & 0 & 0 & 0 & 0.00 \\
Word finding difficulty & 0 & 1 & 1 & 1 & 1 & 0 & 0.67 & 0 & 0 & 0 & 0 & 1 & 1 & 0.33 \\
Narrative difficulty & 2 & 1 & 0 & 4 & 0 & 0 & 1.17 & 0 & 0 & 0 & 0 & 0 & 0 & 0.00 \\
Mazes present & 1 & 0 & 0 & 4 & 0 & 0 & 0.83 & 0 & 0 & 0 & 0 & 1 & 0 & 0.17 \\
Unfinished Words & 1 & 1 & 0 & 3 & 0 & 2 & 1.17 & 0 & 0 & 0 & 0 & 0 & 0 & 0.00 \\
Revisions & 3 & 1 & 0 & 2 & - & 1 & 1.40 & 0 & 1 & 1 & 1 & 1 & 1 & 0.83 \\
Interjections & 2 & 1 & 0 & 2 & 3 & 1 & 1.50 & 0 & 1 & 1 & 1 & 2 & 1 & 1.00 \\
Hesitations & 2 & 1 & 0 & 2 & 2 & 3 & 1.67 & 0 & 1 & 0 & 0 & 2 & 0 & 0.50 \\
Part-word Repetitions & 0 & 1 & 3 & 2 & 0 & 3 & 1.50 & 0 & 0 & 0 & 0 & 1 & 0 & 0.17 \\
Whole-word Repetitions & 0 & 1 & 0 & 2 & 0 & 2 & 0.83 & 0 & 0 & 0 & 0 & 1 & 0 & 0.17 \\
Speed & 5 & 2 & 2 & 5 & 5 & 5 & 4.00 & 3 & 3 & 3 & 3 & 3 & 3 & 3.00 \\
Regularity & 3 & 1 & 0 & 4 & 3 & 3 & 2.33 & 0 & 0 & 0 & 0 & 0 & 0 & 0.00 \\
Pausing & 2 & 0 & 0 & 3 & 0 & 2 & 1.17 & 0 & 0 & 0 & 0 & 0 & 0 & 0.00 \\
\hline
\end{tabular}




\section{Appendix $\mathbf{J}$}

Table J1.

Clutterer 1 speaking rate in syllables per second during five experimental tasks.

\begin{tabular}{|c|c|c|c|}
\hline Utterance & Syllables & $\mathrm{S}$ & SPS \\
\hline 1. I don't answer it. & 5 & 0.80 & 6.25 \\
\hline 2. I prefer to stay home because I usually end up not having much fun when I go out. & 23 & 3.47 & 6.63 \\
\hline 3. I prefer chocolate because I'm not that big of a fan of peanut butter. & 19 & 4.02 & 4.73 \\
\hline 4. Answer the phone. & 4 & 0.87 & 4.60 \\
\hline 5. I go looking for another parking spot. & 11 & 1.96 & 5.61 \\
\hline Mean & 12.40 & 2.22 & 5.56 \\
\hline
\end{tabular}

Table J2.

Control 1 speaking rate in syllables per second during five experimental tasks.

\begin{tabular}{|c|c|c|c|}
\hline Utterance & Syllables & Length & SPS \\
\hline 1. I tell them I'm not interested. & 8 & 1.29 & 6.20 \\
\hline 2. I call information & 6 & 0.94 & 6.38 \\
\hline 3. I check the batteries. & 6 & 0.85 & 7.06 \\
\hline 4. I move over. & 4 & 0.94 & 4.26 \\
\hline 5. I say excuse me I have to go and walk away. & 13 & 2.50 & 5.2 \\
\hline Mean & 5.00 & 1.30 & 5.82 \\
\hline
\end{tabular}


Table J3.

Clutterer 2 speaking rate in syllables per second during five experimental tasks.

\begin{tabular}{|c|c|c|c|}
\hline Utterance & Syllables & Length & SPS \\
\hline 1. Politely decline. & 5 & 1.15 & 4.35 \\
\hline 2. Usually stay home because I don't like big crowds. & 12 & 2.30 & 5.22 \\
\hline 3. Excuse me, I was here first. & 7 & 1.47 & 4.76 \\
\hline 4. Tell them to be more careful in the future and hang up. & 14 & 2.78 & 5.04 \\
\hline 5. I don't prefer working out at all. & 9 & 1.07 & 8.41 \\
\hline Mean & 9.40 & 1.75 & 5.56 \\
\hline
\end{tabular}

Table J4.

Control 2 speaking rate in syllables per second during five experimental tasks.

\begin{tabular}{|c|c|c|c|}
\hline Utterance & Syllables & Length & SPS \\
\hline 1. Try again. & 3 & 0.63 & 4.76 \\
\hline 2. I would politely tell them. & 7 & 1.39 & 5.04 \\
\hline 3. Chocolate because I like the flavor better. & 11 & 1.80 & 6.11 \\
\hline 4. Sorry you have the wrong number. & 8 & 1.28 & 6.25 \\
\hline 5. Patiently wait or pick another line. & 10 & 1.68 & 5.95 \\
\hline Mean & 7.80 & 1.36 & 5.62 \\
\hline
\end{tabular}


Table J5.

Clutterer 3 speaking rate in syllables per second during five experimental tasks.

\begin{tabular}{|c|c|c|c|}
\hline Utterance & Syllables & Length & SPS \\
\hline 1. Tell them I'm not interested. & 7 & 1.13 & 6.19 \\
\hline 2. I prefer chicken but I don't know why. & 10 & 2.18 & 4.59 \\
\hline 3. Uh I prefer a landline because I don't like to be reached when I'm out and about. & 21 & 2.91 & 7.22 \\
\hline 4. I prefer sausage because [unintelligible] because it goes good in biscuits & 15 & 2.65 & 5.66 \\
\hline 5. I prefer to use a PC because I really don't "luh" know much about Macs. & 20 & 3.09 & 6.47 \\
\hline Mean & 14.60 & 2.39 & 6.03 \\
\hline
\end{tabular}

Table J6.

Control 3 speaking rate in syllables per second during five experimental tasks.

\begin{tabular}{|c|c|c|c|}
\hline Utterance & Syllables & Length & SPS \\
\hline 1. I answer the door and tell them I don't want any. & 13 & 1.85 & 7.03 \\
\hline 2. I look it up online. & 6 & 0.76 & 7.89 \\
\hline 3. I'm sorry you must have the wrong number. & 10 & 1.54 & 6.49 \\
\hline 4. I stop and help them get up. & 7 & 1.43 & 4.90 \\
\hline 5. I point it out to someone who works there. & 10 & 1.48 & 6.76 \\
\hline Mean & 9.20 & 1.41 & 6.61 \\
\hline
\end{tabular}


Table J7.

Clutterer 4 speaking rate in syllables per second during five experimental tasks.

\begin{tabular}{|c|c|c|c|}
\hline Utterance & Syllables & Length & SPS \\
\hline 1. I listen, usually politely tell them I'm not interested, and send them away. & 21 & 4.33 & 4.85 \\
\hline 2. Try to find a replacement and return the new one. & 13 & 2.24 & 5.80 \\
\hline 3. I haven't eaten at either place in over 10 years, 'cause I'm always on a diet. & 22 & 4.46 & 4.23 \\
\hline 4. I ask the clerk to keep the groceries, go home, get my wallet, [unintelligible] back and pay. & 18 & 4.26 & 4.46 \\
\hline 5. I answer the phone, and ask if I can call back. & 12 & 3.60 & 3.33 \\
\hline Mean & 17.20 & 3.78 & 4.53 \\
\hline
\end{tabular}

Table J8.

Control 4 speaking rate in syllables per second during five experimental tasks.

\begin{tabular}{lccc}
\hline \multicolumn{1}{c}{ Utterance } & Syllables & Length & SPS \\
\hline 1. I usually listen to the pitch, 'cause I sss worked, 'cause I worked in sales. & 18 & 3.96 & 4.55 \\
2. Replace the DVD. & 6 & 0.97 & 6.19 \\
3. Neither, I have high cholesterol. & 9 & 1.64 & 5.49 \\
4. Bacon. & 2 & 0.85 & 2.35 \\
5. Answer the phone, I can do two things at once. & 11 & 1.99 & 5.53 \\
Mean & 9.20 & 1.88 & 4.82 \\
\hline
\end{tabular}


Table J9.

Subject 5 speaking rate in syllables per second during five experimental tasks.

\begin{tabular}{|c|c|c|c|}
\hline Utterance & Syllables & Length & SPS \\
\hline 1. I do not open the door. & 7 & 1.56 & 4.49 \\
\hline 2. I prefer chicken 'cause I love chicken. & 10 & 1.54 & 6.49 \\
\hline 3. Wrong number. & 3 & 0.70 & 4.29 \\
\hline 4. Go in bare feet. & 4 & 1.04 & 3.85 \\
\hline 5. I prefer salad because it's more healthy. & 11 & 1.54 & 7.14 \\
\hline Mean & 7.00 & 1.28 & 5.25 \\
\hline
\end{tabular}

Table J10.

Control 5 speaking rate in syllables per second during five experimental tasks.

\begin{tabular}{|c|c|c|c|}
\hline Utterance & Syllables & Length & SPS \\
\hline 1. It depends on who I'm going out with. & 10 & 2.15 & 4.65 \\
\hline 2. Nothin', I like the cold. & 6 & 1.26 & 4.76 \\
\hline 3. Put my things back, go home and get my wallet, come back to the store. & 16 & 3.40 & 4.71 \\
\hline 4. Answer the phone and probably screw up a part of the recipe. & 17 & 2.92 & 5.82 \\
\hline 5. That's an interesting outfit you're wearing. & 10 & 1.67 & 5.99 \\
\hline Mean & 11.80 & 2.28 & 5.19 \\
\hline
\end{tabular}


Table J11.

Clutterer 6 speaking rate in syllables per second during five experimental tasks.

\begin{tabular}{|c|c|c|c|}
\hline Utterance & Syllables & Length & SPS \\
\hline 1. Um um try and sell them something. Try and sell them something. & 14 & 2.13 & 6.57 \\
\hline 2. Um chicken and swine flu. & 6 & 1.96 & 3.06 \\
\hline 3. um sss um see see if it's see if it's on the ver or orn or or or another clock. & 24 & 6.96 & 3.45 \\
\hline 4. mm tell them bye and walk away. & 8 & 1.38 & 5.80 \\
\hline 5. Um get out of line and and find another cashier. & 13 & 2.23 & 5.83 \\
\hline Mean & 13.00 & 2.93 & 4.94 \\
\hline
\end{tabular}

Table J12.

Control 6 speaking rate in syllables per second during five experimental tasks.

\begin{tabular}{lrrr}
\hline \multicolumn{1}{c}{ Utterance } & Syllables & Length & SPS \\
\hline 1. Ignore them and wait for them to go away. & 11 & 1.36 & 8.09 \\
2. Call information. & 5 & 0.73 & 6.85 \\
3. Cell phones 'cause they' re readily available. & 11 & 2.00 & 5.50 \\
4. Winter 'cause I like the snow. & 7 & 1.18 & 5.93 \\
5. Desktop because it's the only thing I have. & 11 & 1.60 & 6.88 \\
Mean & 9.00 & 1.37 & 6.65 \\
\hline
\end{tabular}




\section{Appendix K}

Table K1.

Control sentence timing results for clutterers.

\begin{tabular}{|c|c|c|c|c|c|c|c|c|}
\hline Sentence & $\begin{array}{c}\text { Researcher } \\
\text { Time* }\end{array}$ & CL1 & CL2 & CL3 & CLA & CL5 & CL6 & Mean \\
\hline \multirow[t]{2}{*}{1} & 4.07 & 5.19 & 3.95 & 4.47 & 4.15 & 3.93 & 4.10 & 4.30 \\
\hline & Difference & -1.12 & 0.12 & -0.52 & -0.20 & 0.22 & 0.05 & \\
\hline \multirow[t]{2}{*}{2} & 3.1 & 3.59 & 3.26 & 3.41 & 3.14 & 2.99 & 3.58 & 3.33 \\
\hline & Difference & -0.49 & -0.16 & -0.15 & 0.12 & 0.15 & -0.44 & \\
\hline \multirow[t]{2}{*}{3} & 5.76 & 5.76 & 5.74 & 5.90 & 5.81 & 5.71 & 5.98 & 5.82 \\
\hline & Difference & 0.00 & 0.02 & -0.16 & -0.07 & 0.10 & -0.17 & \\
\hline \multirow[t]{2}{*}{4} & 3.2 & 3.74 & 3.28 & 3.26 & 3.45 & 3.35 & 3.52 & 3.43 \\
\hline & Difference & -0.54 & -0.08 & 0.02 & -0.17 & 0.10 & -0.07 & \\
\hline \multirow[t]{2}{*}{5} & 1.81 & 1.97 & 1.83 & 1.69 & 1.75 & 1.60 & 1.92 & 1.79 \\
\hline & Difference & -0.16 & -0.02 & 0.14 & 0.08 & 0.15 & -0.17 & \\
\hline \multirow[t]{2}{*}{6} & 5.31 & 5.52 & 5.42 & 5.47 & 5.24 & 5.32 & 5.46 & 5.41 \\
\hline & Difference & -0.21 & -0.11 & -0.05 & 0.18 & -0.08 & -0.22 & \\
\hline
\end{tabular}

*Note: Researcher time (column two) is based on an average of three timings conducted by the researcher using the CLASP program. 
Table K2.

Control sentence timing results for controls.

\begin{tabular}{|c|c|c|c|c|c|c|c|c|}
\hline Sentence & $\begin{array}{c}\text { Researcher } \\
\text { Time* }\end{array}$ & $\mathrm{CO} 1$ & $\mathrm{CO} 2$ & $\mathrm{CO} 3$ & $\mathrm{CO} 4$ & $\mathrm{CO} 5$ & CO6 & Mean \\
\hline \multirow[t]{2}{*}{1} & 4.07 & 4.03 & 4.14 & 4.10 & 4.10 & 4.32 & 4.23 & 4.15 \\
\hline & Difference & 0.07 & -0.04 & 0.04 & 0.04 & -0.22 & -0.13 & \\
\hline \multirow[t]{2}{*}{2} & 3.1 & 3.54 & 3.46 & 3.00 & 3.13 & 3.26 & 3.33 & 3.29 \\
\hline & Difference & 0.04 & 0.12 & 0.46 & 0.33 & -0.13 & -0.20 & \\
\hline \multirow[t]{2}{*}{3} & 5.76 & 5.62 & 5.88 & 5.84 & 5.93 & 5.97 & 5.85 & 5.85 \\
\hline & Difference & 0.36 & 0.10 & 0.04 & -0.05 & -0.04 & 0.08 & \\
\hline \multirow[t]{2}{*}{4} & 3.2 & 4.09 & 3.44 & 3.18 & 3.40 & 3.49 & 3.28 & 3.48 \\
\hline & Difference & -0.57 & 0.08 & 0.26 & 0.04 & -0.09 & 0.12 & \\
\hline \multirow[t]{2}{*}{5} & 1.81 & 1.77 & 1.84 & 1.85 & 1.67 & 1.88 & 2.34 & 1.89 \\
\hline & Difference & 0.15 & 0.08 & -0.01 & 0.17 & -0.21 & -0.67 & \\
\hline \multirow[t]{2}{*}{6} & 5.31 & 5.41 & 5.27 & 5.39 & 5.34 & 5.44 & 5.29 & 5.36 \\
\hline & Difference & 0.05 & 0.19 & -0.12 & -0.07 & -0.10 & 0.05 & \\
\hline
\end{tabular}

*Note: Researcher time (column two) is based on an average of three timings conducted by the researcher using the CLASP program.

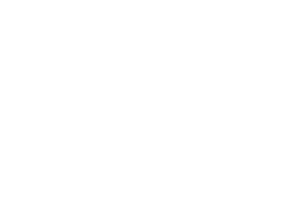

